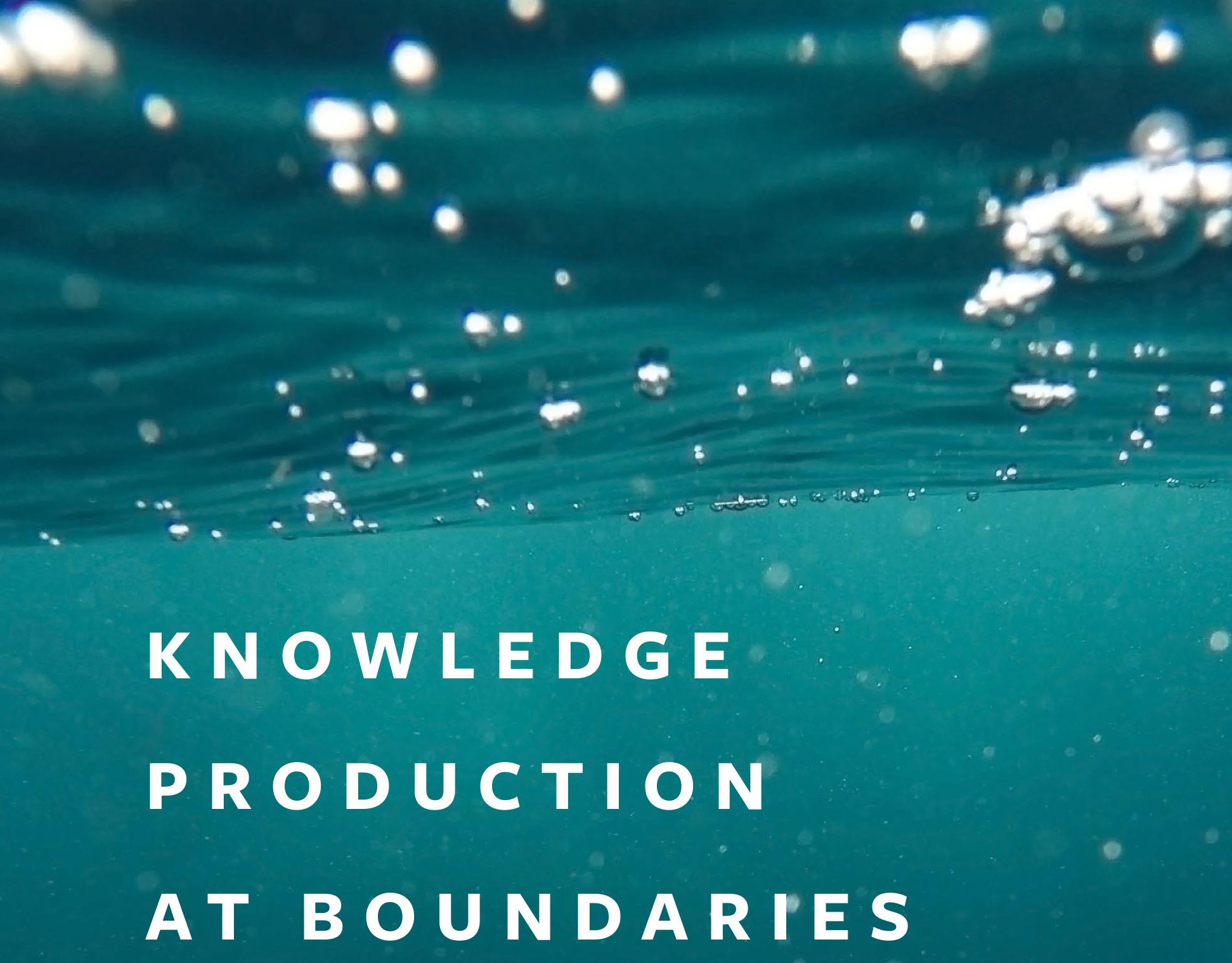

An inquiry into collaborations to make management plans for European fisheries

Kari Stange 


\section{Propositions}

1. Definitions of knowledge trigger unknowing. (this thesis)

2. Management plans as collaborative initiatives are more important to European fishery management than management plans as tools.

(this thesis)

3. Good interdisciplinary science requires solid disciplinary foundations.

4. Fifty years from now, historians will explain how scientific knowledge advanced even in the era before open access became the norm.

5. Libraries are goldmines, not negotiable budget lines.

6. Lifelong learning makes following your nose a legitimate strategy.

Propositions belonging to the thesis entitled

Knowledge production at boundaries: An inquiry into collaborations to make management plans for European fisheries

Kari Stange

Wageningen, 13 March 2017 


\section{Knowledge production at boundaries:}

An inquiry into collaborations to make management plans

for European fisheries

Kari Stange 


\section{Thesis committee}

\section{Promotor}

Prof. Dr J.P.M. van Tatenhove

Personal chair at the Environmental Policy Group

Wageningen University \& Research

\section{Co-promotor}

Dr J. van Leeuwen

Assistant professor, Environmental Policy Group

Wageningen University \& Research

\section{Other members}

Prof. Dr A.D. Rijnsdorp, Wageningen University \& Research

Prof. Dr J. Raakjær; Aalborg University, Denmark

Dr M.L. Kraan, Wageningen University \& Research

Dr S. Linke, University of Gothenburg, Sweden

This research was conducted under the auspices of Wageningen School of Social Sciences (WASS). 


\title{
Knowledge production at boundaries: \\ An inquiry into collaborations to make management plans for European fisheries
}

\author{
Kari Stange
}

Thesis

submitted in fulfilment of the requirements for the degree of doctor at Wageningen University

by the authority of the Rector Magnificus,

Prof. Dr A.P.J. Mol,

in the presence of the

Thesis Committee appointed by the Academic Board

to be defended in public

on Monday 13 March 2017

at 1:30 p.m. in the Aula. 


\section{Kari Stange}

Knowledge production at boundaries: An inquiry into collaborations to make management plans for European fisheries,

178 pages.

PhD thesis, Wageningen University, Wageningen, the Netherlands (2017)

With references, with summary in English

ISBN: 978-94-6343-062-3

DOI: $10.18174 / 402072$ 
For Doug C. K. Wilson

who asked thought-provoking questions

and inspired me to become a social scientist 



\section{Acknowledgements}

What a privilege to spend five years - mid-life, mid-career - to pursue a $\mathrm{PhD}$ in a new field, in a new country. The first word of thanks goes to Martin Pastoors, whose enthusiasm for stakeholder involvement in fishery science and management brought me into the GAP project and made me embark on this PhD journey. That enthusiasm seems to have been contagious and now I look forward to put it to use "out there". Next, a very big thanks to my promotor Dr. Jan van Tatenhove and co-promotor Dr. Judith van Leeuwen: The three of us were not so often in the same room, but often - and increasingly - on the same wavelength. Thank you both for guiding me into the secret life of conceptual frameworks. It took some time, but now I do agree; they are indeed pretty useful.

I wished to do a $\mathrm{PhD}$ in a setting where my work would be part of a bigger context. The GAP2 project proved to be exactly that. Thanks to Dr. Steven Mackinson for excellent project leadership and to GAP2 "family members" at different nodes around Europe for your positive attitude and good collaboration. Also, my engagement with the ICES Working Group on Marine Systems (WGMARS) was very rewarding. Thank you WGMARSians for good discussions, and special thanks to Dr. Dorothy Dankel and Dr. Kåre Nolde Nielsen for your dedication to the What hat idea.

My PhD journey started at the Centre for Marine Policy in Leeuwarden. Thanks to David, Sarah and Dolfie for good companionship up there. Thanks also to Dr. Luc van Hoof for guidance during the early stages and for reminding me to zoom in on the problem. Keep drumming! When I relocated to Wageningen and the Environmental Policy Group my world became amazingly international. Again; what a privilege! Thank you ENP staff and PhDs for making me feel at home as a Swedish Norwegian among Dutch, Belgian, Australian, Irish, Canadian, American, I-Kiribati, Ghanaian, Brazilian, Indian, Chilean, Russian, Chinese, Thai, Indonesian, Ethiopian, English, German and Mexican colleagues. Special thanks to ENP secretary Corry Rothuizen for always finding quick and good solutions to what I thought were problems. Thanks to Bill Anthony for help with the language in Chapters 1,2 and 7. Thanks also to my VADA kayaking friends for refreshing Sunday mornings on the Nederrijn. Finally, tack Erik for supporting this crazy idea from start to finish from home base Stockholm.

Kari Stange

Stockholm, November 2016 



\section{Contents}

Acknowledgements................................................................................................................................. vii

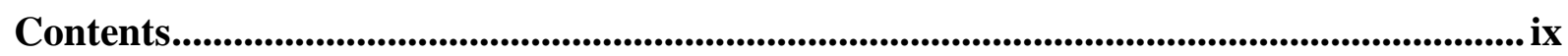

List of figures ...................................................................................................................................... xiii

List of tables........................................................................................................................ xiii

List of abbreviations..................................................................................................................... xiv

Chapter 1: Introduction...................................................................................................................... 1

1.1 A call for knowledge systems with greater openness .............................................. 3

1.2 The European fishery-management system......................................................... 5

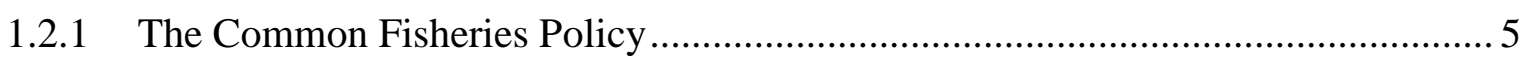

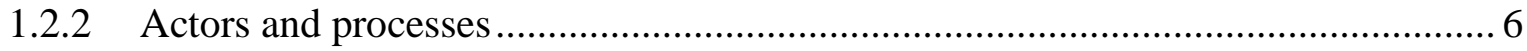

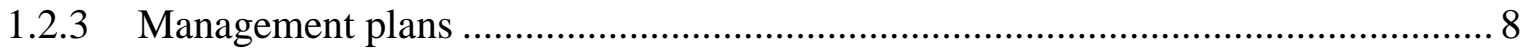

1.3 The challenge of knowledge integration ……………..................................... 10

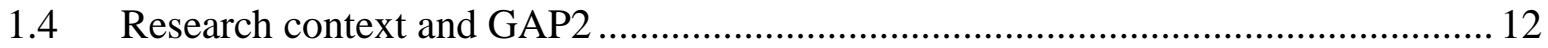

1.5 Understanding knowledge at boundaries ........................................................... 16

1.6 Aims, objectives, and research questions ........................................................... 19

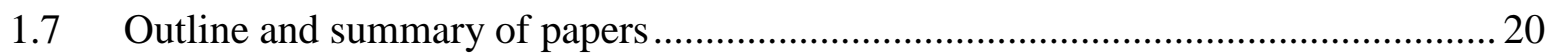

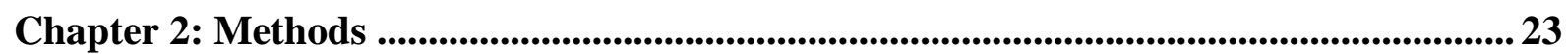

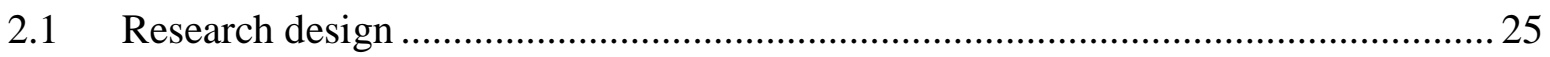

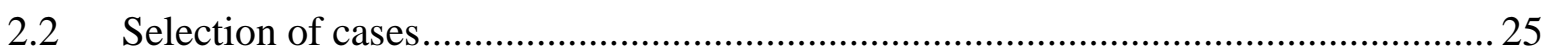

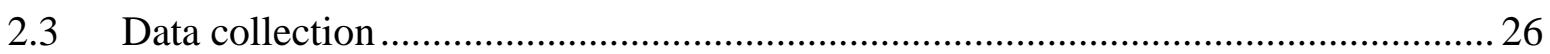

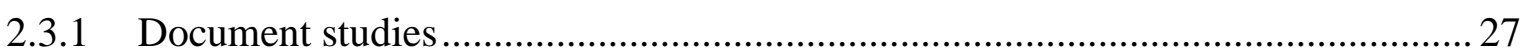

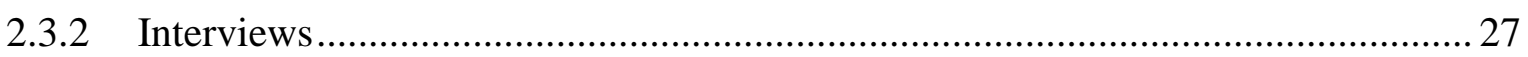

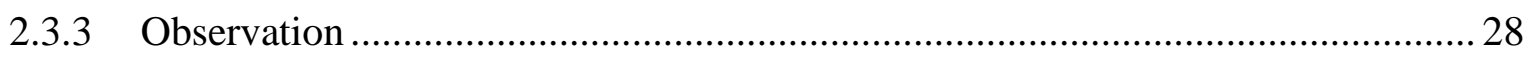

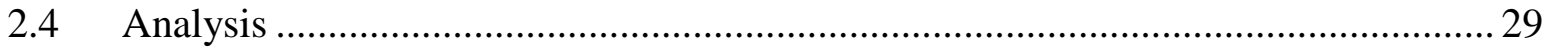

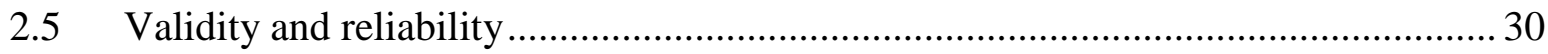

Chapter 3: Stakeholder-led knowledge production: Development of a long-term management plan for North Sea Nephrops fisheries...................................................................33

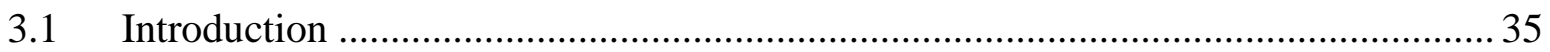

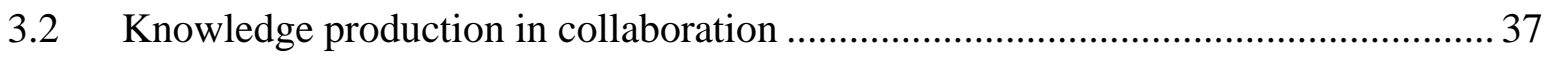




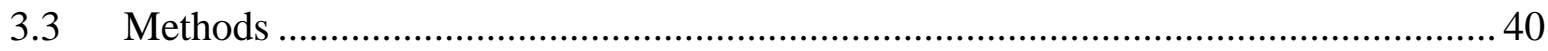

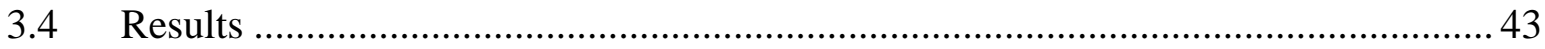

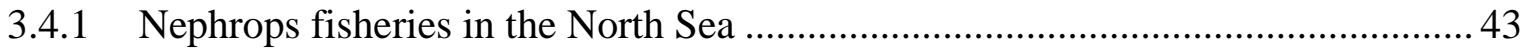

3.4.2 Stakeholders take the lead: The Nephrops Focus Group .................................... 43

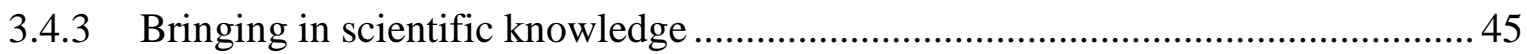

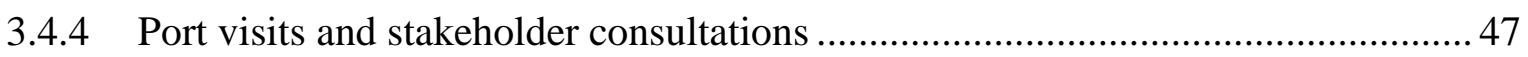

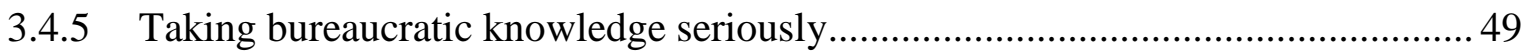

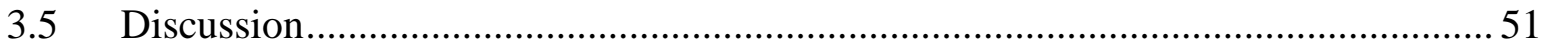

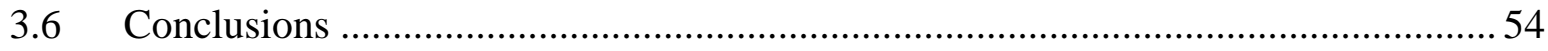

Chapter 4: Building a knowledge base for management of a new fishery: Boarfish

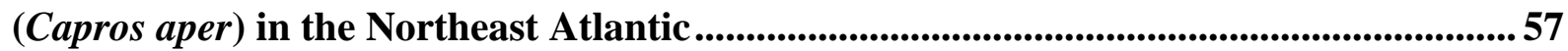

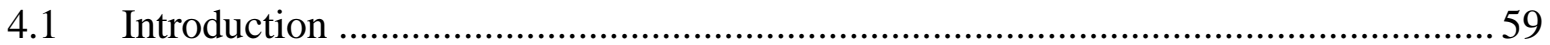

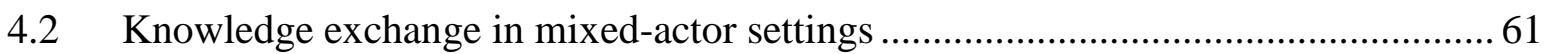

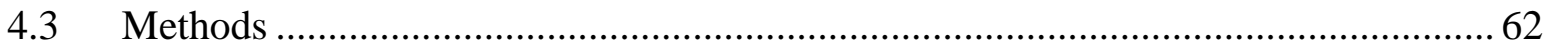

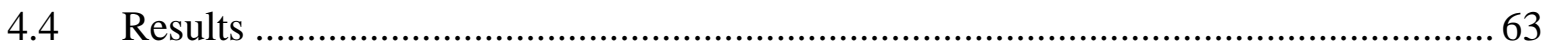

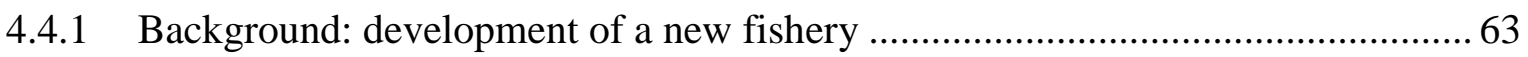

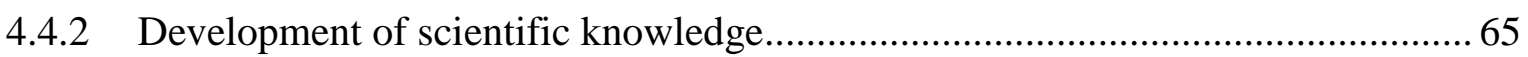

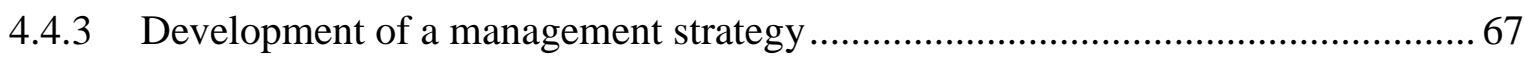

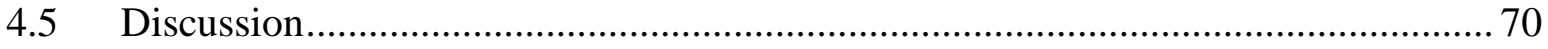

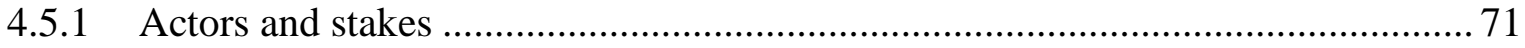

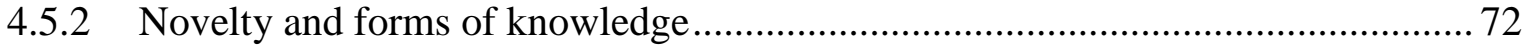

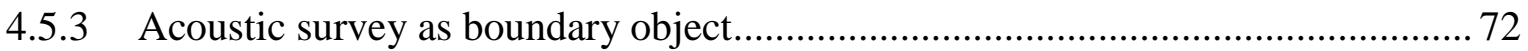

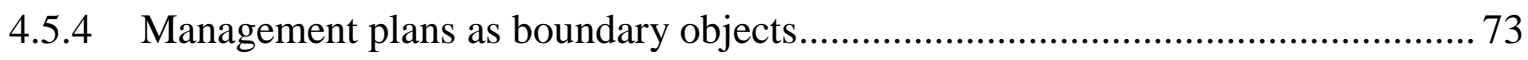

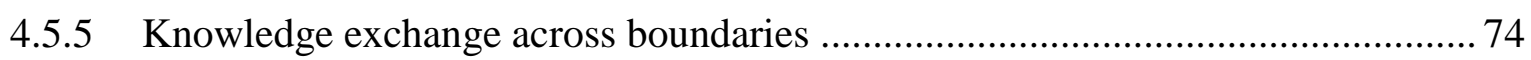

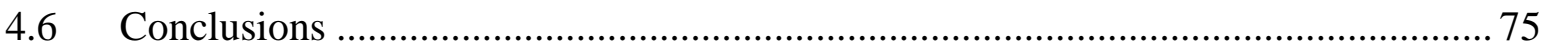

Chapter 5: Boundary spaces, objects and activities in mixed-actor knowledge production: Making fishery management plans in collaboration .................................... 77

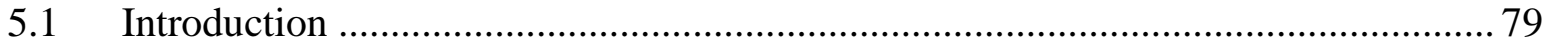

5.2 Theory on boundary processes in mixed-actor collaborations ................................ 81

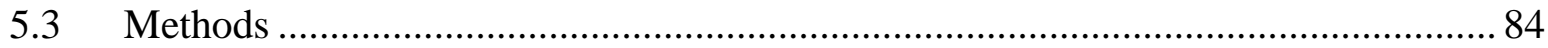

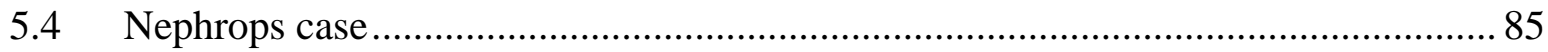

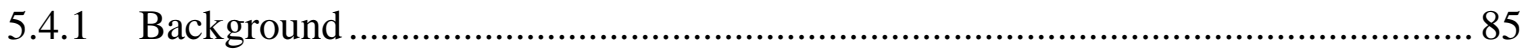

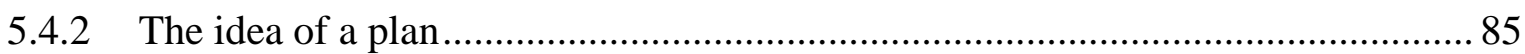




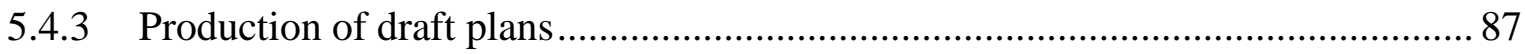

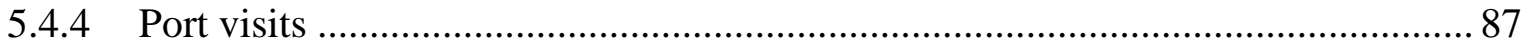

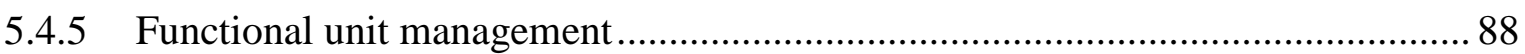

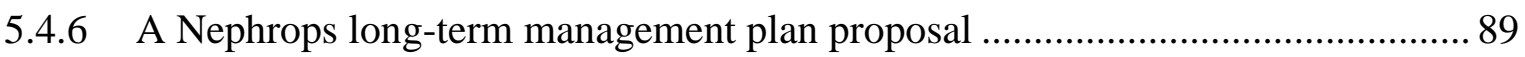

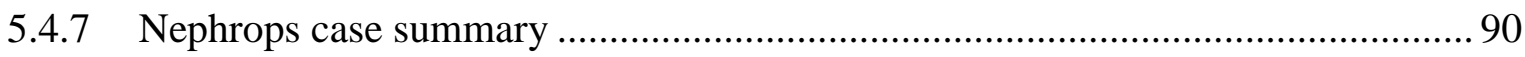

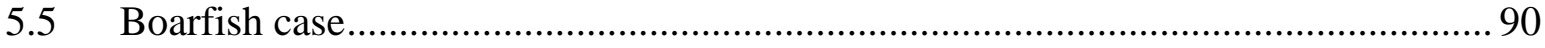

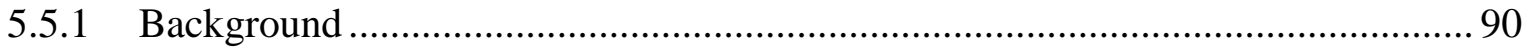

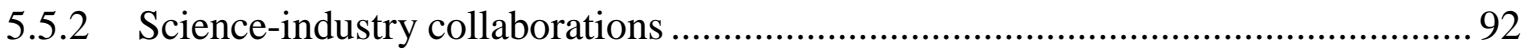

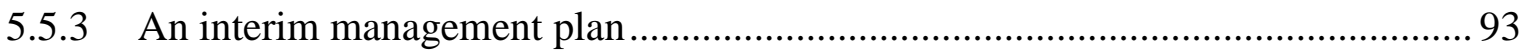

5.5.4 A long-term management plan proposal ........................................................ 94

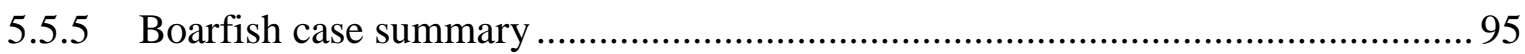

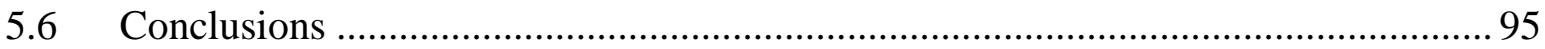

Chapter 6: What hat are you wearing? On the multiple roles of fishery scientists in the ICES community ...................................................................................................................................... 99

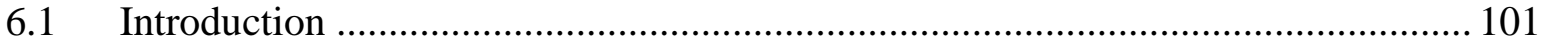

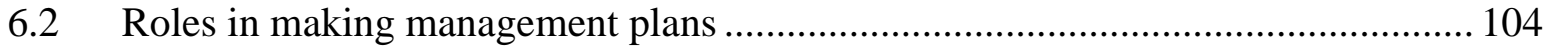

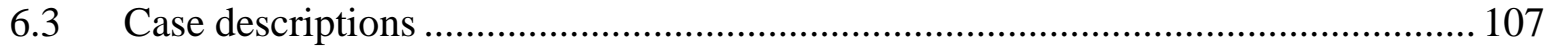

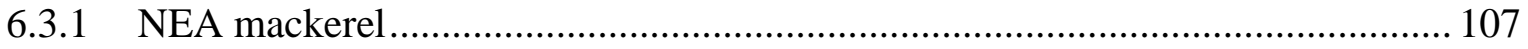

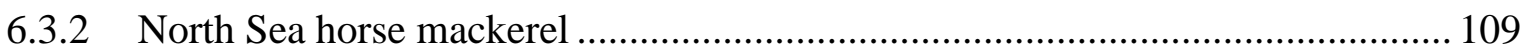

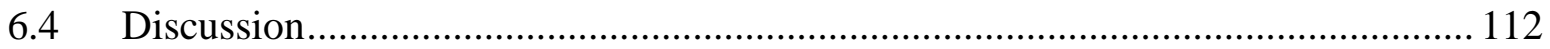

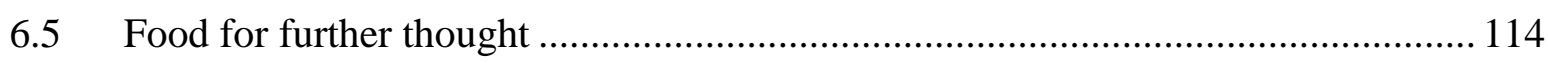

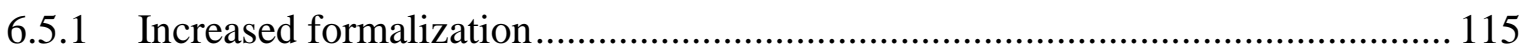

6.5.2 Enhanced reflective capacity and role communication...................................... 115

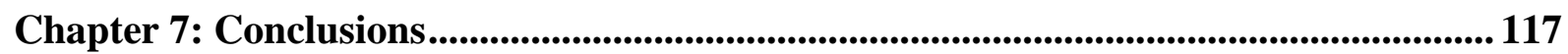

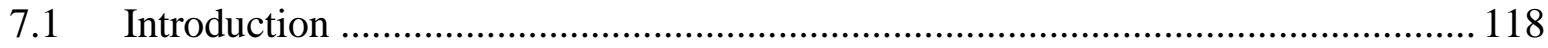

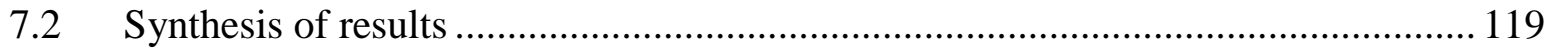

7.2.1 Conceptual frameworks for understanding mixed-actor knowledge production. 119

7.2.2 Management-plan development as arenas for knowledge exchange .................. 121

7.2.3 Actors and roles in management-plan collaborations ........................................ 124

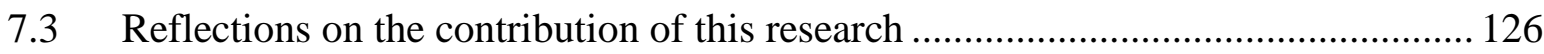

7.3.1 New actors and instruments in EU fishery management .................................. 126

7.3.2 Scientific knowledge and other forms of knowledge...................................... 129 
7.3.3 Boundary-object theory and knowledge exchange.

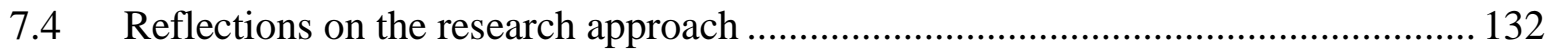

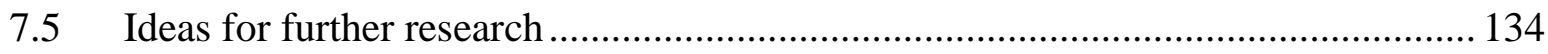

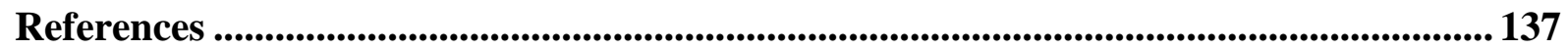

Appendix 1: List of meetings, workshops and conferences ............................................... 147

Appendix 2: Interview guide. (Supplement 1 to Paper III) ............................................... 149

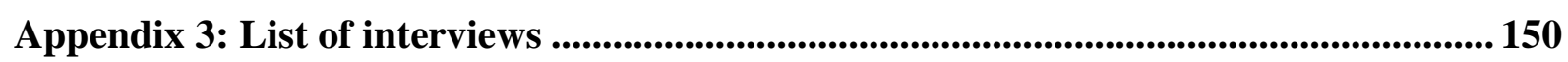

Appendix 4: Coding Scheme. (Supplement 2 to Paper III) ................................................ 152

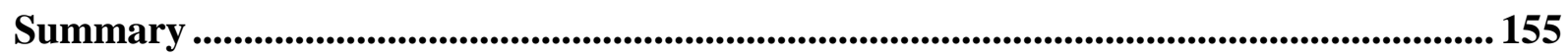

WASS education certificate ........................................................................................... 159

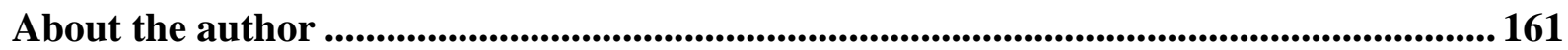




\section{List of figures}

$\begin{array}{lll}\text { Figure 1.1 The EU fishery system } & 7\end{array}$

Figure 1.2 GAP2 conceptual overview 13

Figure 1.3 Watering cans with knowledge contributions from stakeholders and from 15 scientists to the knowledge base of EU fishery management

Figure 1.4 An integrated/3T framework for managing knowledge across boundaries 17

Figure 3.1 Processes at boundaries between actors 39

Figure 3.2 Functional units for Nephrops norvegicus fisheries in the North Sea, $\quad 42$ Skagerrak and Kattegat

Figure 4.1 Framework for analysing knowledge exchange in mixed-actor settings 61

$\begin{array}{lll}\text { Figure 4.2 } & \text { Boarfish (Capros aper) } & 64\end{array}$

Figure 4.3 Resources that enable knowledge-sharing between actors 75

Figure 5.1 A conceptual framework for understanding knowledge exchange between 83 actors facilitated through an interplay between objects and activities within boundary spaces

Figure 6.1 Illustration to "What hat are you wearing?" 102

Figure 7.1 Watering-can cartoon visualizing output from the Nephrops and boarfish 123 collaborations

\section{List of tables}

Table 5.1 Boundary spaces and knowledge exchange in the Nephrops long-term management plan process

Table 5.2 Boundary spaces and knowledge exchange in the Boarfish long-term management plan process 


\section{List of abbreviations}

\begin{tabular}{|c|c|}
\hline ACOM & (ICES) Advisory Committee \\
\hline BSAC & Baltic Sea Advisory Council \\
\hline CFP & Common Fisheries Policy \\
\hline DCF & (EU's) Data Collection Framework \\
\hline DG & Directorate-General \\
\hline DG MARE & $\begin{array}{l}\text { European Commission's Directorate-General for Maritime Affairs and } \\
\text { Fisheries }\end{array}$ \\
\hline DPPO & Danish Pelagic Producers Organisation \\
\hline DTU & Danish Technical University \\
\hline DWG & (NSRAC and NSAC) Demersal Working Group \\
\hline EASST & European Association for the Study of Science and Technology \\
\hline EC & European Commission \\
\hline ECJ & The Court of Justice of the European Communities \\
\hline EU & European Union \\
\hline ExCom & Executive Committee \\
\hline FDI & Fisheries Dependent Information \\
\hline GAP2 & $\begin{array}{l}\text { EU FP7 project: "Bridging the gap between science, stakeholders, and } \\
\text { policy-makers Phase } 2: \text { Integration of evidence-based knowledge and its } \\
\text { application to science and management of fisheries and the marine } \\
\text { environment" }\end{array}$ \\
\hline ICES & International Council for the Exploration of the Sea \\
\hline KFO & Killybegs Fisherman's Organisation \\
\hline LDAC & Long Distance Advisory Council \\
\hline MEDAC & Mediterranean Sea Advisory Council \\
\hline MIACO & (Annual meeting with) ICES and Advisory Councils \\
\hline MIRAC & (Annual meeting with) ICES and RACs \\
\hline MSY & Maximum Sustainable Yield \\
\hline NEA & The Northeast Atlantic \\
\hline
\end{tabular}


NFFO

NFG

NGO

NSAC

NSRAC

NSSS

NWWAC

PELAC

PFA

PO

PRAC

RAC

RRI

RSW

SFF

SGMAS

STECF

STS

SWWAC

TAC

UK

WG

WGMARS

WGWIDE
National Federation of Fishermen's Organisation

(NSRAC and NSAC) Nephrops Focus Group

Non-Governmental Organisation

The North Sea Advisory Council

The North Sea Regional Advisory Council

Fishers' North Sea Stock Survey

North-western waters Advisory Council

Pelagic stocks Advisory Council

Dutch Pelagic Freezer-Trawler Association

Producer Organisation

Pelagic Regional Advisory Council

Regional Advisory Council

Responsible Research and Innovation

Refrigerated Sea Water

Scottish Fishermen's Federation

(ICES) Study Group on Management Strategies

Scientific, Technical and Economic Committee for Fisheries

Science and Technology Studies

South-west waters Advisory Council

Total Allowable Catch

United Kingdom

Working Group

(ICES) Working Group on Marine Systems

(ICES) Working Group on Widely Distributed Stocks 

Chapter 1: Introduction 


\subsection{A call for knowledge systems with greater openness}

Complex environmental problems, such as climate change, biodiversity loss, and overfishing, highlight the need to understand links within and between natural systems and socioeconomic systems (Ludwig, 2001; Folke et al., 2005; Levin et al., 2013). Mobilizing relevant knowledge is a key challenge when striving for such understanding. But whose knowledge is relevant? Furthermore, how can existing relevant knowledge be mobilized, and how can new knowledge be produced to inform decision-making? In this thesis, I will explore the challenge of knowledge production in the context of European fishery management.

The need for holistic approaches to environmental management has generated an interest in system perspectives on knowledge (Cash et al., 2003; Garcia and Charles, 2008; Cornell et al., 2013). Cornell et al. (2013) argue that the goal of sustainable development calls for replacement of existing knowledge systems, because the current ones simply do not deliver what is needed. They propose that new knowledge systems with greater openness should include, among other things, societal agenda setting, collective problem framing, better treatment of uncertainty and diversity of values, and stakeholder participation. For knowledge systems to become more open, scientific practices must be oriented towards the arenas where problems are being tackled, and interactions between scientists and other actors must be intensified. These proposals are not new; they are reiterations and developments of ideas associated with the concepts Mode 2 science and post-normal science, which were introduced more than two decades ago and continue to stimulate academic debate about the role of science in society. The Mode 2 concept was promoted by Gibbons and colleagues to describe what they saw as a societal shift towards a new form of knowledge production (Gibbons et al., 1994). This differs from traditional academic knowledge production - which they call Mode 1 - in several ways: It draws on contributions from many disciplines and is characterized by a heterogeneity of skills; it has a preference for organizational arrangements that are less hierarchical than traditional academic structures; it is more accountable to the wider society; and it involves an expanded system of quality control. This development towards a more open and distributed knowledge production reflects the emergence of a more open society, i.e. a Mode 2 society. A more dynamic interaction between society and academic knowledge production allows society to "speak back" to science, which allows interests and perspectives from a wider knowledge base to be further integrated into the research process (Gibbons, 2000; Nowotny et al., 2001; Nowotny et al., 2003). The post-normal science concept was introduced by Silvio Funtowicz and Jerome Ravetz and emphasizes the need for a novel approach to science that considers uncertainty (Funtowicz and Ravetz, 1993). The term post- 
normal science alludes to Thomas Kuhn's "normal" science, i.e. science that is carried out according to established routines and practices within academic disciplines and is only occasionally interrupted by scientific revolutions, which are termed paradigm shifts (Kuhn, 1962). Post-normal science is characterized by a combination of high uncertainty, disputed values, and high stakes. Decision-making in such settings calls for a knowledge base that, they argue, cannot be produced by traditional academic disciplines alone. Therefore, an extended peer community is needed (Funtowicz and Ravetz, 1993, p. 739).

Fishery management has many characteristics that echo the call for knowledge systems that are more open. Garcia and Charles (2008, p. 505) attribute the complexity of fishery systems to several factors acting in combination:

a) the fundamentally limited and extremely complex nature of a renewable resource, b) the exceptionally high level of uncertainty in fisheries resulting particularly from the non-observability of the fish in the sea, c) arguably higher level of complexity (multiple species, multiple fishing sectors, etc.) than found in most economic sectors, and d) strong global political and economic drivers due to both the high levels of societal interest in ocean ecosystems and the very high proportion of fish production that is internationally traded.

Fishery stakeholders' differing interests and conflicting social values further contribute to the notorious difficulty of managing fishery systems (Jentoft and Chuenpagdee, 2009). This complexity has inspired scientists to apply Mode 2 and the ideas of post-normal science to research on fishery science and management (Hauge et al., 2007; Wilson, 2009b; Dankel et al., 2012). Such contributions help improve our understanding of the role of uncertainty and the implications of the limits of scientific knowledge for fishery management. Challenges remain, however, when aiming for more open and efficient knowledge systems where contributions from an extended peer community can be considered.

Helping to clarify the debate about how to achieve efficient knowledge systems is the proposal that such efficiency involves trade-offs between the three attributes of salience, credibility, and legitimacy (Cash et al., 2002). Salience refers to the relevance of information to an actor's decision choices, or to the choices that affect a given stakeholder. Credibility refers to an actor's perception of whether or not information meets the standards of scientific plausibility and technical adequacy. Legitimacy refers to an actor's perception of whether or not the process in a system is unbiased and meets standards of political and procedural fairness (Cash et al. 2002, p. 4-5). The dilemma, and key point, is that it is difficult - maybe impossible - to optimize all three attributes simultaneously. For example, science is expected to produce knowledge that is credible, i.e. that can be trusted. Opening up the knowledge- 
production process through stakeholder participation can have a positive effect on the output's legitimacy; however, if broad participation leads to questions about the science's subordination to political influences, the increase in legitimacy can have a negative effect on the output's credibility. Also, if the knowledge produced fails to address problems that are on the decision-makers' agendas, it is likely to be ignored owing to lack of salience, no matter how credible and legitimate it may be. Therefore, a key challenge in environmental management is designing knowledge-production processes that optimise efficiency in blending these three attributes. Holm (2003), Jentoft (2000), and Wilson (2009b) offer indepth examinations of legitimacy issues in fishery science, and Röckmann et al. (2015) provide an illustrative application of salience, legitimacy, and credibility as effectiveness criteria for clarifying stakeholder roles and interactions in marine-ecosystem-based fishery management.

Further, the nature of knowledge itself makes it difficult to achieve efficient knowledge systems; knowledge is difficult to move and manage. Research on knowledge exchange (Fazey et al., 2013, Section 1.5) highlights the great divide between the above-mentioned visions of what more open systems can deliver and the current realities of knowledge production and use within environmental management. To improve our understanding of knowledge exchange, this thesis explores knowledge production in participatory processes in European fishery management, specifically in stakeholder-led collaborations in formulating management plans. The process of making fishery-management plans provides potential arenas or agoras, which Nowotny et al. (2003) envision as a "domain of primary knowledge production - through which people enter the research process, and where 'Mode 2' knowledge is embodied in people and projects." In these agoras, knowledge production takes place through the collaboration of actors from different knowledge domains, e.g. scientific, stakeholder, management, and policy domains. I will return to the challenge of knowledge exchange in Section 1.5. First, however, the following section gives an overview of the European fishery-management system. It introduces the relevant policy, the main actors, and the management plans used as instruments within this system.

\subsection{The European fishery-management system}

\subsubsection{The Common Fisheries Policy}

Ocean and coastal-fishery management in the EU is highly complex, involving many actors operating at several geographical and jurisdictional levels. Many fish stocks in EU waters are 
shared with non-EU countries and are subject to bilateral and multilateral negotiations and regulations. Within fishery-policy, the EU has exclusive competence vis-à-vis the Member States; common rules are adopted at the EU level and implemented at the Member State level. The Common Fisheries Policy (CFP) is the instrument used, and it is subject to reform every ten years. The 2002 CFP reform introduced two elements that are particularly relevant to the topic of this thesis: stakeholder participation through advisory bodies, and long-term approaches through multi-annual plans. During the research phase of this thesis, the 2002 version of the CFP Basic Regulation (Council, 2002) was replaced by a reformed 2013 version (EU, 2013). In the years leading up to the 2013 reform, policy-makers, managers, scientists, and stakeholders engaged in intensive deliberations about how to improve the $\mathrm{CFP}^{1}$. The debates were influenced by a critical analysis of the CFP's performance (Sissenwine and Symes, 2007) and by the European Commission's green paper (European Commission, 2009a). The documents highlighted several shortcomings of the management system under the 2002 CFP and presented ideas for improvement. See Lado (2016) for an indepth description of the CFP and its evolution, Hegland (2012) for a comprehensive analysis of CFP reforms in light of societal changes, and Eliasen et al. (2015) for some early observations and analyses related to the implementation of the 2013 CFP.

\subsubsection{Actors and processes}

Figure 1.1 gives a simplified overview of the EU fishery system after the 2013 CFP reform. It illustrates the representation and positioning of the three main categories of actors, i.e. the managers/policy-makers, scientists, and stakeholders. Through its departments (DirectoratesGeneral, DGs), the European Commission (Commission) is responsible for formulating EU regulations and policies. DG for Maritime Affairs and Fisheries (DG MARE) handles the CFP as well as the Integrated Maritime Policy. DG MARE is located in Brussels and employs approximately 400 staff members. The Commission drafts and proposes legislative measures to the Council of the European Union (Council) and to the European Parliament. Following the Lisbon Treaty, new legislation is adopted through co-decision between the two bodies. The European Parliament is an elected body with 751 delegates $^{2}$ representing the EU Member States. In the Council, Member States are represented by their ministers, which in matters

\footnotetext{
${ }^{1}$ Reform of the common fisheries policy. http://ec.europa.eu/fisheries/reform/index_en.htm (accessed 13 November 2016).

${ }^{2}$ The European Parliament: Organisation and operation. Fact sheets on the European Union 2016. http://www.europarl.europa.eu/ftu/pdf/en/FTU_1.3.3.pdf (accessed 13 November 2016).
} 
related to the CFP is the one who has fisheries in his/her portfolio. The Court of Justice of the European Communities (ECJ) rules in disputes related to EU, and thus CFP, legislation.

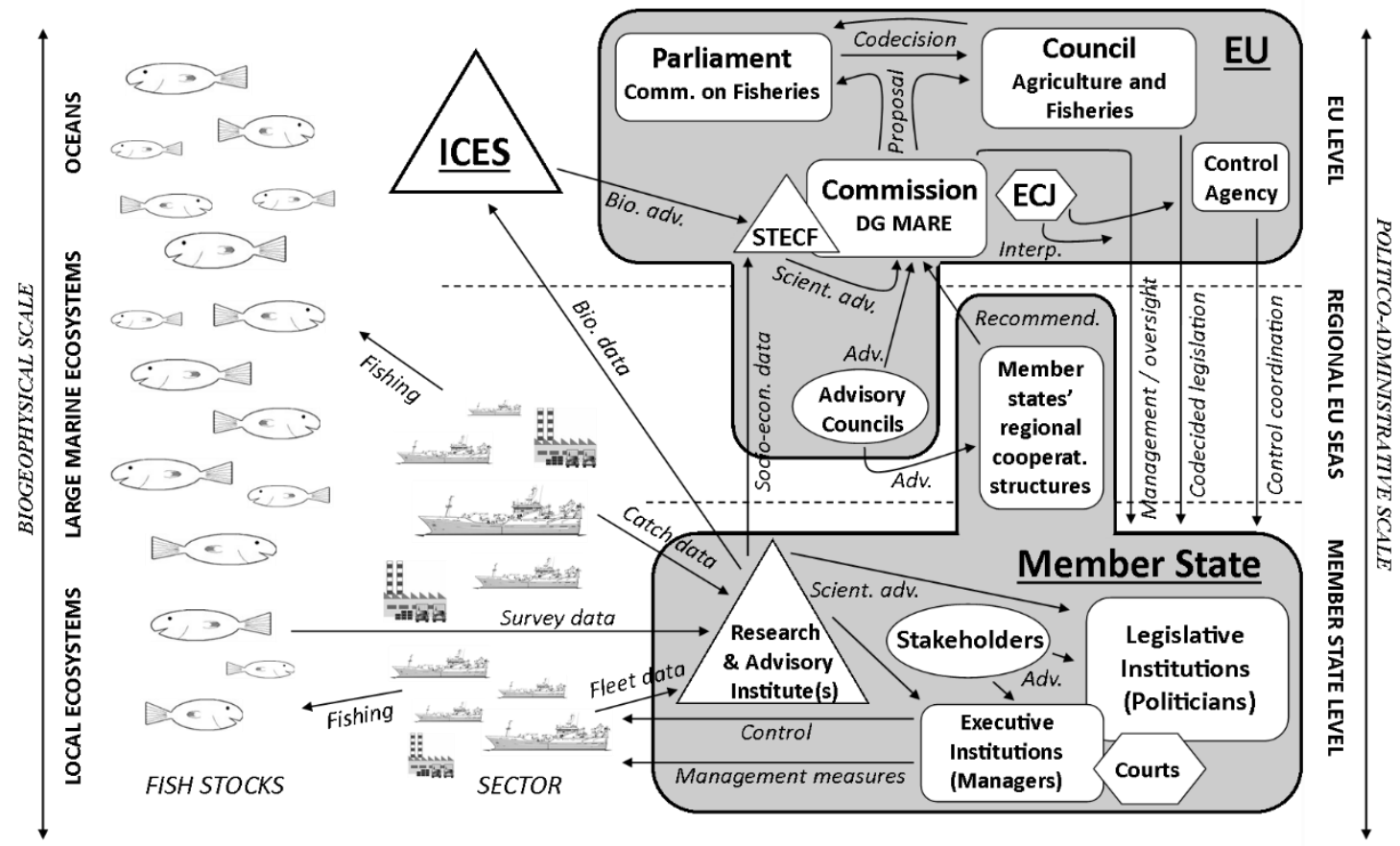

Figure 1.1. The EU fishery system.

Triangles $=$ scientific bodies. Hexagons $=$ legal bodies. Ellipses $=$ stakeholder bodies .

Rectangles with rounded corners = policy/management bodies. ICES = International Council for the Exploration of the Sea. STECF = Scientific, Technical and Economic Committee for Fisheries. ECJ = Court of Justice of the European Communities. Modified from Hegland, 2012, p. 22, updated by Hegland 2016; used with permission.

The annual setting of fishing opportunities is not subject to co-decision, and each year the Council decides on fishing quotas (total allowable catch; TAC) for fish stocks in EU waters, based on proposals prepared by DG MARE. This one-year-at-the-time routine on single species quota decisions gives the Council room to manoeuvre; however, it also makes longterm management difficult. The annual quota-setting process in the Council has been described as "horse trading", alluding to the political bargaining between Members States for highest national quotas possible. This culture has led to TACs being set inconsistently, frequently at levels higher than those recommended by scientists (Lado, 2016, p. 62).

The scientific advice underpinning TAC setting is supplied to DG MARE by the International Council for the Exploration of the Sea (ICES). ICES is a large, intergovernmental scientific network with headquarters in Copenhagen. The ICES network 
represents wide expertise on issues relevant to the biological and ecological components of the CFP. In Figure 1.1, ICES is positioned outside the EU and Member State administrative systems, reflecting ICES' independent status as a scientific body. The process of producing scientific advice has been perceived as being non-transparent and offering limited opportunities for stakeholder interaction (Daw and Gray, 2005; Hawkins, 2005). Recent reforms of ICES organizational structure and procedures have improved the situation to some extent (Wilson, 2009b; Stange et al., 2012). ICES advice to DG MARE is reviewed by the Scientific, Technical and Economic Committee for Fisheries (STECF), a scientific advisory body in the EU system, consisting of 30-35 experts appointed by the Commission. STECF provides DG MARE with advice on technical and economic issues relevant to fisheries.

Stakeholder involvement in EU fishery management was addressed in the 2002 round of CFP reforms. One tangible outcome was the establishment of the Regional Advisory Councils (RAC) "to enable the Common Fisheries Policy to benefit from the knowledge and experience of the fishermen concerned and of other stakeholders and to consider the diverse conditions throughout Community waters" (Council, 2002, p. 358/60). With the 2013 reform, the name of these stakeholder forums changed to Advisory Councils; both names are used in this thesis. The Advisory Councils advise DG MARE on issues related to fishery and marine management. ${ }^{3}$ From the outset, two-thirds of the seats in the RAC general assemblies and executive committees were allocated to fisher representatives and one-third to other interest groups. After the 2013 CFP reform, the Advisory Council seat allocation was adjusted to 60\% to fisher representatives and $40 \%$ to other interest groups (EU, 2013, p. 354/60). Currently, there are seven operational Advisory Councils" ${ }^{4}$ for the Baltic Sea (BSAC), the Long Distance Fleet (LDAC), the Mediterranean (MEDAC), the North Sea (NSAC), the North Western Waters (NWWAC), the South West Waters (SWWAC), and for Pelagic stocks (PELAC). The voices of these formalized stakeholder bodies within the EU fishery-management system are important to opening up the EU fishery-management knowledge system.

\subsubsection{Management plans}

Management plans were introduced in the 2002 CFP as instruments to allow longer term planning:

\footnotetext{
${ }^{3}$ Details about Advisory Councils' functioning are specified in Council Decision of 19 July 2004, establishing Regional Advisory Councils under the Common Fisheries Policy (Council, 2004) and Commission Delegated Regulation (EU) No ...... Laying down detailed rules on the functioning of the Advisory Councils under the Common Fisheries Policy (Commission, 2014a).

${ }^{4}$ Advisory Councils: http://ec.europa.eu/fisheries/partners/advisory-councils/index_en.htm (accessed 13 November 2016).
} 
...multi-annual plans should establish targets for sustainable exploitation of the stocks concerned, contain harvesting rules laying down the manner in which annual catch and/or fishing effort limits are to be calculated and provide for other specific management measures, taking account also of the effect on other species (Council, 2002, p. 358/5).

The terms recovery plans, multi-annual plans, long-term plans, and long-term management plans are used by the EU when referring to plans that have been formally implemented as regulations in EU waters ${ }^{5}$. In this thesis, the terms commonly applied in each specific setting referred to are used. The Commission saw management plans as a tool to reduce problems related to the Council's horse-trading culture during annual TAC setting, as mentioned above (Lado, 2016). More stable and predictable TACs would also be welcomed by the industry actors, as it would help their business planning.

The CFP 2002 did not specify how management plans should be produced. In practice, the development process would often start with a proposal generated by policy officers in DG MARE. Developing TAC-setting mechanisms, expressed as harvest control rules, became the key component of the plans developed, and the terms harvest rules and management plans have sometimes been used as synonyms (ICES, 2013d; Pastoors, 2016). ICES advises DG MARE whether or not a proposed harvest-control rule is in accordance with management objectives. An impact assessment is needed before a management-plan proposal can become EU legislation, and DG MARE requests advice on such assessments from ICES and/or STECF. Stakeholder involvement in the development and evaluation processes has generally been limited (Wilson, 2009a; Simmonds et al., 2011; Kraak et al., 2013). An exception was a long-term management plan for western horse mackerel which emerged in 2006-07 as an initiative of the Pelagic Regional Advisory Council (Pelagic RAC) (Clarke et al., 2007; Hegland and Wilson, 2009). The proposal developed by the Pelagic RAC was welcomed by DG MARE and was in 2009 proposed by the Commission to the Council for adoption as a formal regulation (European Commission, 2009b). However, the Lisbon Treaty, which entered into force in 2009, prevented the proposal from being adopted as a regulation, because the Council and the European Parliament had differing views on management plans as legislative instruments and disagreed on the need for co-decision. This so-called interinstitutional deadlock prevented the development of management plans between 2009 and 2015. An inter-institutional Task Force attempted to clarify how to proceed with management plans as tools in the reformed CFP policy landscape, given these legal complications (Anon, 2015). ECJ decisions were needed to determine that management plans are indeed subject to

\footnotetext{
${ }_{5}^{5}$ Multi-annual plans. http://ec.europa.eu/fisheries/cfp/fishing_rules/multi_annual_plans/index_en.htm (accessed 13 November 2016).
} 
co-decision (ECJ, 2015). The first co-decided plan: a multiannual plan for the stocks of cod, herring and sprat in the Baltic Sea, has only recently been adopted as a regulation (EU, 2016).

In the 2013 reformed CFP (EU, 2013), multi-annual plans are prioritized as management tools to meet overall policy objectives: "Multi-annual plans shall be adopted as a priority, based on scientific, technical and economic advice, and shall contain conservation measures to restore and maintain fish stocks above levels capable of producing maximum sustainable yield" (Article 9-1). Stakeholder involvement is also specifically mentioned: "Those plans should be adopted in consultation with Advisory Councils, operators in the fishing industry, scientists and other stakeholders having an interest in fishery management" (preamble 24).

This short overview of management plans illustrates that many actors from different knowledge domains are involved in developing and evaluating such plans. Management plans are therefore interesting as arenas for mixed-actor knowledge production. In this context, three of the principles of good governance guiding the CFP are especially relevant and need to be considered, i.e. "decision-making based on best available scientific advice, broad stakeholder involvement and a long-term perspective" (EU, 2013, p. 354/23). As illustrated in Figure 1.1, scientific advice enters the EU fishery-management system through ICES and STECF, while stakeholder advice is channelled through the Advisory Councils. The combination of science-based management and stakeholder involvement creates tensions and interesting dilemmas about whose knowledge is relevant and how knowledge should be produced and used to support decision-making. The next section discusses the challenges related to knowledge integration as further clarification about how these tensions and dilemmas are manifested in European fishery management.

\subsection{The challenge of knowledge integration}

Scientific knowledge, that is knowledge systematically recorded and validated by the scientific method, has a unique status in modern western societies. Accordingly, descriptions in the scientific literature of various forms of knowledge typically identify scientific knowledge as a distinct category, whereas labels such as local, lay, traditional, and informal are used to describe and categorize other non-scientific forms of knowledge (Raymond et al., 2010; Nursey-Bray et al., 2014). In the context of fishery science and management, this "other" category encompasses the terms fishers' ecological knowledge and the broader fishers' knowledge (Soto, 2006; Bjørkan, 2011; Hind, 2015). Fishers' knowledge that can be used in an open and participatory knowledge system includes information about temporal and spatial fish abundance, location of spawning grounds, seabed characteristics, use and 
efficiency of gear types, and fishing-fleet behaviour. Historically, however, integration of such contributions into research and management has been limited, as pointed out in a recent review of fishers' knowledge research: 'Fishers' knowledge has been neglected by not just the scientists at the forefront of fishery research but also by eminent policy-makers at governance institutions" (Hind, 2015, p. 341).

A more nuanced picture emerges when the fit of fishers' knowledge - or lack of fit - is addressed, emphasizing the qualitative nature of such knowledge. Part of the problem with knowledge integration is that CFP-related fishery science and management is deeply rooted in a quantitative scientific paradigm. This science-based system has been described using the metaphor of a TAC-machine. The "machine" alludes to the routine of quantitative fish-stock assessment and advice based on TACs produced by ICES, followed by TAC proposals advanced by the Commission, and finally decisions taken by the Council (Holm and Nielsen, 2004; Schwach et al., 2007). An apparent consequence of this routine is the lack of entry points into the CFP "machinery" for qualitative fisher knowledge. An example is the limited use and utility of information collected by fishers in the Fishers' North Sea Stock Survey (NSSS) $^{6}$. In this survey, fishers' perceptions of the state of fish stocks in the North Sea have been collected annually since 2002 to make this knowledge available to scientists and managers. A review conducted after the first few years highlighted some problems preventing efficient use of the survey results:

One of the main problems from a methodological perspective is that the Survey is neither qualitative nor quantitative. This means that the Survey does not gain the benefits (high validity or high reliability) from being in-between but collect all the losses (low on both validity and reliability) (ICES, 2006, p. 9).

Some adjustments were made, based on recommendations from the review; however, the opening paragraph of the annual NSSS reports still reads, "Given the non-quantitative and subjective nature of this survey the results contained in this report should be interpreted and used with caution" (Napier, 2014, p. 4). Lack of uptake of NSSS results has generated frustration among the fishers, which possibly explains their declining interest in participating in the survey:

Anecdotal evidence in previous years suggests that a factor behind the decline in the number of responses over recent years may be that fishers do not perceive that the results of the survey have any influence on assessments of fish stocks or on management decisions, and thus are losing faith in the value of the survey (Napier, 2014, p. 97).

\footnotetext{
${ }^{6}$ Fishers’ North Sea Stock Survey. http://nsss.eu/ (accessed 13 November 2016).
} 
In addition to illustrating challenges related to the integration of knowledge between scientific and non-scientific knowledge domains, the NSSS example also serves to illustrate that collaborative efforts between scientists and fishers often emphasize collection of data by fishers for use by biologists; see the review by Hind (2015). Recent developments, however, including interdisciplinary research projects such as GAP2 (see below) and conferences addressing how fisheries dependent information (FDI) can enrich science and management, signal an ambition to broaden such collaborations (Graham et al., 2011; Dorner et al., 2015; Stephenson et al., 2016). Observations shared by the conveners of the second FDI conference in 2014 point to substantial ongoing changes in "opening up" fishery-knowledge systems: "We noted that since the 2010 FDI conference a paradigm shift towards full engagement of key stakeholders started to take place" (Dorner et al., 2015, p. 1133). The research presented in this thesis took place in the middle of this paradigm shift. To clarify how the research context and setting influenced the framing of questions, approach, and implementation, the next section introduces the project in which this research was one of several activities.

\subsection{Research context and GAP2}

This thesis presents research undertaken as part of the project "GAP2: Bridging the gap between science, stakeholders, and policy-makers Phase 2: Integration of evidence-based knowledge and its application to science and management of fisheries and the marine environment ${ }^{7}$." Building on outcomes, experiences, and collaborations established in GAP1, (Mackinson et al., 2011), the GAP2 project set out to further stimulate collaboration between scientists and fishery stakeholders, based on an understanding that (i) the evidence base for management improves if fishers' knowledge and experience are integrated consequentially with scientific and policy knowledge; (ii) sharing and co-constructing knowledge improves the implementation and effectiveness of management measures; and (iii) sharing and coconstructing knowledge improves the support for policy and societal goals to achieve responsible, sustainable, and productive fisheries ${ }^{8}$. Figure 1.2 illustrates GAP2's vision.

\footnotetext{
${ }^{7}$ GAP2. http://gap2.eu/ (accessed 13 November 2016).

${ }^{8}$ GAP2 Report Summary, CORDIS: http://cordis.europa.eu/result/rcn/171726_en.html (accessed 13 November 2016).
} 
(a) Stakeholder collaboration

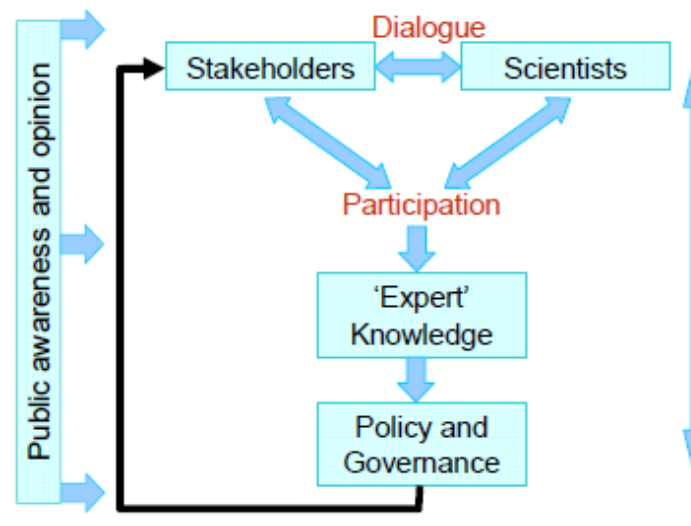

(b) Stakeholder consultation

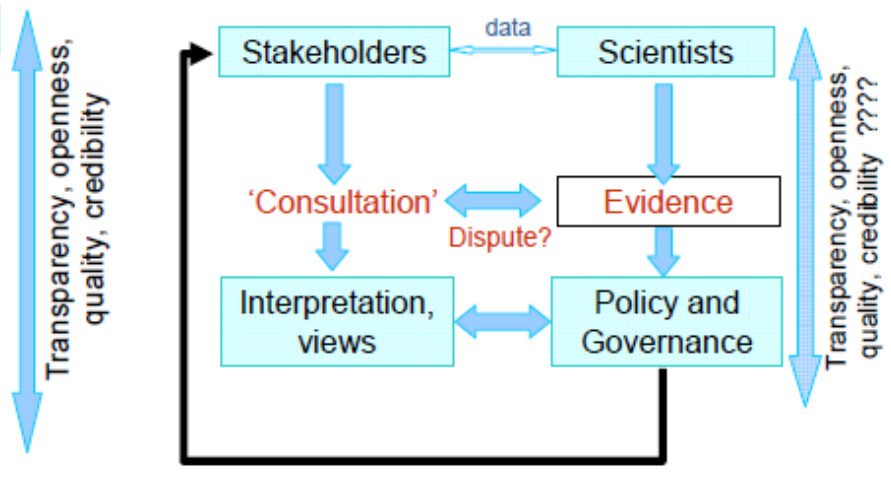

Figure 1.2 GAP2 conceptual overview. (a) Conceptual overview of the collaborative or participatory approach rationale supporting GAP2's aims. (b) A consultation type of approach as contrast. In both cases, public awareness and opinion influence the demand for knowledge and how it is applied. Source: GAP2 Work Programme, p. 10.

Figure 1.2 draws attention to the differences between collaboration and consultation in the roles of scientists and stakeholders in producing knowledge (or evidence) for decisionmaking. In a collaborative setting (Figure 1.2a), it is envisioned that stakeholder input can be integrated with scientific input in "expert knowledge" through dialogue and participation. Such a collaborative approach is perceived as being different from a consultative approach (Figure 1.2b), where the stakeholder's role is to supply data and comment on evidence produced by scientists. The latter alludes to the arguably not-very-open, TAC-machine-driven knowledge system that currently supports the CFP, in which evidence produced by fishery scientists tends to be disputed by the fishers, e.g. on the status of fish stocks (Gray et al., 2008). The consultative role of stakeholders in the current system is manifested in the role of the Advisory Councils. These stakeholder bodies are typically asked to comment on proposals and evidence produced by scientists and managers (Linke et al., 2011; Linke and Bruckmeier, 2015). In the GAP2 project, Advisory Councils were involved as project partners, and their representatives participated in workshops and meetings together with scientists and managers. This mixed-actor setting provided valuable opportunities for sharing views, testing ideas, and framing problems on e.g. the role of management plans as instruments and the involvement of stakeholders in management-plan processes ${ }^{9}$.

A "watering can" cartoon (Figure 1.3) was developed to stimulate discussion about collaborative and integrative processes that might be involved in the co-production of the

${ }^{9}$ GAP2 WP3 workshop on long-term management plans: http://gap2.eu/gap2wordpress/wpcontent/uploads/2012/11/GAP2-LTMP-workshop-20120705-report-FINAL.pdf (accessed 13 November 2016). 
mixed "expert knowledge", as shown in Figure 1.2a. The cartoon (Figure 1.3) illustrates the different qualities of and perceptions about knowledge contributions from the stakeholder and scientific domains. It also suggests that the system is designed to allow only scientific contributions to become part of the knowledge base. The "entry requirements" would therefore need to be modified to allow the integration of stakeholder contributions into the knowledge base, which forms the basis for decision-making. Alternatively, stakeholder knowledge can be amalgamated into outputs that are recognized as scientific contributions. Such a "scientific route" to uptake of stakeholder knowledge can be exemplified by participatory research projects driven by scientists. This form of collaboration is widely studied and best practices are proposed based on experiences in various research settings (Reed, 2008; Hegger et al., 2012; Thornton and Scheer, 2012; Reed et al., 2014). An alternative "stakeholder route" would emerge when stakeholders engage scientists with the aim of making their own stakeholder output more scientific, and so better aligned with the system's entry requirement for knowledge contributions. The western horse mackerel management plan mentioned above (Hegland and Wilson, 2009) exemplifies such a stakeholder-route collaborative process. Knowledge production in stakeholder-led, mixedactor collaborations is rarely studied, but the GAP2 project provided the necessary research context for investigation. Referring to the watering-can cartoon, the research presented in this thesis emphasizes processes in the mixing zone, where knowledge contributions from stakeholders and scientists meet. Such explorations call for a conceptual framework to understand the dynamics of knowledge and knowledge sharing between actors from different knowledge domains. The next section introduces insights from the scientific literature on knowledge and boundary processes to clarify the choice of the theoretical approach in the research undertaken. The conceptual considerations are further discussed in Chapters 3-5. 


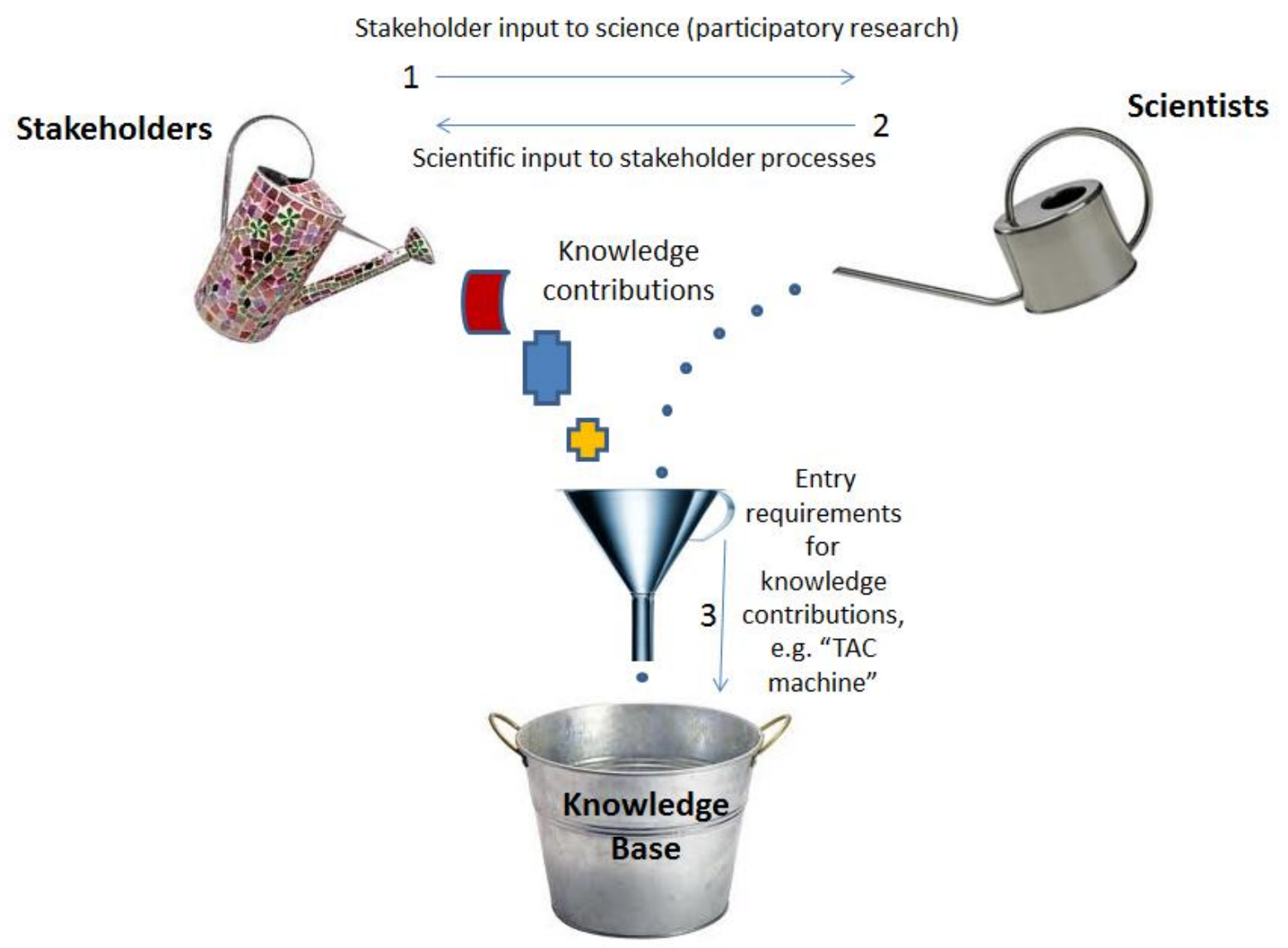

Figure 1.3 Watering cans with knowledge contributions from stakeholders and scientists to the knowledge base of EU fishery management. The two watering cans represent scientific and stakeholder knowledge. The bucket represents the knowledge base that EU fishery managers draw from when making decisions. The funnel represents the strict entry requirements for knowledge contributions aiming for the bucket; knowledge has to be packaged in a certain way to align with the system requirements. Arrow 1: Involvement of stakeholders in the production of scientific knowledge. Such collaborations would allow stakeholder knowledge to be taken into account, whereas the output is still recognized as scientific knowledge contributions. Arrow 2: Involvement of scientists in the production of stakeholder knowledge. Such collaborations would make stakeholder knowledge contributions aimed for management more scientific and possibly better aligned with the entry requirements. Arrow 3: Uptake of knowledge contributions into the knowledge base for EU fishery management. The funnel indicates that access is restricted to knowledge contributions with certain characteristics. Changing the shape of the funnel would allow different kinds of knowledge contributions to pass through and thus be integrated into the knowledge base. 


\subsection{Understanding knowledge at boundaries}

Knowledge is a multifaceted concept that has occupied philosophers and scientists since ancient times. Building on traditional epistemology, Nonaka (1994, p. 2) describes knowledge as "justified true belief". Knowledge can be understood as something "inherently personal" (Raymond et al., 2010, p. 1769), as people interpret the same information in different ways, depending on their personal perspectives and ideologies. Attempts to categorize knowledge include the labels tacit and explicit. Tacit knowledge refers to subjective knowledge that is based on an individual's experiences and is difficult to express in words; it is explained by Polanyi as "we can know more than we can tell" (cited in Nonaka, 1994, p. 16). Explicit knowledge, in contrast, can be articulated in language and can thus be passed on to others through spoken or written records. How tacit knowledge can be made explicit is thus of particular interest when trying to understand how new knowledge is generated. Dialogue has been proposed as a key factor in such processes; however, generation of new knowledge through dialogue is challenged when the individuals engaged start out with different kinds of knowledge (Nonaka, 1994; Carlile, 2004; Tsoukas, 2009). Sharing knowledge between actors from different social worlds, e.g. scientists and stakeholders (Verweij et al., 2010; Garrett et al., 2012) and across epistemic boundaries, e.g. between different disciplines (Degnbol et al., 2006; Roux et al., 2006), is particularly challenging.

Research that aims to advance our understanding of knowledge processes in environmental management is currently emerging under the label knowledge exchange, a term that encompasses sharing, generation, co-production, co-management, and brokerage of knowledge (Fazey et al., 2013; Cvitanovic et al., 2015). Several process-related knowledge gaps have been identified within this field; we need to better understand the effectiveness of different forms of interaction and how knowledge is transformed (Fazey et al., 2013, p. 31). Insights from science and technology studies (STS) and organization science on processes at boundaries can be used to understand such processes. Carlile (2004) describes a framework for analysing knowledge transfer between actors, across boundaries (Figure 1.4).

The framework describes boundaries at three levels: syntactic, semantic, and pragmatic. The different levels call for tailored processes of knowledge management to match the degree of complexity: transfer, translation, and transformation (i.e. 3T). Increasing novelty implies a decreasing overlap between the actors' domain-specific knowledge; as a result, knowledge management and exchange processes become more complex. Attention to different levels of complexity at boundaries between actors sheds light on the need to tailor collaborative processes to allow knowledge sharing and generation of new knowledge. An example of what 


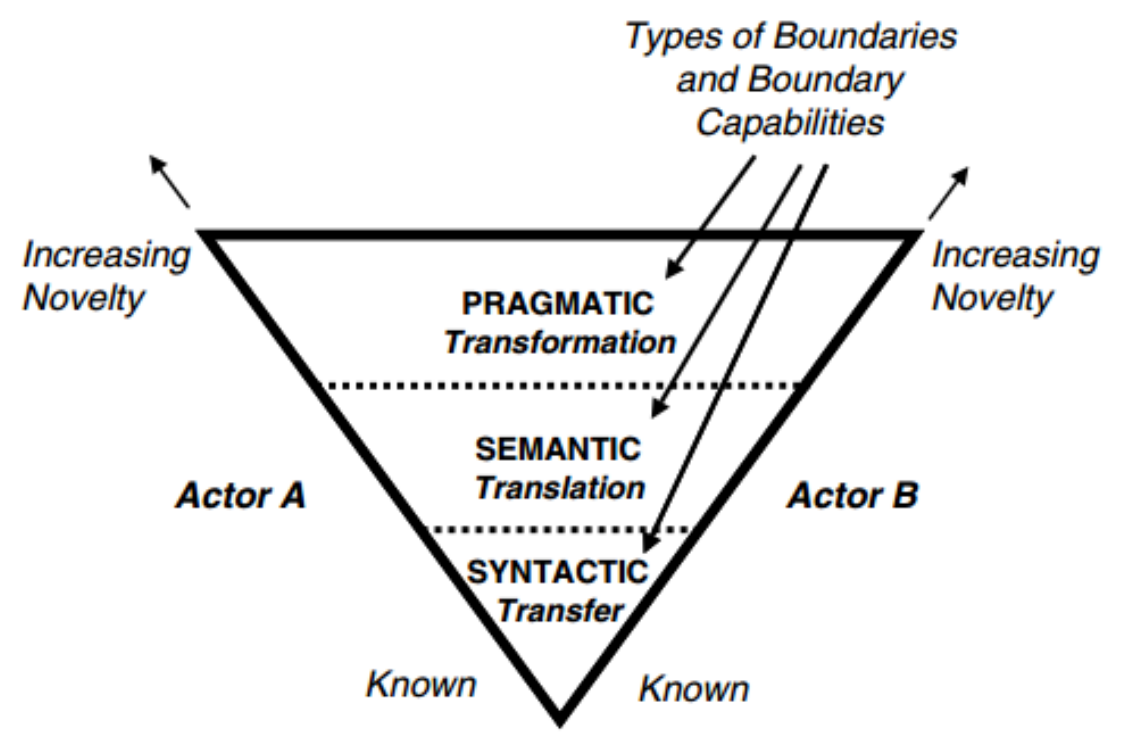

Figure 1.4 An integrated/3T framework for managing knowledge across boundaries. A boundary is imagined as a vector between at least two actors. At the origin, differences and dependencies are known. As novelty increases, the vector spreads, scaling the increasing complexity and the amount of effort required to manage the boundary. Source: Carlile, 2004. Reproduced with permission. Copyright, INFORMS, http://www.informs.org.

Carlile identifies as a semantic boundary when developing a management plan could be actors developing a common understanding of how the term maximum sustainable yield (MSY) should be understood, or how a scientific fish-stock assessment relates to quota setting. A translation approach is then called for to facilitate the sharing of knowledge between actors from different knowledge domains. Another example could be actors trying to agree on the formulation of specific objectives to be included in a plan. For instance, negotiations and trade-offs are required when balancing conservation interests represented by NGOs and economic interests represented by the fishing industry or balancing different interests of fishing fleet components. In that case, a pragmatic approach, in Carlile's terminology, involving transformation boundary-knowledge management processes comes into play. The kinds of tools that can be applied or structures that must be in place to allow knowledge transfer between actors depend on the context. Boundary objects exemplify tools that can help connect actors at boundaries (Star and Griesemer, 1989; Lamont and Molnar, 2002; Star, 2010). Carlile's framework highlights the distinctions between the types of boundaries involved in knowledge exchange between actors, requiring boundary objects with different capacities. Analysing the dynamics of knowledge generation during the collaborative processes of developing management plans can elucidate the characteristics of boundary objects in these particular settings. The insights form the basis of an approach to studying 
knowledge exchange between actors from different knowledge domains, which is used and further developed in this thesis.

The concept of boundary objects is one of several that has proven useful when studying processes at boundaries. The boundary of primary interest in this study is between individual actors who come together to produce new knowledge. However, the research context is at the science-policy interface, which is also a boundary. At the science-policy interface, the role of science in society and the uptake of knowledge by managers and policy-makers are research fields in their own right, and boundary objects as well as other boundary concepts are highly applicable as research tools. A brief review of boundary concepts is therefore included here to clarify the meaning and uses of boundary terms.

[I]f the notion of boundaries has become one of our most fertile thinking tools, it is in part because it captures a fundamental social process, that of relationality. ... This notion points to fundamental relational processes at work across a wide range of social phenomena, institutions, and locations (Lamont and Molnar, 2002, p. 169).

Among the four ${ }^{10}$ general areas of research where Lamont and Molnar found the study of boundaries to be prominent, the area of professions, knowledge, and science is particularly relevant to the topic of this thesis, because it explains the role of science, scientists, and knowledge at various boundaries. The concept of boundary work was coined by Thomas Gieryn (1983) in a paper in which he discussed why and how social boundaries are constructed to separate science from non-science and to create ideological demarcations of disciplines, specialties, or theoretical orientations within science. Gieryn presented his paper as a contribution to (and escape from):

...seemingly interminable debates over the uniqueness and superiority of science among knowledge producing activities: Demarcation is as much a practical problem for scientists as an analytical problem for sociologists and philosophers. Descriptions of science as distinctively truthful, useful, objective or rational may best be analysed as ideologies (pp. 792-793).

Gieryn acknowledged that the demarcation between science and non-science is something of a moving target, because the boundaries of science are "ambiguous, flexible, historically changing, contextually variable, internally inconsistent, and sometimes disputed" (p. 792). Gieryn's ideas resonated with the debate about the role of science in society (e.g. Gibbons, 1999), and are frequently cited in the literature on new forms of knowledge production, e.g. Mode 2, see Section 1.1. The boundary work concept has also been used in a broader sense in studies of knowledge systems (Cash et al., 2002; Cash et al., 2003) and in evaluations of

10 a) Social and collective identity; b) class, ethnic/racial, and gender/sex inequality; c) professions, knowledge, and science; and d) communities, national identities, and spatial boundaries (Lamont and Molnar 2002, p. 169). 
natural resource-management programmes (Clark et al., 2010). These studies approach boundaries as both barriers and gaps in processes that aim to link knowledge with action.

The demarcation between science and non-science is highly relevant when engaging in research that addresses the gap between scientists and policy-makers. Sheila Jasanoff's studies of co-production of knowledge (2004) shed light on how better understanding of processes at the interface between science and politics can lead to more productive policymaking. At the science-policy interface, boundary organizations (Guston, 1999) act as intermediaries. They are characterized as being accountable to both sides of the boundary and by the use of boundary objects.

Star and Griesemer (1989) coined the term boundary objects and argued that the "creation and management of boundary objects is a key process in developing and maintaining coherence across intersecting social worlds" (p. 393). They describe boundary objects as:

...objects which are both plastic enough to adapt to local needs and the constraints of the several parties employing them, yet robust enough to maintain a common identity across sites. They are weakly structured in common use, and become strongly structured in individual site use. They may be abstract or concrete. They have different meanings in different social worlds but their structure is common enough to more than one world to make them recognizable, a means of translation (p. 393).

Although the concept of boundary objects first emerged in STS, its application has since spread to other academic fields where it has been adapted to fit the settings studied (Zeiss and Groenewegen, 2009). Carlile (2002; 2004) brought the concept of boundary objects into organization and management studies by exploring how boundary objects with different characteristics can support knowledge exchange in a new product development (factory) setting. As described above, Carlile argues that distinctions exist between types of boundaries between actors who must connect to exchange knowledge, requiring boundary objects with different capacities. In this thesis, these insights form a starting point for understanding knowledge exchange.

\subsection{Aims, objectives, and research questions}

The aims of this thesis are twofold. Set in the context of "opening up" knowledge systems for environmental management, one aim is to contribute to our understanding of knowledge production in participatory processes in CFP-related European fishery management. The CFP is subject to revision every ten years, and the debate continues about how this policy performs and how it can be improved and implemented. The topic of the thesis - how knowledge is produced and used in collaborations where stakeholders take the lead and engage others in 
developing EU fishery-management plans - is relevant to this debate. A second aim is to make a theoretical contribution to the interdisciplinary field of knowledge exchange. The objective is to investigate the use and production of knowledge in stakeholder-led collaborations to produce fishery-management plans by applying and developing boundary concepts.

The research question posed is: How is knowledge used and produced in stakeholder-led collaborations to make management plans for EU fishery management?

Three subquestions guided the research:

- How do boundary processes and boundary objects explain knowledge-production processes in stakeholder-led collaborations to make management plans for EU fishery management?

- How does stakeholder-led development of management plans provide arenas for bringing the knowledge and interests of different actors together?

- How are stakeholders, scientists, and managers involved in stakeholder-led collaborations to make management plans for EU fishery management, and what roles do they play in these knowledge-production processes?

\subsection{Outline and summary of papers}

This thesis has a paper-bundle format, which means that Chapters 3-6 are published separately as peer-reviewed papers in scientific journals. Chapters 1, 2, and 7 (Introduction, Methods, and Conclusions) provide the "wrapping" that makes the thesis a coherent contribution to academic scholarship. In this Introduction, I have set the stage by explaining the overall context in which this thesis aims to contribute and introducing the research questions. The methodology used is described at an overarching level in Chapter 2, and casespecific method details are included in each of the papers (Chapters 3-6). In Chapter 7, the findings are discussed, and conclusions are drawn based on cross-cutting insights from the four papers. A short synopsis of Papers I-IV is given below.

In Paper I (Chapter 3), a conceptual framework developed by Carlile (2004) is described and used to analyse boundary processes between diverse actors in a collaborative knowledgeproduction process. The paper presents a case study of a collaboration in which stakeholders in the North Sea (Regional) Advisory Council engage with scientists and fishers to make a long-term management plan for the Nephrops fishery in the North Sea. The case illustrates the challenge of transforming knowledge and reaching a common understanding when strong and diverging interests exist between the stakeholders involved. The findings point to the kind of 
resources that must be mobilized to allow knowledge sharing between actors at various levels of complexity. Paper I is co-authored with Jan van Tatenhove and Judith van Leeuwen and is published as an open-access research article in Science and Public Policy, an international journal that emphasizes public policy for science, technology, and innovation.

In Paper II (Chapter 4), Carlile's framework is used again in the case study of a collaboration between fishery stakeholders and scientists. Producing a long-term management plan was one of several elements in this collaboration, which aimed to develop a knowledge base for a new pelagic fishery for boarfish (Capros aper) in the Northeast Atlantic. The findings illustrate how several boundary objects helped transform knowledge. Boundary objects facilitated the development of a common understanding of what needed to be accomplished, which made the collaborations efficient. Paper II is published as an open-access research article in Fisheries Research, a multidisciplinary international journal that emphasizes fishery science, fishing technology, and fishery management.

Paper III (Chapter 5) builds on findings from Papers I and II and further investigates the interaction between boundary objects and activities in collaborations. In this paper, the Nephrops and boarfish cases are analysed using a framework that introduces boundary activities and boundary spaces as concepts to explain why and how boundary objects connect actors and facilitate knowledge exchange in mixed-actor collaborations. The paper aims to make a theoretical contribution to the understanding of knowledge-exchange processes in such mixed-actor settings. Paper III is co-authored with Judith van Leeuwen and Jan van Tatenhove. It is published as a research article in Maritime Studies, an open-access journal that concentrates on the social dimensions of coastal and marine issues throughout the world.

Paper IV (Chapter 6) considers management-plan making as illustrative examples of how increased participation in EU fishery science and management influences the work of fishery scientists. The paper describes the multiple roles that scientists may assume in a process of promoting management plans, from idea to implementation. Interaction with stakeholders in the Advisory Councils in these contexts points to new tasks and roles for scientists in the ICES community, and to the need for clear procedures to ensure that different roles are acted out transparently. Paper IV evolved from discussions at the 2013 meeting of ICES Working Group on Marine Systems (WGMARS) and is co-authored with Dorothy J. Dankel and Kåre Nolde Nielsen. It is published as an editor's choice, open-access Food for thought article in 
ICES Journal of Marine Science, an international journal focussing on scientific understanding of marine systems and the impact of human activities. 
Chapter 2: Methods 


\subsection{Research design}

In this research, "how" questions were formulated to address knowledge-exchange processes between actors collaborating on long-term management plans. To ensure the richness and depth of data required for investigating a real-life phenomenon, a qualitative research approach was chosen. Qualitative data are, according to Miles and Huberman (1994, p. 10), "well suited for locating the meanings people place on events, processes, and structures of their lives ... and for connecting these meanings to the social world around them" (emphasis in the original). A strength of qualitative data studies is their inherent flexibility; data collection and methods can be varied as the study proceeds. Qualitative data collected over sustained periods can provide "thick descriptions" suitable for investigation of processes (Miles and Huberman, 1994, p. 10).

In this research, the qualitative data strategy was combined with a case-study approach. According to Yin (2009, p. 13), a case-study research method is suitable when: (i) "how" and "why" questions are posed, (ii) the investigator has little control over the events, and (iii) the focus is on contemporary phenomena within a real-life context. All three conditions were met in the research contexts applied here. To allow the research questions to be explored in several settings and contexts, and for the issues to be illuminated from different angles, a multiple-case strategy was used. A multiple-case approach is preferable to a single-case approach, because it adds rigor (Yin, 2009). The unit of analysis in the case studies in this research is collaborations to make management plans.

\subsection{Selection of cases}

One overarching case selection criterion was that the process of developing a management plan should be initiated by stakeholders. Ideally, the process of developing the plan should be ongoing to allow observations of interactions between actors in real time. Also, the collaboration should have evolved beyond the idea stage so that sufficient material would be available to allow an analysis of the knowledge-production process.

To learn about Advisory Councils' engagement with management plans, I participated as an observer in several meetings of the NSAC and the PELAC; see Appendix 1. These two Advisory Councils deal with different fisheries - demersal vs. pelagic, mixed fisheries vs. single species, and many diverse operators vs. a few large operators - and it was deemed interesting to select cases that could illuminate differences between the NSAC and PELAC experiences with management plans. When I started attending NSAC meetings as an observer 
in 2012, their work with a management plan for North Sea Nephrops had been going on for several years, and was still ongoing. I was invited to attend their Nephrops Focus Group meetings to gain further insight into the process of plan making. With all three desired casestudy selection criteria met, the collaboration to make a North Sea Nephrops plan became the first in-depth case study (Chapter 3). From observing meetings of the PELAC, I learned about management issues and plans for several pelagic stocks, including boarfish, North Sea horse mackerel, and mackerel. When I started to attend PELAC meetings as an observer in 2013, their management plan for boarfish had recently been finalised and submitted. The fact that the boarfish plan was already finished meant that the opportunity to observe the development phase was past; however, those who had been involved in hands-on work with the plan were available for interviews. The selection criteria were thus reasonably well met, and the boarfish collaboration became the second in-depth case study (Chapter 4).

The third study (Chapter 5) involved developing and testing a new boundary spaces framework for analysing knowledge exchange between actors in mixed-actor collaborations. Together, the Nephrops and boarfish cases provided a rich context for this (re-)analysis. Although the initial analysis of the Nephrops case (Chapter 3) followed the development of the Nephrops plan until July 2013, the re-analysis (Chapter 5) spanned a longer period and included developments up until the plan was finalised and submitted in February 2015.

The fourth study (Chapter 6) examined the many different roles played by scientists in the making of management plans. The topic emerged within the ICES Working Group on Marine Systems (WGMARS) when the group was asked by ICES to comment on procedures for evaluating fishery-management strategies and plans. A WGMARS scoping exercise highlighted that a wide variety of actors and procedures are involved in the management-plan processes (ICES, 2013b). Two cases, the Northeast Atlantic mackerel and North Sea horse mackerel, were selected for further investigation of this diversity in management-plan processes. Access to data from observations in PELAC meetings and access to informants with in-depth knowledge of the issues of interest were important factors when choosing these two cases as illustrative examples of scientist involvement in management-plan processes.

\subsection{Data collection}

This research builds on qualitative data collected from documents, interviews, and observations. The use of multiple methods allowed triangulation, i.e. to check and validate findings by combining evidence from different sources (Yin, 2009). The three methods 
complemented each other. For example, document studies allowed me to identify key actors who could be approached for interviews. The interviews were useful in clarifying issues that had been mentioned in meetings that I had attended. Interviews also provided opportunities for going into depth and adding richness and context to issues that were described in documents or mentioned in meetings. Sometimes this worked the other way around, i.e. issues mentioned in interviews spurred me to investigate documents.

\subsubsection{Document studies}

Documents were used to gain an overall understanding of the issues investigated, establish timelines, and identify key actors in the collaborations of interest. Minutes from NSAC meetings (http://www.nsrac.org/) and PELAC meetings (http://www.pelagic-ac.org/) were a rich source of information. These freely available minutes are detailed, and information about who said what is often included. The level of detail allowed identification of individuals who had interests and stakes in issues related to management plans. In the boarfish case (Chapter 4), newsletters from the Killybegs Fishermen's Organsiation (KFO; http://www.kfo.ie/) gave useful insights into how issues related to the need for new knowledge to support management decisions in the boarfish fishery were communicated within a fishery stakeholder organisation. Reports from various ICES Working Groups and ICES Advice were likewise useful sources. These ICES reports - also freely available at http://www.ices.dk/ - provide information on the status of fish stocks and the work by scientists who are producing scientific advice for EU fishery management. Policy documents studied included the CFP and documents related to the Advisory Councils and management plans, which are freely

available from the website of the European Commission at http://ec.europa.eu/fisheries/cfp_en.

\subsubsection{Interviews}

The interviews conducted as part of the qualitative data collection strategy were semistructured, i.e. "with the purpose of obtaining descriptions of the life world of the interviewee in order to interpret the meaning of the observed phenomena" (Kvale and Brinkmann, p. 3). Some interviews were of a scoping character; they aimed at collecting information about management plans in general and about the role of stakeholders, scientists, and managers in making them. Other interviews were narrower in scope and sought to bring out or verify facts related to a specific management-plan process. Interview guides, with mostly open-ended questions, were prepared for each interview to focus the conversation on issues about which 
the interviewee's competence and experience were particularly relevant to this study. An example of an interview guide is included in Appendix 2.

Potential interviewees were identified in several ways. As mentioned, documents provided names of individuals who were - or had been - involved in the collaborations of interest. Also, observing the meetings made it possible to identify individuals with interests and stakes in issues related to management plans. "Snowballing" was also practiced; interviewees were asked for names of others who could provide relevant information. In total, 43 interviews were conducted; see Appendix 3. An effort was made to conduct the interviews face-to-face; however, for logistical reasons, 13 interviews were conducted via telephone or Skype. Six of the interviews related to studying the roles of scientists (Chapter 6) were conducted together with co-authors. I conducted the other interviews in my role as principal investigator. The interviews ranged between 20 and 120 minutes, with an average time of approximately 40 minutes. With a few exceptions, they were recorded and transcribed. For others, detailed notes were taken.

\subsubsection{Observation}

Observation as a research method "puts you where the action is" (Bernhard, 2006, p. 344). The phenomena studied here, i.e. collaborations to make management plans, do not have a physical location. It was not possible, therefore, to observe the process "on site" over time, as in an anthropological study. Instead, observations took place in a variety of settings (see the overview of meetings in Appendix 1). Those involved in the collaborations of interest to this research are typically employed by stakeholder (fishers') organisations, marine research institutes, and government laboratories, and they are located in different countries. They meet in various constellations, e.g. in Advisory Councils, ICES working groups, and project meetings where issues related to management plans are discussed. Participation as observer provided insights into the complex field of European fishery management. Importantly, it provided opportunities to learn about the roles of various actors and how the actors interrelate. In the Nephrops case (Chapter 3), several meetings were arranged to work specifically on the Nephrops management plan. I was able to attend two such meetings, which provided valuable opportunities for first-hand observation of the process of making the Nephrops management plan, in real time.

I took detailed field notes during all observed events. With a few exceptions, my role in the meetings was as a passive observer. Prior to these events, I had explained my situation and research interests to the organisers. My affiliation and interest in management plans were 
explained in the tour de table introductions that are typically part of the routine in these meetings. In the GAP2 project meetings, I played an active role as participant, and in one GAP2 workshop my role was co-organiser.

A month-long study visit to the Scottish Fishermen's Federation in Aberdeen provided opportunities to observe fisher representatives in informal settings, i.e. outside meetings. My study visit included field trips to the Scottish fishing harbours Fraserburgh, Peterhead, and Lerwick. Fieldwork for the boarfish study included study visits to Killybegs Fishermen's Organisation in Donegal and the Marine Institute in Galway. These visits contributed to my understanding of the social context of the fisheries for which the management plans were produced.

\subsection{Analysis}

Documents, interview transcripts, and observer notes were assembled and organised with the aid of ATLAS.ti qualitative analysis software (www.atlasti.com). The software made it possible to structure, retrieve, and combine information from a large number of documents. Coding schemes (Miles and Huberman, 1994) were used to label and identify text segments. An example of a coding scheme is given in Appendix 4. The coding schemes were created to make links between the research questions and the empirical data. As such, they represent operationalisations of the conceptual frameworks used for the analysis.

In each case, a detailed narrative of the process of making the management plans was created. These narratives established timelines, identified key actors, and ascertained milestones achieved for tangible output produced by the collaborations. These narratives (what happened?) were used as starting points to investigate in more depth the roles of actors and their knowledge (how did they produce knowledge together?). Boundaries were investigated as interfaces between actors and between forms of knowledge (how did boundary objects and activities facilitate the collaborative process?). In each case, ideas and interpretations were tested and developed in an iterative process that included dialogue with co-authors and other research colleagues at meetings and conferences. Key informants were asked to review draft versions of manuscripts and provide feedback on the story of how the collaborations had evolved. The data were revisited several times, and the findings were revised in an iterative process. 


\subsection{Validity and reliability}

The terms validity and reliability are central to ensuring and evaluating the quality of research. Validity refers to a method's success at investigating what it intends to investigate; reliability addresses the findings' consistency and trustworthiness and the research's reproducibility by others leading to the same results (Kvale and Brinkmann, 2009, pp. 245246). Validity has an internal and an external dimension. Internal validity refers to the credibility and authenticity of the findings; external validity addresses transferability with regards to how the findings can be generalised (Miles and Huberman, 1994, pp. 278-279). A characteristic of qualitative research is that it can contribute generalizable knowledge by generating, testing and validating theory (Patton, 2015, p. 719). Qualitative data can be analysed to develop theoretical ideas about processes that have relevance beyond the data themselves (Coffey and Atkinson, 1996). In this thesis, considerations of external validity are applicable to the theoretically oriented findings, and I will return to this issue in Section 7.4.

Kvale and Brinkmann (2009) emphasise that the quality of an interview investigation depends on the craftsmanship of the researcher. Validity can be ensured by integrating checks on credibility, plausibility, and trustworthiness into every step of the research process - from thematising and designing, via interviewing, transcribing and analysing, to validating and reporting of findings (ibid, pp. 248-249). In this research, internal validity is addressed in several ways. The study design included use of multiple methods for data collection, as described in Section 2.3. Triangulation allowed the confirmation of the consistency and convergence of data from multiple sources. Diverging information from various sources triggered questions about possible alternative interpretations and explanations. Interviews were planned and conducted following the requirements outlined for qualitative research interviewing (Kvale and Brinkmann, 2009). This included the use of interview guides that were designed to focus the semi-structured interviews on issues related to the research questions, and using multiple approaches to identify potential informants. The findings were validated by asking for informant feedback on project reports and draft versions of manuscripts. Finally, presentations at scientific conferences (see the list in Appendix 1) and publication of findings in scientific journals (Papers I-IV) provided opportunities to validate the research approach and to interpret the results through peer review.

As in all research endeavours, my own interests, knowledge, and prejudices have unavoidably influenced the way I framed questions and how I interpreted information. The descriptions and reflections in this Method chapter provide transparency and allow evaluation of biases. Section 1.4 provided information about the GAP2 research context and highlighted 
a general positive attitude to science-stakeholder collaboration among project participants, an attitude that I share. To ensure rich data material, I selected cases of collaborations that had advanced beyond the idea stage. These were implicitly "success stories" in that the collaboration had progressed towards a common goal, i.e. without implying that the collaborations had produced output evaluated as a "success". The research benefited from access to informants with hands-on experience with the management-plan development processes of interest. Some of the informants had themselves taken the initiative to get the work with the management plans started, and had played key roles in driving the initiatives forwards. Thus, the plan and process studied were "theirs", and I considered myself a guest in "their process". The informants' attitudes to my study were generally very positive; some found my academic interest in their collaborative initiative stimulating. I followed their collaborations over some time and developed an interest in the fisheries related to the management plans in question.

Reliability of qualitative research can be enhanced by providing opportunities for audit. Copies of data - interview guides, recordings, transcripts, observer notes, and coding schemes used for the analysis - have been deposited according to the Data Management Policy of the Environmental Policy Group at Wageningen University and Research, version March 2014. Details regarding how data were collected and analysed (Sections 2.1-2.4. above and Appendices 1-4) further enhance the study's reliability. It is important to note, however, that a qualitative study of real-life phenomena, such as the ones investigated in this research, is context dependent and cannot be repeated the same way a quantitative experiment can be replicated (Yin 2009, Patton, 2015). Further reflections on the research approach are included in Section 7.4. 


\section{Chapter 3: Stakeholder-led knowledge production: Development of a long-term management plan for North Sea Nephrops fisheries ${ }^{11}$}

\section{Paper I}

11 This paper is published as Stange, K., Van Tatenhove, J., and Van Leeuwen, J. 2015. Stakeholder-led knowledge production: Development of a long-term management plan for North Sea Nephrops fisheries. Science and Public Policy, 42: 501-513. Numbering of sections, figures and footnotes has been edited to integrate this text as a thesis chapter. 


\begin{abstract}
This paper investigates how different kinds of knowledge are mobilised in interactions between the stakeholders, scientists and bureaucrats who are involved in EU fisheries management. It reports on an initiative led by the North Sea Regional Advisory Council aimed at making a long-term management plan for Nephrops fisheries in the North Sea. The sharing of knowledge between the actors is explored using insights from organisation management, focusing on the kinds of resources and efforts that are needed at different boundaries to allow knowledge sharing and knowledge production to occur. The findings point to the challenge of reaching a common understanding between actors when both novelty and high stakes are involved. Experiences gained during this pioneering initiative raise questions about how far it is possible to take a 'bottom up' collaborative process aimed at developing management instruments within a setting where there are conflicts of interests between the stakeholders involved.
\end{abstract}

Keywords: knowledge production, fisheries management, stakeholder participation, Common Fisheries Policy, knowledge exchange 


\subsection{Introduction}

The production and use of knowledge are important elements of sustainable environmental management (Cash et al., 2003; Cornell et al., 2013). Over the last few decades, the dominant role of scientific knowledge in management and policy processes has been challenged. Decision-making may take place within networks of interdependent actors who all have a share of knowledge and who do not take scientific authority for granted (Metze, 2010). At the same time, researchers point to a gap between the knowledge produced by science and the use of knowledge in policies and politics (Etzkowitz and Leydesdorff, 2000; Gibbons, 2000; McNie, 2007; Nowotny et al., 2001; Seijger et al., 2013; Van de Ven and Johnson, 2006). Several participative or interactive ways of producing knowledge have been suggested to bridge this gap. These include Mode 2 (Gibbons et al., 1994), post-normal science (Funtowicz and Ravetz, 1993), and engaged scholarship (Van de Ven and Johnson, 2006). In these forms of knowledge production, emphasis is given to producing salient, credible and legitimate knowledge (Cash et al., 2003) in deliberation (Metze, 2010) and the involvement of nonscience actors in the process (Hegger et al., 2012; Hessels and Van Lente, 2008). Collaborations between actors from different knowledge domains are faced with numerous challenges related to how various forms of knowledge interact (Garrett et al., 2012; Verweij et al., 2010; Mackinson and Wilson, 2014). Mixed-actor knowledge production has a different dynamic from that of scientific knowledge production. However, our understanding of the detailed dynamics of knowledge exchange processes is limited (Fazey et al., 2013).

In this paper, we analyse a collaborative knowledge exchange process in which a mixed group of actors with different types of knowledge is engaged and comes together to produce a specific tool for European fisheries management. The focus is on how different forms of knowledge are mobilised in the interaction between stakeholders, scientists and bureaucrats in a process led by the North Sea Regional Advisory Council (RAC) ${ }^{12}$ to make a long-term management plan for North Sea Nephrops fisheries. ${ }^{13}$ The North Sea RAC is one of seven advisory councils established as stakeholder forums as a result of the 2002 reform of the European Common Fisheries Policy (CFP). ${ }^{14}$ RACs were formed to provide recommendations on the management of fisheries to the European Commission's DirectorateGeneral for Maritime Affairs and Fisheries (DG MARE) in Brussels, and to EU Member

\footnotetext{
12 The Regional Advisory Councils (RACs) were renamed Advisory Councils in December 2013. The name North Sea RAC is used throughout this paper, reflecting the identity of this group during the time period studied. ${ }^{13}$ The process is still ongoing at the time of this writing. This paper addresses how it evolved up until July 2013.

${ }^{14}$ A reform of the CFP (Regulation (EU) No 1380/2013) was adopted in December 2013, following a period of wide consultations centred around ideas put forward in the European Commission's 'Green paper' (COM (2009) 163 final) in April 2009.
} 
States. From the outset, their membership consisted of two-thirds representation from the fisheries sector and one-third from other interest groups, including non-governmental organisations (NGOs) (Council of the European Union, 2004).

The kind of management tool that the North Sea RAC aims to produce in the process analysed in this paper serves as guidance for the European fisheries ministers when setting quotas (total allowable catches (TACs) during their annual Council meetings. In the context of EU fisheries management, long-term management plans usually specify the measures to be used to reach the overall management objectives for each fish stock. The initiative to make such plans would normally come from DG MARE. Limited stakeholder involvement in these processes has generated a sense within the fishing industry that management plans represent 'top-down' management instruments imposed on them 'from Brussels', resulting in limited support from the fishers (Kraak et al., 2013; Wilson, 2009a). The North Sea RAC initiative to develop a management plan for Nephrops fisheries, which is analysed here, exemplifies a different and non-standard approach: a ‘bottom up' process in which the stakeholders are in the driving seat while other actors (scientists and bureaucrats) are invited into their process to contribute with relevant knowledge. This sets the case apart from the more frequently encountered settings in which stakeholders are mobilised to contribute to research projects run by scientists (O’Brien et al., 2013; Röckmann et al., 2012; Talwar et al., 2011).

The central question addressed in this paper is how knowledge is used and produced in interactions between actors who have different forms of knowledge and who are engaged in developing a long-term management plan for the North Sea Nephrops fisheries. Our aim is to contribute to the understanding of knowledge production in multi-actor settings. Inspired by Edelenbos et al. (2011), we here refer to collaborative knowledge production as the interactive process between stakeholders, scientists and bureaucrats aimed at exchanging, combining and harmonizing facts, interpretations, assumptions and causal relations from different knowledge domains when developing a tool for fisheries management. To analyse the way in which knowledge is produced in collaboration between different actors, we apply the framework proposed by Carlile (2004). This framework focuses on how knowledge is exchanged between actors, and how actors are challenged to overcome their differences in perspectives and interests when aiming to produce new knowledge together. The approach allows for indepth exploration of processes at boundaries. This is an area where the research interests of science and technology studies scholars and organisation and management studies scholars overlap (Zeiss and Groenewegen, 2009). Managing processes at boundaries is also recognized as an important element of effective knowledge systems in support of sustainable 
development and environmental management (Cash et al., 2003). In the present study, boundaries refer to the interfaces between actors who engage in knowledge sharing to achieve a common goal.

The remainder of this paper is as follows: In Section 3.2, we discuss knowledge production in the collaborative setting of making a management plan and introduce Carlile's (2004) framework. The actors, and the roles and forms of knowledge they represent in the context of developing a tool for European fisheries management, are introduced. We then describe the methods used to collect and analyse data for the case study. Section 3.4 starts with a brief introduction to the Nephrops fisheries in the North Sea. This is followed by descriptions of how the knowledge and interests of stakeholders, scientists and bureaucrats interacted in the process of producing a management plan. In the Section 3.5 we reflect on the dynamics of knowledge sharing in the light of the various challenges encountered and the resources mobilised to overcome them. Finally, conclusions are drawn in Section 3.6.

\subsection{Knowledge production in collaboration}

Groups of actors contribute with different forms of knowledge. The terminology used to describe types of knowledge in the environmental management literature include 'indigenous', 'traditional', 'personal', 'lay', 'local', 'tacit', 'explicit', 'formal' and 'informal' (Raymond et al., 2010, p. 1768). It illustrates the diversity in types of knowledge that may be brought into a collaboration in a mixed-actor setting. The allocation of types of knowledge into categories such as 'scientific', 'local' or 'hybrid' should be done with caution, given that knowledge is 'inherently personal' (Raymond et al., 2010, p. 1769). In this paper, the actors who are engaged in the development of the long-term management plan for Nephrops fisheries are divided into categories (stakeholders, scientists and bureaucrats), signalling an underlying assumption that the type of knowledge that individuals bring to a collaborative process is somehow associated with their role. As a further general simplification: stakeholder knowledge can be characterized by its social validity, scientific knowledge by its scientific validity, and bureaucratic knowledge by its usefulness for the policy process (Edelenbos et al., 2011). While scientific knowledge production follows established practices that include the application of academic discipline-specific methods and quality assurance of the output through peer review of publications, the mechanisms of mixed-actor knowledge production are not equally well established, nor are the tangible outcomes from such collaborations always easy to pinpoint. 
The generation of knowledge is a multi-faceted and complex process resulting from interactions in which tacit and explicit knowledge is produced (Nonaka, 1994). Tacit knowledge is based on the individual's action, commitment and involvement and is difficult to express in words, while explicit knowledge is articulated in language and can be captured and transmitted, for example through written records. Nonaka distinguishes four modes of interplay between tacit and explicit knowledge: socialization (tacit-tacit), externalization (tacit-explicit), combination (explicit-explicit) and internalization (explicit-tacit). Interactions that can make tacit knowledge explicit are important to understand the dynamics of knowledge production in mixed-actor settings. Actors must be able to share their experiences and perspectives. The ability to communicate thus becomes a key issue in such interactions. Collins and Evans (2008) suggest that interactional expertise plays an important role in enabling communication across knowledge domains. They define interactional expertise as:

... the ability to master the language of a specialist domain in the absence of practical competence. (Collins and Evans, 2008, p. 14)

Collaborative knowledge production is challenged when the actors engaged start out with different kinds of knowledge, with little overlap between their domain-specific knowledge (Carlile, 2002, 2004; Tsoukas, 2009). A framework proposed by Carlile (2004) was developed to investigate the dynamics of knowledge sharing in collaborative processes aimed at innovation Figure 3.1 illustrates a modified version used here to analyse the knowledgesharing processes between the actors who were engaged in developing a management plan for North Sea Nephrops fisheries.

The boundaries between the actors have different characteristics, ranging from low to high complexity, depending on the setting. Elements that contribute to increased complexity include high degrees of novelty related to the issue and high stakes among the actors. These elements might be present separately or simultaneously.

The framework distinguishes three levels of complexity. The purpose of making such a distinction is to clarify what kinds of resources and efforts are needed to succeed with knowledge sharing, given different circumstances. The high or low complexity setting indicates which boundary process is at play and points to the kinds of resources and efforts that must be mobilised. For example, different kinds of communicative processes are needed at the three levels. They are illustrated in Figure 3.1 as: exchange, deliberation and negotiation. At low levels of complexity, having a shared vocabulary might suffice to allow the exchange of knowledge between actors through the boundary processes referred to as 


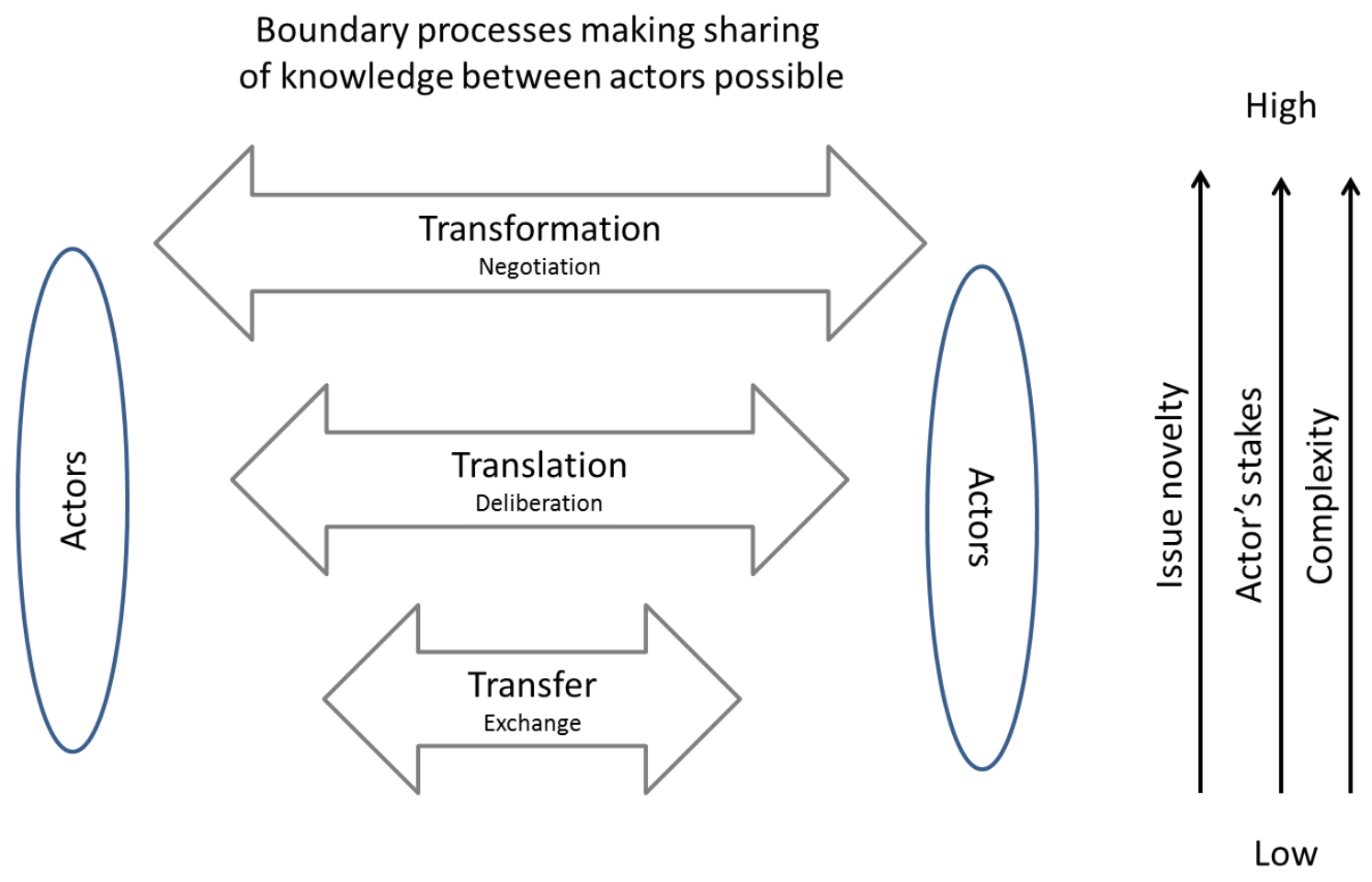

Figure 3.1 Processes at boundaries between actors. Adapted from Carlile (2004).

transfer. As novelty, stakes and complexity increase, deliberation, including multiple iterations, will be needed to allow sharing of knowledge through translation processes. Boundary objects with appropriate characteristics for the task at hand (Carlile, 2002), and boundary spanners (Williams, 2002) who can mobilise resources and efforts and facilitate deliberations between actors with diverging knowledge and interests, are examples of resources that will be useful in such settings. At the highest level of complexity, the high degree of novelty of the issue and the actors' high stakes challenge the sharing of knowledge between them. In such settings, the knowledge needs to be transformed for it to be shared and developed. For transformation of knowledge to take place, the actors must be willing - and able - to move outside their own familiar territory. Trade-offs might be needed, which implies that the transformation of knowledge is a political process and that knowledge production in this setting comes at a cost. At this high-complexity boundary, the sharing of knowledge takes the form of negotiations and the communicative process between actors is likely to benefit from support from a neutral facilitator. Given the complexity at this level, the distinction between knowledge production and decision-making might become blurred. 
A key message embedded in this framework is that knowledge production in settings where the goal is to move beyond existing, collective knowledge and to produce something new is a challenging endeavour. Resources and efforts that enable the actors to share their knowledge at various levels of complexity must be available for the collaboration to be fruitful. If the actors involved start out with little common knowledge, the process must allow common knowledge to evolve before complex issues can be addressed. If the actors involved have high stakes in the issues, this further adds to the challenge of producing new knowledge together. The transformation of knowledge at a high-complexity boundary requires different kinds of resources and efforts than exchange of knowledge at a low complexity boundary. We use this framework to illuminate the kinds of resources and efforts that are in place to facilitate knowledge production within the setting of the Nephrops management plan collaboration. Conversely, elements that are lacking, or that hinder progress in this mixedactor setting, can be identified.

The actors involved in this study are categorized as stakeholders, scientists and bureaucrats, reflecting the roles they represent in the collaboration analysed. The stakeholders are members of the North Sea RAC. Their collective knowledge encompasses both fishing industry interests and nature conservation issues. This stakeholder knowledge base is thus wider than what is captured by the term 'fishers' knowledge', which refers to insights about issues such as: temporal and spatial fish abundance, spawning grounds, seabed characteristics, gear types and fleet behaviour (Bjørkan, 2011; Soto, 2006). Scientists involved in knowledge production for EU fisheries management are typically marine ecologists and fisheries biologists employed by national marine research institutes (Wilson, 2009b). Collectively, the scientists form the knowledge base of the International Council for the Exploration of the Sea (ICES). The bureaucrats in the setting of interest in this study are the civil servants in DG MARE and in government offices in the EU Member States who are involved with the implementation of the CFP. Bureaucratic knowledge encompasses knowledge about processes and contexts that are of relevance when identifying viable policy options (Hunt and Shackley, 1999).

\subsection{Methods}

A case study approach (Yin, 2009) was used to investigate the dynamics of knowledge production in a mixed-actor collaboration where stakeholder knowledge, scientific knowledge and bureaucratic knowledge come together. Empirical data were collected through document 
review, observations in meetings, and semi-structured interviews. Combining the three methods gave opportunities for triangulation through assembling multiple records of key issues and events via several sources. The document review focused on establishing the time line for the making of the Nephrops management plan, identifying the key actors involved and key issues discussed. The process is well documented. Detailed minutes from meetings organised by the North Sea RAC are publically available via the North Sea RAC server (www.nsrac.org). Additional material was kindly supplied by the North Sea RAC rapporteur. In addition to minutes of meetings and draft versions of the management plan, documents of interest included scientific advice for North Sea Nephrops provided by ICES and correspondence between the North Sea RAC and the European Commission.

The principal investigator participated as an observer in six meetings of the North Sea RAC Demersal Working Group in 2012 and 2013, and in two meetings of the North Sea RAC Nephrops Focus Group in 2013. These events provided opportunities for observing the interaction between the key actors and gaining an understanding of the issues being discussed. In addition, the investigator spent April 2013 visiting a large fisheries stakeholder organisation in the UK to gain insights into how individuals, who represent the interests of fisheries stakeholder constituencies in RACs, operate. The on-site visit provided opportunities for learning about the diversity of views and interests within fisheries stakeholder organisations and the issues and challenges encountered by their representatives.

Ten semi-structured interviews were conducted with stakeholder representatives and five with scientists. Interview guides (Kvale and Brinkmann, 2009) with open questions were tailored to each interviewee to address issues where their area of competence was of particular relevance to this study. Some of the interviews were of a scoping character, aimed at gathering background information on the role of stakeholder knowledge in the context of EU fisheries management. Five interviews focused specifically on the Nephrops management plan process. These interviews involved fishers' representatives and environmental NGO representatives in the North Sea RAC, and scientists who had participated in meetings of the Nephrops Focus Group. The interviews lasted between 40 minutes and two hours and were conducted face-to-face $(n=10)$, via Skype $(n=3)$, and via telephone $(n=2)$. Eleven of the interviews were recorded and partly transcribed. For the others, detailed notes were taken.

Minutes of meetings, observer notes and interview transcripts were analysed using the ATLAS.ti (www.atlasti.com) qualitative data analysis software. The analysis aimed to pinpoint how knowledge was shared and accessed, both within and across groups of actors (i.e. stakeholders, scientists and bureaucrats). A coding scheme (Miles and Huberman, 1994) 
was created to identify the kinds of knowledge the actors brought into the process (i.e. scientific, stakeholder and bureaucratic knowledge) and the process of sharing knowledge among and between the actor groups. Tangible outcomes of the collaborative process that could represent individual tacit knowledge becoming explicit - and thus being made available to a wider audience - were of particular interest. The analysis also aimed to identify factors that facilitated the sharing of knowledge between actors, and also factors that restricted such sharing.

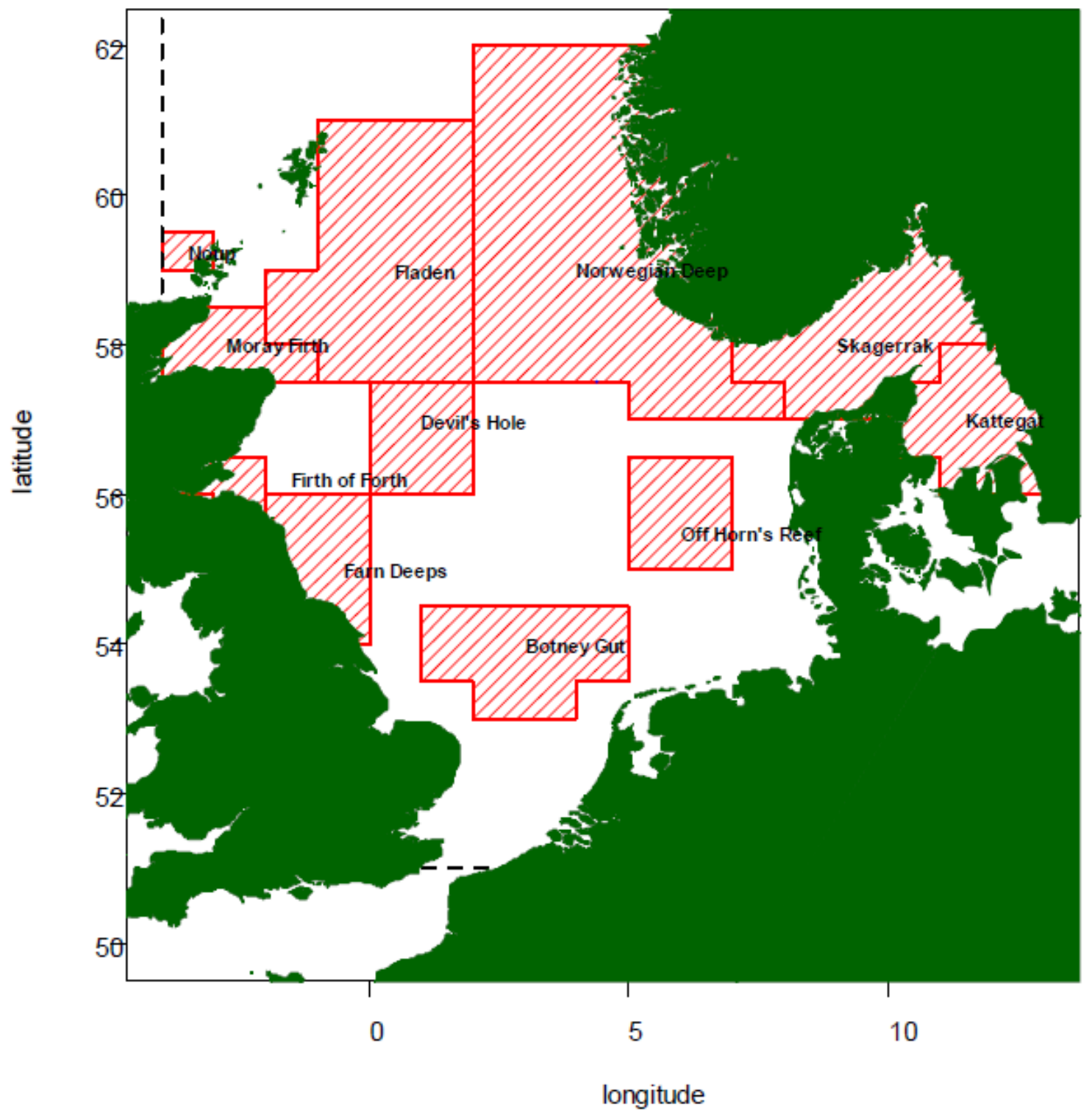

Figure 3.2 Functional units for Nephrops norvegicus fisheries in the North Sea, Skagerrak and Kattegat. Reproduced from International Council of the Exploration of the Sea (2013) with permission. 


\subsection{Results}

\subsubsection{Nephrops fisheries in the North Sea}

Nephrops norwegicus ${ }^{15}$ (referred to as Nephrops in this paper) are known under a number of names including Norwegian or Norway lobster, prawn, scampi and langoustine. They are pale orange crustaceans that live in burrows in soft sediments down to 800 meters deep (Johnson et al., 2013). In the North Sea, Nephrops are primarily caught by bottom trawlers in targeted Nephrops or mixed Nephrops-whitefish fisheries. The UK has $87 \%$ of the North Sea quota ${ }^{16}$ while Denmark, the Netherlands, Belgium and Germany each have small shares. Nine areas, called functional units, are important for the Nephrops fisheries in the North Sea (see Figure 3.2). Nephrops do not move great distances and the functional units are considered to have separate stocks (International Council for the Exploration of the Sea, 2013). The functional units differ in many respects, including data availability, distance from the shore, and importance for different segments of the fishing fleet. Offshore areas, such as the Fladen, are mainly visited by large vessels based in the Scottish harbours of Fraserburgh and Peterhead. Areas close to the coast, particularly the Farne Deeps, are important to smaller vessels that operate locally out of ports on the North East coast of England (Bailey et al., 2012).

The current management regime for Nephrops in the North Sea does not include a management plan. The quota is set annually by a Council decision based on a proposal put forward by the European Commission, which again is based on scientific advice from ICES. One quota (TAC) is set for the North Sea as a whole. This quota is divided between the Member States according to an allocation principle referred to as relative stability. ${ }^{17}$ The current system allows fishers who hold a share of the North Sea quota the freedom to 'roam', that is, to move between the functional units.

\subsubsection{Stakeholders take the lead: The Nephrops Focus Group}

The idea to make a long-term management plan for North Sea Nephrops fisheries evolved within the North Sea RAC soon after its establishment in 2004. A proper management plan, as envisaged by the North Sea RAC, would be different from the 'standard' ones with regards to both process and content. It would be developed with involvement from fishermen and it would encompass the biological, economic and social aspects of sustainability. Such a holistic plan had never been made before within the context of EU fisheries management and the

\footnotetext{
${ }^{15}$ Correct spelling is "norvegicus".

16 The total North Sea quota was 17,350 tonnes in 2013 (Council Regulation (EU) No 39/2013).

17 The principle of relative stability refers to an element of the CFP that specifies how quotas for each fish stock are shared between the Member States of the EU according to a fixed allocation key based on historic catches.
} 
North Sea RAC was entering unfamiliar territory. North Sea Nephrops was given priority because this fishery was thought to be relatively uncomplicated with only a limited number of countries and fleets involved. Lessons learned from the Nephrops experience could then be applied later when making management plans for more complex fisheries.

A Nephrops Focus Group was established as a subset of the North Sea RAC Demersal Working Group to do the hands-on work of producing the plan. This group first assembled in May 2007, re-started in April 2009, and has continued to meet irregularly since then. The meetings of the Nephrops Focus Group usually attract around ten participants, some of whom are North Sea RAC members and others who are invited to attend as experts to share their knowledge on specific issues. A rapporteur writes detailed minutes and transforms oral and written contributions from the meetings into updated versions of the management plan. Meeting documents are made publicly available via the North Sea RAC website. A core group consisting of fishing industry representatives from the UK attend most meetings and drive the work forward. There is a strong presence of North Sea RAC members who are employed to represent the Scottish catching sector and producer organisations, reflecting the importance of the Nephrops fishery to Scotland. A fisher who represents small vessels that operate out of English ports attends occasionally, and brings the concerns of this segment of the fleet into the discussions. An interviewee, who was invited to attend the meetings on several occasions, offered a view on the implications of this widening of the group: "The group has evolved as a result of that; so has their thinking". (Interview, Scientist)

North Sea RAC members who represent the Dutch and Danish fishing industries are also involved. Although their quotas for Nephrops in the North Sea are small, a management plan for Nephrops will affect their fisheries and could potentially set a precedent that will have wider implications for EU fisheries management. Environmental NGO members of the North Sea RAC attended regularly during the first few years. Their involvement ensured that conservation perspectives on sustainable fisheries were taken into account during the deliberations and drafting of the plan. The NGO representatives kept reminding the fishing industry interests in the group that EU Member States would need to reduce the impacts of fisheries on the ecosystem to comply with the Marine Strategy Framework Directive. ${ }^{18}$ The idea to include conservation measures in the Nephrops management plan was not, at least not initially, embraced with enthusiasm by all. However, ecological objectives and measures were

\footnotetext{
${ }_{18}$ The Marine Strategy Framework Directive (2008/56/EC) provides a legislative framework for community action in the field of marine environmental policy.
} 
repeatedly discussed and sections on how to reduce discards, protect endangered species, and minimise damage to the seabed were incorporated into draft plans.

\subsubsection{Bringing in scientific knowledge}

When the Nephrops Focus Group first assembled in May 2007, its priority was to gain an overview of scientific knowledge about Nephrops. At that time, Scottish stakeholders were exploring possibilities for having their Nephrops fisheries certified. This acted as an incentive for them to search for management arrangements that would meet accreditation requirements. Scientists from Marine Scotland Science (then the Fisheries Research Services) were invited to bring the group up-to-date on the biology and stock status of Nephrops in the North Sea. After listening to the scientists' presentations, and brainstorming around how these scientific contributions could possibly be translated into management options, the group concluded that:

We are not equipped with responsiveness to changes in stocks. There is no answer to what is best. There are simply too many uncertainties. (Nephrops Focus Group, minutes, May 2007) ${ }^{19}$

In spite of this disappointing situation, the information provided by the scientists regarding the way Nephrops are distributed in separate stock components clarified that some choices needed to be made with regards to the overall management strategy:

The current exploitation regime treats the North Sea Nephrops as one stock, but in fact this stock consists of seven components. Question is, "could we manage risk better regionally'? From a biological point of view a regional approach might be better although this would be very difficult in view of the current management framework and relative stability issues. Two management extremes are plausible, broad brush or deep detail (in respect of the areas concerned). (Nephrops Focus Group, minutes, May $2007)^{19}$

The comment pinpoints an issue which became a key challenge for the Nephrops Focus Group. The fact that Nephrops in the North Sea are found in separate geographical stock components, referred to as functional units, motivated the implementation of management measures for each stock, at least from a scientific point of view. However, a politically rooted complication was immediately spotted by participants who had knowledge about how the principle of relative stability works in practice. The producer organisation representatives had in-depth knowledge about the complexity associated with handling quota allocations and this made these stakeholders sceptical of the prospect of introducing 'deep detail' management solutions.

19 Minutes and other documents from the meetings of the Nephrops Focus Group are available at <http://www.nsrac.org/category/reports/meetings-c/nfg/> accessed 31 October 2014. 
The first meeting made it obvious that there were many knowledge gaps in the scientific understanding of Nephrops stock dynamics and that it would be problematic to proceed with making a management plan in light of all these uncertainties. Further work with the management plan was therefore put on hold while the scientists engaged in scientific projects and networks to improve the situation. A question was raised: Could the fishers assist with collection of survey data? The costs associated with the necessary underwater TV camera equipment were considered prohibitively high for this to be a viable option. Fishers' perceptions of change in the abundance of Nephrops in the area are routinely collected through the North Sea Stock Survey (Napier, 2012). However, the format of the data produced makes it of limited use in stock assessment work:

If the scientists were saying the stocks are going up and the fishers say the stocks were going down, then how would you use the qualitative information from the fishers? How would you put a quantitative number on that? It is very difficult to see how you could do that in any scientifically justifiable and supportable manner. [...] It is difficult to plug that into an analytical assessment. (Interview, Scientist)

When the Nephrops Focus Group re-assembled in April 2009, the methods to assess stocks had been developed further. UK scientists were again invited to share their latest knowledge with the Nephrops Focus Group. Extracts from the scientists' presentations were included as background information in a first draft of the management plan (Nephrops Focus Group, minutes, April 2009). ${ }^{19}$ The same scientists were also involved in various ICES expert groups, the groups that produce the science which underpins ICES advice to the European Commission on Nephrops stocks in the North Sea. In 2009, ICES provided the European Commission with advice that management should no longer be at the overall North Sea level, but at the functional unit level (International Council for the Exploration of the Sea, 2009). According to the latest scientific knowledge, functional unit management was needed to align catch opportunities with the status of the different stocks in the North Sea. However, the Nephrops Focus Group did not let go of the idea that a 'broad brush' solution, which would imply continuing with one quota (TAC) for the whole of the North Sea, was a viable option:

It would seem that the TAC system applied to the Nephrops fishery is effective and appropriate for controlling the impact of the fishery upon Nephrops stocks, although there is a clear problem in deciding whether the TACs should relate to each functional unit or to the North Sea as a whole. The Development Group is proposing that the main control should be through the setting of North Sea TACs, with the functional units being dealt with through 'no more than' clauses. Some functional units may require additional measures to protect them if stocks fall outside given parameters (Nephrops Focus Group, minutes, April 2009). ${ }^{19}$ 
Thus, the next challenge for the Nephrops Focus Group was to identify appropriate instruments to put into the management plan that would meet the requirement of aligning catch opportunities with stock status while avoiding the implementation of functional unit quota management. A 'no more than' clause was one of several instruments identified as promising. They then turned to the active fishers for wider stakeholder consultations about potential management tools and strategies.

\subsubsection{Port visits and stakeholder consultations}

The North Sea RAC wanted the development of their management plan to be a truly 'bottom up' process. However, lack of funding had made wider engagement difficult. In 2010, a collaboration between the North Sea RAC and a research project made it possible to arrange a series of meetings with fishers in English and Scottish ports. The port visits were announced in the local press and were arranged at weekends to make it easier for active fishers to attend. At the meetings, Nephrops Focus Group members explained the rationale behind the management plan and summarised progress to date regarding formulating biological and economic objectives. An extensive list of possible management measures was presented. The research project component of the meetings involved a participatory modelling exercise driven by scientists (Röckmann et al., 2012). An interviewee explained the role of the scientist:

I was there in a scientific capacity. We broke up into small discussion groups and people moved around between tables. I was there to try and answer things and post questions and receive information that could be beneficial in terms of putting together a scientific evaluation model for the types of management and the types of issues that the fishermen wanted to see. (Interview, Scientist)

A wide range of concerns were brought forward by the fishers, mirroring and re-emphasizing the divergent interests that had already been encountered within the Nephrops Focus Group:

Any sort of measures on the Farne Deeps would affect us disproportionally because we don't fish anywhere else. The Scottish and Irish vessels tend to cherry pick fisheries. If there were specific measures in the Farne Deeps they could just go and fish somewhere else. It wouldn't hurt them as much as it would hurt the local boats. (Interview, Fishers' representative)

The comment alludes to conflict of interests between large and small, inshore and offshore operators. Fishers who use small boats wished to protect their local grounds from exploitation by larger vessels that move opportunistically between different areas. Potential problems with damage to the grounds caused by heavy multi-rig gear were also pointed out. On the other 
hand, fishers operating larger boats defended the use of multi-rig gear and highlighted the need for efficiency to ensure profitability. It was also clear that the enthusiasm among the stakeholders in the Nephrops Focus Group - who saw the making of a management plan as an opportunity to get their ideas through to the European Commission - was not shared by all. The rapporteur summarised some of the issues encountered:

There had been strong differences of opinion from fishers from different ports. In fact some fishers did not accept that any change was needed and did not support any move to change the current system of management in any way. As long as that position was maintained there would be difficulties in completing a management plan for Nephrops in the North Sea. (Nephrops Focus Group, minutes, July 2012) ${ }^{19}$

The magnitude of the challenge of engaging in a constructive dialogue with the fishers took the Nephrops Focus Group by surprise. Differences in the level of interactional expertise between the fishers' representatives in the Nephrops Focus Group and the active fishers were noted as a concern by one of the scientists:

I think a lot of individual fishers can't reconcile the differences between what is going on in the sea in the areas where they fish and the broad scale impressions that we get coming out of fisheries data and surveys. Because we are not seen out at sea very often it is quite often stated that we don't know what is going on. At the individual fisher's level there is still quite a lot of that sensed. The further up the fisheries organisations one goes, the organisations' representatives have a better understanding of where we are coming from, and of our processes. Obviously, that possibly means that they are being as institutionalized as the rest of us - which is also one of the comments from the grass root fishermen. (Interview, Scientist)

Experiences from the port visits highlighted the importance of good communication between the stakeholder representatives and their constituencies. However, as the work with the plan evolved, more and more complex scientific jargon was used in the discussions in the Nephrops Focus Group. It became increasingly challenging to communicate about their progress in a meaningful way:

Participation by the three scientists made the discussions at times very detailed and scientific today. At the end of a lengthy exchange about Btriggers, Bmsy, Blim, Bbuffs - and fishing mortalities in all shapes and forms, too - X [A fishers' representative] reminded us: We need to think about language. At some point we will need to explain this. We need to have an outward surface. (Observer notes, Nephrops Focus Group, July 2013)

The lack of common ground between the fisheries stakeholders that became evident during the port visits was problematic for the Nephrops Focus Group. An idea was brought forward to gain new momentum with the management plan work by making a separate fishing plan for the Farne Deeps, the functional unit where the conflicting interests were most pronounced and 
where the status of the stock was becoming a concern. Scientists were commissioned to consult further with fishers and to explore which objectives and management options might be suitable, given the local characteristics of the Farne Deeps. Mobilising more knowledge through more interaction in the Farne Deeps study could possibly clarify how to move forward with the management plan. The study re-confirmed the diverging views and interests that had been encountered during the port visits: small versus large operators, and local versus roaming fleets (Bailey et al., 2012). It enabled the Nephrops Focus Group to narrow in on the 'of which no more than' clause as the most promising instrument for management of this particular functional unit, but tension between the various interests within the group remained:

In reality, what we are proposing is functional unit management under another name. It's very much the same thing, slightly different measures. It is probably more acceptable to the Scottish interests than it is to us. They are very well represented. They have larger vessels to protect. As small individual boats, we are not as strong as the larger sections of the industry. (Interview, Fishers' representative)

It would be a lot to ask from stakeholder representatives to endorse a proposed management measure that would benefit competing interests or hurt the interests of their own constituency without knowing if anything can be offered in return. In spite of this tension the collaborative spirit remained high:

I would say there is willingness on all sides [...]. It is an extremely difficult process. Sometimes we don't get agreement on everything. [...]. We have to balance everybody's views to get this plan together. There will be bits of the plan that I don't like and there will be bits of the plan they don't like. It is the art of compromising. (Interview, Fishers' representative)

Another pilot study was later commissioned for the Fladen functional unit to incorporate knowledge from fishers who have in-depth experience with that particular fishing ground. The Nephrops Focus Group saw the Fladen study as an opportunity to try out if, and how, the various potential management measures could be applicable in an offshore functional unit with different characteristics to those of the Farne Deeps. How to integrate individual functional unit fishing plans into an overall management plan for North Sea Nephrops fisheries was, at the time of this writing, yet to be decided.

\subsubsection{Taking bureaucratic knowledge seriously}

Several of the Nephrops Focus Group members interact frequently with managers and policymakers as part of their daily jobs. Insights into bureaucratic processes at international and national levels enable them to align their work with the bureaucrats' needs and thus enhance 
the saliency of the outputs produced. Direct involvement by bureaucrats in the Nephrops Focus Group has been limited. Scottish government representatives attended occasionally and provided links between the Nephrops Focus Group and bureaucrats at national and EU levels by, for example, sharing insights on what was high on the bureaucrats' list of priorities. The primary addressee for the Nephrops management plan, once finalised, would be the European Commission's DG MARE. DG MARE representatives were kept informed about the Nephrops plan through North Sea RAC Executive Committee and Demersal Working Group meetings, in which the status of the plan would regularly be on the agenda. Feed-back from bureaucrats has generally been very positive and this has served as welcome encouragement for the Nephrops Focus Group to continue to work on the plan, in spite of the challenges encountered. A draft was brought to the attention of the DG MARE Commissioner, who responded with complements to the North Sea RAC for their work:

We are very much aware of the excellent work that is being done by the NSRAC on the development of a management plan for Nephrops in the North Sea. Indeed, my services consider that it constitutes some of the best work done by any of the RACs. ${ }^{20}$

At the same time, the Commissioner indicated what the current priorities were for the bureaucrats, adding yet more complexity to the task at hand:

I would also urge you bear in mind that we aim to develop a mixed fisheries plan for the North Sea. I would be interested in hearing your ideas on how we should go about this, and on how your work on Nephrops can be integrated into a mixed fisheries plan. $^{20}$

Finding solutions to the mixed fishery management dilemma for DG MARE was no small favour to ask from a RAC. The Nephrops plan evolved during a period characterized by hectic activities in preparation for reform of the CFP in December 2013. This meant that the emerging plan could potentially serve as a test bed for new, innovative management measures to address high-priority issues such as mixed fisheries or discards. It also meant that the key actors involved - both the bureaucrats and the stakeholders - had many other, and more urgent, issues than Nephrops management on their agendas. Progress with the plan was slow, and there was a growing concern within the North Sea RAC that the Commission would move towards setting functional unit-specific quotas before they could present their final product. The problems foreseen with such a management regime were communicated to the DG MARE Commissioner, who in response assured the North Sea RAC of the Commission's intention to carefully evaluate all alternative management options. ${ }^{20}$ While this gave the

\footnotetext{
${ }^{20}$ Reply dated 31 October 2012 from Brussels from DG-MARE to NSRAC's letter of 24 August 2012 on the management of Nephrops functional units in the North Sea.
} 
Nephrops Focus Group some breathing space, the threat of functional unit-specific quota implementation continued to act as a driver for the North Sea RAC to produce a plan that better reflects the stakeholders' ideas of good management options.

\subsection{Discussion}

The fact that the process described in the previous sections is still ongoing after more than six years indicates that the making of an holistic management instrument through an inclusive 'bottom up' process, encompassing different forms of knowledge, proved to be much more challenging than was originally envisaged by the North Sea RAC. The overarching goal for the collaboration (i.e. to produce a management plan that will make North Sea Nephrops fisheries sustainable), was rather abstract. It was not clear to the Nephrops Focus Group what their final product could, or should, look like. The process is characterized by high complexity. The actors involved have high stakes and their own agendas, and the issues they need to tackle are novel. The actors collectively referred to as stakeholders, are a mixed group of individuals who represent producer organisations, NGOs and the fisheries catching sector from several countries. Their wide range of - sometimes conflicting - interests makes it clear that there is no such thing as one collective view or opinion that can be 'extracted' out of the heads around the table and brought forward to managers and policy-makers as 'stakeholder knowledge'. Here, we discuss how the Nephrops Focus Group encountered and handled these challenges by drawing attention to the three knowledge-generating processes illustrated in Figure 3.1: transfer through exchange, translation through deliberation, and transformation through negotiation, respectively.

A foundation for deliberations and negotiations was built during an initial phase in which facts and views that were considered relevant for the management plan by the Nephrops Focus Group were exchanged. Multiple meetings in a small-scale setting allowed for exchanges where the actors' individual tacit knowledge could be made explicit through dialogue and a common vocabulary could emerge. The collective stakeholder knowledge base of the Nephrops Focus Group was complemented through consultations with scientists and bureaucrats. Through these interactions, the stakeholders in the Nephrops Focus Group acquired interactional expertise (Collins and Evans, 2008) about issues that are typically situated within the scientific and bureaucratic knowledge domains. From the scientists, the stakeholders learned about Nephrops distribution and developments related to stock assessment methodology (i.e. scientific knowledge) that was highly relevant to the task of producing a management plan. From the bureaucrats, they learned about shifting management 
priorities related to the CFP reform process. They also became aware of the need to have a strategy to deal with uncertainties. Equipped with a common vocabulary on a wide range of issues, the Nephrops Focus Group engaged in deliberations and negotiations in search of a common understanding around issues where their interests diverged.

Diverging views within the Nephrops Focus Group were not problematic as long as everybody's interests could be represented in the draft plans and no firm decisions had to be made. The early drafts of the management plan became a place to put 'everything': they became repositories for information gathered and insights gained. They also served as a means of keeping the wider North Sea RAC and DG MARE updated about progress. By adopting this strategy of filling drafts with content as they went along, and sharing them widely, the draft plans became boundary objects with exchange and transfer characteristics (Carlile, 2002): they helped to establish a shared language and allowed the members of the Nephrops Focus Group to articulate, specify and learn about their differences with regards to interests and stakes. Importantly, they represented tangible products of their collective knowledge production efforts, thus making their collective knowledge explicit.

Functional unit management illustrates an issue where it became difficult for the Nephrops Focus Group to move on from talk to action. Putting together a list of management measures that could potentially be applicable for North Sea Nephrops fisheries was not in itself controversial. However, narrowing the list down to a set of measures that could be presented as the management tool of choice was much more difficult. This experience points to the challenge of transforming knowledge in a situation where there are conflicting interests involved, for example between the fishing fleets operating in the Farne Deeps. Conflicting interests, in combination with high stakes, the novelty of the issues, and different management options (including some that were entangled in the principle of relative stability) made functional unit management a conundrum. A central aspect of producing a management plan was to find solutions to this issue. Thus, putting functional unit management to the side when challenges were encountered was not an option. The Nephrops Focus Group experimented with negotiation to try to establish a common stakeholder view. However, there was no neutral facilitator present, nor was the informal Nephrops Focus Group setting necessarily the preferred place for individual actors to make trade-offs. The way forward became to try to address the management problem at a local scale. The making of fishing plans brought new actors and new knowledge into the process. It allowed the Nephrops Focus Group to further explore which management instruments could be considered most applicable, given the 
specifics of each functional unit. This implied a shift - at least temporarily - to a lower level of complexity: away from negotiation back to exchange and deliberations.

When addressing ecological objectives and measures, all members of the Nephrops Focus Group saw the potential benefits of aligning the Nephrops management plan with the implementation of the Marine Strategy Framework Directive. With this factor acting as an external driver, it became less of a problem to formulate text in the draft plan on ecological objectives and measures that everybody could agree on. Further measures would eventually be specified in other directives and policies anyway, separate from the Nephrops management plan. How to align the content of the plan with a reformed CFP was, however, more problematic. In this case, the problem was not primarily associated with conflicting interests but with lack of direction. During the CFP reform process, creating a salient management instrument became like 'shooting at a moving target'. The bureaucrats could not give clear answers as to what their priorities would be once the new CFP was implemented. These experiences highlight the challenge of making a management plan that is adaptable, not only to the changes in status of the resource in question (i.e. the status of Nephrops stocks in the various functional units) but to shifting management priorities.

Establishing common interests around issues that have high levels of complexity calls for a transformation of knowledge (Carlile, 2004). In order for such transformation to happen, the actors involved must be willing - and able - to move out of their 'comfort zone' and change the way they approach and understand the issue at hand. Kotter (1995) identified a sense of urgency as an important element when implementing change. The Neprops Focus Group did not need to meet any externally imposed deadlines, nor did they have the limits (or benefits) of an operating budget. This sets the context analysed here apart from most collaborative projects where the need to deliver a specified output by a specified deadline, within a specified budget, is usually part of the deal, and which introduces an element of urgency. Although the prospect of 'top-down' imposed functional unit quota management was seen as a threat by some of the Nephrops Focus Group members, it did not trigger a sense of urgency within the wider group of fisheries stakeholders. The reactions from the fishers during the port visits indicate that they were unconvinced that the introduction of a long-term management plan would make things better than 'business as usual'.

It is a paradox that the increased knowledge in the form of interactional expertise acquired by the fisheries stakeholder representatives in the Nephrops Focus Group seemed to create distance between them and the fishers whose interest they are employed to represent. This distance became problematic during the port visits when the interactions turned into 
negotiations between individual interests, rather than informed deliberations around various management options, as initially intended. The fishers were unfamiliar with the scientific and bureaucratic jargon associated with assessment models and management strategies, and the one-off exchange did not allow for the building of common ground.

One way of engaging with fishers' knowledge in collaboration is through participatory data collection arrangements (Hoefnagel et al., 2006; Bjørkan, 2011). In the present case, the involvement of fishers in the North Sea Stock Survey did not promote their sense of ownership of management problems, as the results were hardly used by scientists and managers (Daw, 2008). Other participatory initiatives, such as the voluntary Scottish conservation credits scheme (Holmes et al., 2011), connect fishers more directly with management measures that have an influence on their own operations. Such exposure may contribute to an increased interest among active fishers to engage in mixed-actor deliberations around management options.

Communication-related barriers are common in fisheries management settings. Garrett et al. (2012) draw attention to differences in landscapes of interactive learning between working fishermen and those who are hired to represent their interests. They stress the need to allow adequate time for interactive learning processes in mixed-actor collaborations. As time is often a limited resource, participatory initiatives are likely to be challenged by tight deadlines. While lack of urgency possibly slowed down the overall process of bringing the plan towards the finish line, time constraints were indeed recognized in the research project that took place during the port visits. This participatory modelling exercise added a more traditional sciencedriven participatory element to the process. Ambitious goals were set by the scientists, and when the desired participatory modelling outcomes could not be reached during the short interaction with the stakeholders, the scientists were left with a sense of failure. On the other hand, the stakeholders were more positive in their evaluation of the participatory experience, as the interaction with the scientists had given them the feeling that they were being heard (Röckmann et al., 2012).

\subsection{Conclusions}

In this paper, we have analysed a collaborative knowledge exchange process led by the North Sea RAC in which a mixed group of fisheries stakeholders interacted with scientists and bureaucrats to produce a long-term management plan for North Sea Nephrops fisheries. The collaboration included elements of novelty with regards to both content and process. This inspired us to apply an analytical framework developed specifically to help understand 
knowledge production in innovative settings where the actors involved have different forms of knowledge and interests. The approach was useful, as it highlights the importance of matching challenges with appropriate resources and efforts that will allow actors to connect and knowledge sharing to take place at various levels of complexity. We found that the transfer and translation of knowledge across low and medium complexity boundaries between actors could take place in this collaborative setting. However, the more complex process of knowledge transformation could not be accommodated.

Face-to-face interaction in meetings of the Nephrops Focus Group and the wider North Sea RAC over several years allowed the stakeholders to develop interactional expertise that extended beyond their own stakeholder knowledge domains into scientific and bureaucratic knowledge domains. The ability to communicate by using a common vocabulary, both within and between actor groups and roles, was essential for building common understanding at the lower end of the complexity scale. Draft management plans served as boundary objects, and the Nephrops Focus Group succeeded in producing tangible outcomes from their collaboration in the form of large sections of text that everybody could agree on. However, when hard decisions needed to be made on issues where high stakes were involved, the challenge at hand was not matched by the resources available. Examples of elements that can be helpful in such contexts include: generating a sense of urgency, having a clear common goal, and engaging a neutral facilitator to bridge the actors' knowledge and interests through negotiations. Without the mobilisation of such elements, collaborative knowledge production in complex settings will remain challenging.

A move towards more participatory research and governance practices in EU fisheries is envisaged to result in greater stakeholder buy-in and compliance (Mackinson et al., 2011; Kraak et al., 2013). The difficulties encountered by the North Sea RAC in extending their sense of ownership of the emerging Nephrops management plan to the wider stakeholder community of active fishers is a concern that will need to be addressed when developing such participatory practices. 


\section{Chapter 4: Building a knowledge base for management of a new fishery: Boarfish (Capros aper) in the Northeast Atlantic ${ }^{21}$}

\section{Paper II}

\footnotetext{
${ }^{21}$ This paper has been published as: Stange, K. 2016. Building a knowledge base for management of a new fishery: Boarfish (Capros aper) in the Northeast Atlantic. Fisheries Research, 174: 94-102. Numbering of sections, figures and footnotes has been edited to integrate this text as a thesis chapter. Supplements I and II to the online version are included here as Appendix 2 and Appendix 4.
} 


\begin{abstract}
This paper examines recent collaborative efforts by fisheries scientists and representatives from the pelagic fishing industry in Europe to generate a knowledge base to support management of a new fishery for boarfish (Capros aper) in the Northeast Atlantic. The forms of knowledge used and produced in the collaborations were investigated by applying a conceptual framework developed to help understand the detailed dynamics of knowledge exchange in mixed-actor settings. The collaborative initiatives studied were informal and efficient, and they benefited from financial support and co-ordination efforts by the industry actors. Generation of scientific knowledge was given high priority. Tangible collaborative outputs produced between 2010 and 2013 included new scientific insights into boarfish maturity and aging, initiation of an annual boarfish-specific acoustic survey, data to underpin a stock assessment, and two management plan proposals. The study highlights the information requirements that apply for fish stocks managed under the European Common Fisheries Policy and illustrates that the fishing industry can fill important roles in collaborative processes that aim to generate new scientific knowledge to support fisheries management.
\end{abstract}

Keywords: knowledge production; fisheries science; fisheries management; stakeholders; Common Fisheries Policy; boarfish; management plans 


\subsection{Introduction}

The fishing industry has during the last 20 years become increasingly involved in European fisheries management (Dreyer and Renn, 2011; Linke et al., 2011; Coers et al., 2012; Fitzpatrick, 2014; Linke and Bruckmeier, 2015). Representatives from the fishing industry hold a majority of the seats in the Advisory Councils, ${ }^{22}$ the stakeholder groups established under the Common Fisheries Policy (CFP) to provide the European Commission and European Union (EU) Member States with recommendations on issues related to fisheries management (European Council' ${ }^{23}, 2004$; European Union, 2013). Advisory Councils, as well as individual fishermen and their representatives, regularly participate in large-scale research projects of the European Union's Research and Innovation funding programmes that aim to generate knowledge to support fisheries management. ${ }^{24}$ Such projects exemplify arenas where different forms of knowledge interact (Röckmann et al., 2012; Mackinson et al., 2011; Jacobsen et al., 2012).

Fishermen, scientists and managers operate within different domains and acquire their knowledge in different information environments (Verweij et al., 2010). These differences influence the way information is interpreted and used by the various actors. Based on a review of knowledge exchange processes in environmental management projects, Raymond et al. (2010) draw attention to the importance of specifically addressing how different forms of knowledge will be identified, engaged, evaluated and applied. Fazey et al. (2013) call for an integrative research agenda to enhance our understanding of knowledge exchange. There is a growing body of literature that addresses fishermen's knowledge (see review by Hind, 2015); however, the detailed dynamics of knowledge generation in settings where the fishing industry interacts with science and management is less studied. Garrett et al. (2012) investigated interactive learning processes in four stakeholder forums in the United Kingdom where fishermen were engaged in dialogues to generate common visions and improve decision-making. Their study highlighted the need to better understand the processes involved, including the role of leadership, group dynamics and knowledge transfer.

Insights from research within organisation management contribute to a better understanding of the specific challenges related to knowledge exchange in settings when there is little overlap in knowledge between the various actors involved (Carlile, 2002, 2004). This

\footnotetext{
${ }^{22}$ With the reform of the Common Fisheries Policy in December 2013 the Regional Advisory Councils (RACs) were renamed Advisory Councils.

${ }^{23}$ Error in the published version; should read "Council of the European Union". Here "Council" in References.

${ }^{24}$ Recent examples of EU-funded research project with industry participation are GAP2 (http://gap2.eu/), MYFISH (http://www.myfishproject.eu/) MAREFRAME (http://www.mareframe-fp7.org/\#) and EcoFishMan (http://www.ecofishman.com/). (Link last accessed 20.08.15.).
} 
paper aims to enhance our understanding of knowledge exchange processes in settings where the fishing industry engages with science and management by applying these insights from organisation management. In this paper, a conceptual framework introduced by Carlile (2004) is applied in a qualitative case study of collaborative efforts by Irish and Danish scientists and fishing industry representatives to build a knowledge base to support management of a new fishery for boarfish (Capros aper) in the Northeast Atlantic. The case was chosen opportunistically to allow in-depth investigation of knowledge exchange processes in a recent mixed-actor collaboration where one of the aims was to produce a long-term fisheries management plan. Such plans are used as management instruments to achieve the objectives of the CFP (European Union, 2013; European Commission, 2014b). The following question guided the study: How was knowledge used and produced within and between actor groups (stakeholders, scientists and managers) in the process that led up to the 2012 Pelagic Advisory Council recommendation for a long-term management plan for boarfish in the Northeast Atlantic?

The groups of people involved are in this paper referred to as stakeholders, scientists and managers, reflecting terminology commonly used in Europe for actors with an interest in the CFP. The stakeholders in this study are the fishermen who catch boarfish, their representatives in Producer Organisations (here referred to as industry representatives), and members of the Pelagic Advisory Council. The scientists are fisheries biologists employed by national marine research institutes or universities who do work related to pelagic fish stocks. The managers are civil servants in the European Commission's Directorate-General for Maritime Affairs and Fisheries (DG MARE) and in government offices in the EU Member States who are involved with implementation of the CFP. These groups of actors contribute with different forms of knowledge. Following Edelenbos et al. (2011), stakeholder knowledge can be characterised by its social validity, scientific knowledge by its scientific validity, and bureaucratic knowledge by its usefulness for the policy process.

The rest of this paper is structured as follows: Section 4.2 introduces the conceptual framework applied to analyse processes of knowledge exchange in mixed-actor settings. Section 4.3 presents the qualitative research methods used for data collection and analysis. Section 4.4 starts with a short overview of the boarfish fishery. This is followed by narrative descriptions of how scientific knowledge was advanced and two management plan proposals were produced between 2010 and 2013. The implications of the findings for our understanding of knowledge exchange are discussed in Section 4.5, and in Section 4.6 conclusions are drawn. 


\subsection{Knowledge exchange in mixed-actor settings}

Carlile (2004) proposed a conceptual framework for investigating the dynamics of mixedactor knowledge exchange in organisational management settings. An application, modified to the context of collaborations within fisheries management where the knowledge and interests of stakeholders, scientists and managers come together, was described by Stange et al. (2015) and is briefly summarised here. The conceptual framework, see Figure 4.1, draws attention to that people need to share and access each other's knowledge for common understanding to develop and new knowledge to emerge. Such knowledge-sharing processes become increasingly challenging if the actors have high stakes in the issue, and if there is novelty involved. High stakes and high degrees of novelty contribute - separately or simultaneously - to complexity, because the gap to be bridged between actors, who need to access each other's knowledge, gets wider. The gap between the actors is here referred to as a boundary.

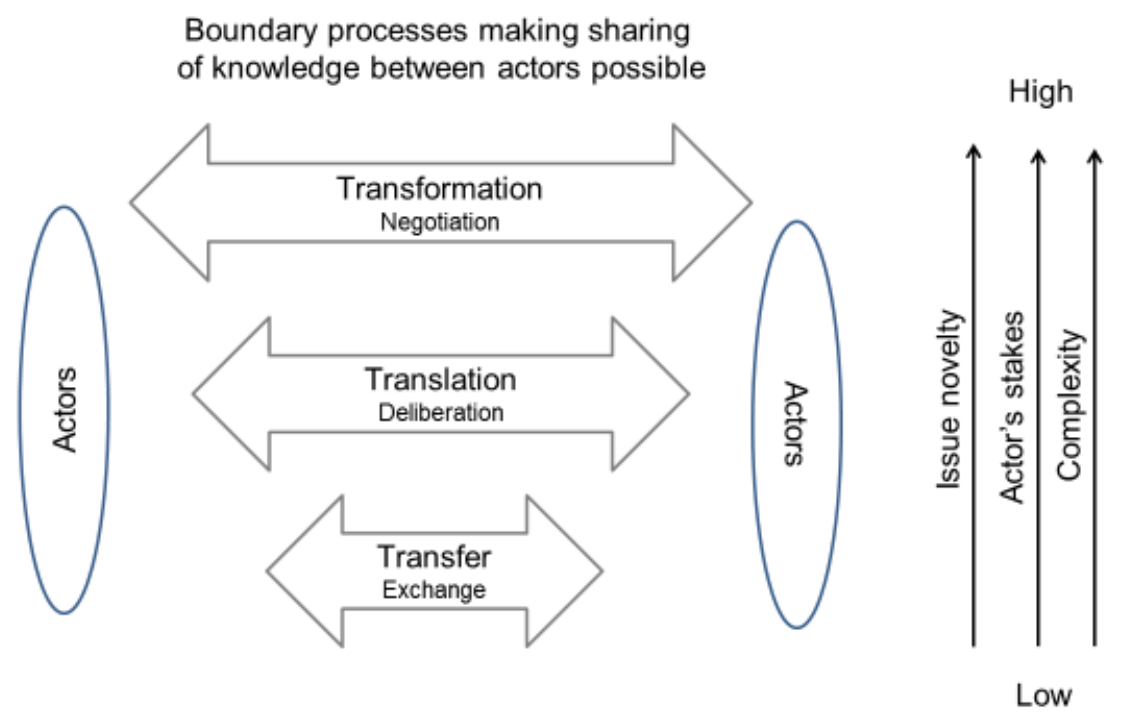

Figure. 4.1 Framework for analysing knowledge exchange in mixed-actor settings. Source: Stange et al. (2015), modified from Carlile (2004).

The framework distinguishes three knowledge exchange processes; transfer, translation and transformation. At the low end of the complexity scale, knowledge is transferred between actors through the communicative process termed exchange. As stakes or novelty increases, 
knowledge needs to be translated in deliberation between the actors. When stakes are high, and novelty contributes to the challenge of knowledge exchange, the actors' existing knowledge needs to be transformed. This requires negotiation around perceptions and knowledge claims. By distinguishing three knowledge exchange processes, the framework draws attention to the need to mobilise resources that match the challenge at hand; more resources are needed to enable actors to connect in complex settings. Examples of resources that enable people to connect across boundaries can be a shared vocabulary, a facilitator, funding, or infrastructure that allows face-to-face interaction. Another example of a resource is boundary objects. Star and Griesemer (1989) introduced the idea that boundary objects can play a key role in connecting different communities who work on a common task, and the concept of boundary objects has become widely applied (Zeiss and Groenewegen, 2009; Wilson, 2009a). In this paper, boundary objects refer to collaborative products that work to establish a shared context between different actors (Star and Griesemer, 1989; Carlile, 2002; Clark et al., 2010). The conceptual framework is in this study used as a lens to identify resources that allowed knowledge exchange between collaborating actors in the process of building a knowledge base for the new boarfish fishery.

\subsection{Methods}

A case study approach (Yin, 2009) was used to investigate how a knowledge base to underpin management of a new fishery for boarfish in the Northeast Atlantic emerged 2010-2013. Qualitative data were collected through document review, observations in meetings, and semistructured interviews. Combining the three methods gave opportunities for cross-checking and verification of data assembled from several sources (triangulation).

Key sources examined as part of the document review were minutes from meetings of the Pelagic Advisory Council (available via http://www.pelagic-ac.org), reports from the International Council for the Exploration of the Sea (ICES) Expert Group meetings (available via http://www.ices.dk), and newsletters from Killybegs Fishermen's Organisation (KFO) (available via http://www.kfo.ie). The document review focused on establishing the time line for the evolution of the boarfish fishery and for the development of management instruments. The documents were also used to study how issues and events were communicated within and between the groups of actors involved.

The investigator participated as observer in six Pelagic Advisory Council Working Group and Executive Committee meetings between February and October 2014. These events provided opportunities for gaining an understanding of the working procedures of this 
particular Advisory Council, and of issues that emerge on the agenda for the European pelagic fisheries stakeholders throughout the course of a calendar year. Additionally, participation in the annual "MIRAC" meetings between ICES and the Advisory Councils in 2012 and 2014 provided opportunities for observation of interactions between representatives from several Advisory Councils and scientists from the ICES Advisory Committee (ACOM).

Semi-structured interviews $(n=22)$ were conducted between May 2012 and November 2014. The interviewees were representatives from the pelagic fishing industry $(n=7)$, scientists who had been involved in boarfish research or in production of management plans for pelagic fish stocks $(n=9)$, and managers in DG MARE $(n=6)$. The initial interviews were designed to gain an overall understanding of pelagic fisheries in EU waters, including the use of long-term management plans as management instruments. Other interviews addressed the specifics of the boarfish fishery. Interview guides (Kvale and Brinkmann, 2009) were used to focus on issues where the interviewees' area of competence was of particular relevance to this study (see example in Appendix 2). The interviews lasted 20-120 min and were conducted face to face $(n=18)$, via Skype $(n=3)$, and via telephone $(n=1)$. Twenty of the interviews were recorded and transcribed. For others, detailed notes were taken. Five of the key informants were asked to review the result section of a draft manuscript to help identify and address any misunderstandings, factual errors and obvious omissions.

Documents, observer notes and interview transcripts were analysed aided by ATLAS.ti (http://atlasti.com/), a software package used in qualitative research to help organise, retrieve and combine document data. A coding scheme (Miles and Huberman, 1994) was created (see Appendix 4) to focus the analysis on the research question (actors involved and forms of knowledge mobilised to support fisheries management), applying concepts from the conceptual framework (processes of knowledge exchange).

\subsection{Results}

\subsubsection{Background: development of a new fishery}

Boarfish, a small $(<18 \mathrm{~cm}$ ) pelagic shoaling species (Figure 4.2), have since the 1970s been encountered in increasing quantities in pelagic and demersal fisheries in the Biscay area, and more recently also further north including in the southern Celtic Sea (O'Donnell et al., 2012b; Coad et al., 2014). Because of their rough skin and robust spines, boarfish damage other fish in the catch and fishermen and processors considered them a nuisance. A small group 
of Irish fishermen started to target boarfish on the Celtic Sea shelf edge in the early 2000s, but handling problems initially kept landings low. Since 2006, the fishery has gone through a rapid expansion. Estimated landings increased from 2772 tonnes in 2006 to 137,503 tonnes in 2010 before regulations were implemented (ICES, 2014a). A total allowable catch (TAC) for EU waters was first set by a European Council ${ }^{23}$ regulation in 2011 at 33,000 tonnes (European Council $^{23}, 2011$ ), followed by TACs for 2012 and 2013 at 82,000 tonnes (ICES, 2014a). Boarfish are primarily caught in ICES subdivision VIIj by pelagic trawlers (Refrigerated Sea Water vessels, RSWs) that typically also target mackerel (Scomber scombrus), horse mackerel (Trachurus trachurus), herring (Clupea harengus) and blue whiting (Micromesistius poutassou). There are currently around 23 Irish, 7 Danish, and 5 UKScottish vessels involved in the boarfish fishery. They represent a highly profitable fleet segment; e.g. in 2012, Irish pelagic vessels $>40 \mathrm{~m}$ reported $€ 33$ million net profit (STECF, 2014). Most of the catches 2007-2012 were landed in Skagen, Denmark ${ }^{25}$ for reduction to fishmeal for the aquaculture market. Fishmeal gives relatively low prices, and other uses are being explored to increase the value of boarfish landings.

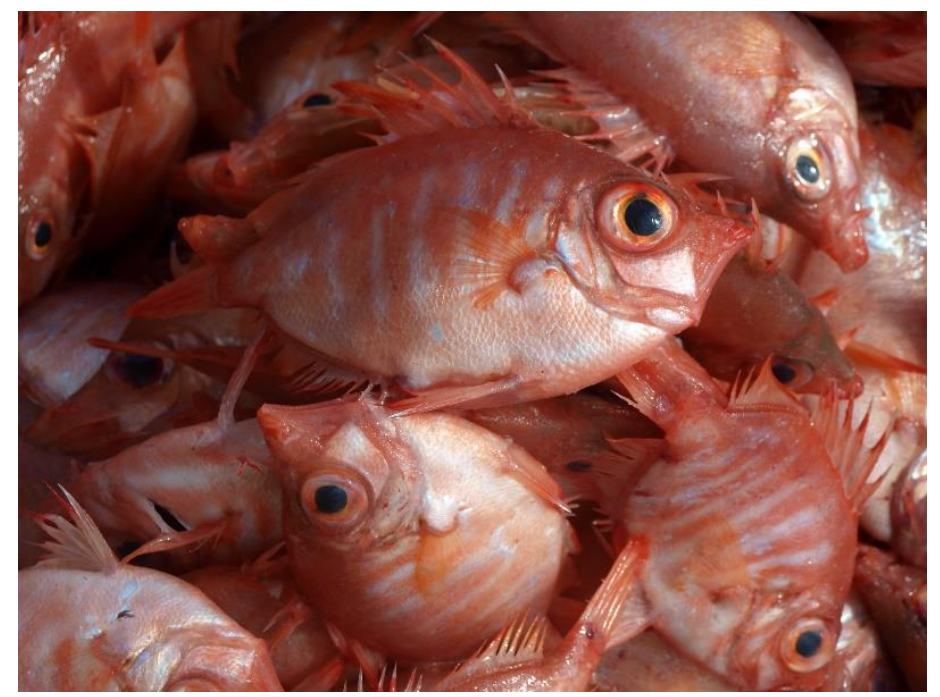

Figure.4.2 Boarfish (Capros aper). Photo (C): C. O’Donnell

\footnotetext{
${ }^{25}$ The Danish AgriFish Agency. Landings- og fangststatistik: Oplysninger om danske og udenlandske fiskeres landinger i Danmark. (In Danish). http://fd-statweb.fd.dk/landingsrapport/landingsrapport_front_matter (Link last accessed 20.08.15).
} 


\subsubsection{Development of scientific knowledge}

\subsubsection{Basic boarfish biology}

The high-volume landings in the new boarfish fishery were of concern to fisheries scientists at the Marine Institute in Ireland who had previously witnessed negative developments in unregulated deep-water fisheries (e.g. Large et al., 2003) and were aware of the risk of overexploitation. The Marine Institute had started to collect boarfish samples in 2005. An initial study indicated that boarfish could reach up to 30 years of age (White et al., 2011). This indicated sensitivity to fishing pressure, and advancing science to allow assessment of ecological consequences of the expanding boarfish fishery was a priority. Networks established during previous collaborations between the Marine Institute and the KFO, as well as between Irish and Danish industry actors, made it possible to take action at short notice. In March 2010, a scientist was engaged full time by the Marine Institute to study the biology of boarfish with a fellowship funded by cost recovery from the fishing industry, including the KFO. A similar Danish science-industry collaboration was also quickly set up, coordinated by the Danish Pelagic Producers Organisation (DPPO). This allowed scientists at the Danish Technical University (DTU-Aqua) to develop and verify boarfish-specific aging techniques. An interviewee explained how the building of a scientific knowledge base for boarfish needed to start from scratch:

We had no information on the size or age at maturity, or how they reproduced, or where they reproduced, or even where the bulk of the stock was. (...) So that was the initial thing; just to figure out when they spawn, at what age they spawn, at what size, and how fast they grow. (Interview, Scientist).

The scientists collaborated with the pelagic fleet to ensure supply of samples appropriate for age and maturity studies. As results from the scientific studies on age and reproduction emerged, the initial alarming indication of age-related sensitivity to fishing pressure became more nuanced: while boarfish are long-lived (up to 30 years), they mature at a relatively early age (3-4 years) (Farrell et al., 2012; Hussy et al., 2012a; Hussy et al., 2012b), and they seem capable of spawning regularly over extended periods (Farrell et al., 2012). Anecdotal information from fishermen about where they had encountered boarfish inspired the scientists to investigate historical fishing records. Data from multiple surveys from a wide geographical area were studied to shed light on the evolution of boarfish distribution in the Northeast Atlantic (Coad et al., 2014). The fishermen had seen large aggregations of boarfish on the shelf of the Celtic Sea in the winter and had also encountered dense schools during summer. These observations, in combination with results emerging from the maturity studies, allowed 
the scientists to identify July as the most appropriate month to study spawning aggregations of boarfish in an acoustic survey.

\subsubsection{Acoustic surveys}

In 2011, a first acoustic survey dedicated to boarfish exploration was organized as part of the collaboration between the Marine Institute and the KFO (O'Donnell et al., 2012b). Similar surveys were conducted again the following years (O'Donnell et al., 2012a, 2013). Financial arrangements for the annual month-long surveys included significant contributions from individual Irish and Danish fishermen. Research to identify target strength relationships for boarfish was also initiated, supported by industry funding (Fässler et al., 2013).

Collection of abundance data for commercially exploited species in Europe is typically coordinated and financed through EU's Data Collection Framework (DCF). Given that boarfish was a new commercial species in EU waters, it was not (yet) part of the DCF. The industry representatives repeatedly reminded the European Commission of the need to revise the DCF and include boarfish. Although the European Commission agreed, progress with updating the DCF was slow and the need for financial commitment from the industry continued. Funding the surveys was a major undertaking by the industry, and repeated deliberations within each Producer Organisation were needed to motivate the fishermen to keep paying their shares. The importance of survey data as part of building a scientific knowledge base for boarfish was explained to the fishermen, as illustrated in this communication in the KFO newsletter:

The boarfish project continues to make good progress and all the sampling effort put in by the pelagic fleet is paying dividends as results are starting to emerge. (...) The age, growth, reproductive and length-frequency data will provide the basis for [an] assessment, whilst the acoustic survey will be the start of a time series which will become increasingly important in future assessments. Thanks to the co-operation of all involved we are in a strong position to produce well founded and reliable advice, which given Ireland's quota share will hopefully ensure the sustainable future of the boarfish fishery. (KFO newsletter April, 2011).

The quote highlights the link between acoustic survey data and an assessment. Exploratory work was needed to fill knowledge gaps on how to scientifically assess the boarfish stock in the Northeast Atlantic, and an expert with specific competence in bio-statistics was brought into the collaboration to assist with this task. 


\subsubsection{Stock assessment}

ICES has since 2011 been requested by the European Commission to provide catch advice on boarfish in the Northeast Atlantic (ICES, 2011a). The ICES Working Group for Widely Distributed Stocks (WGWIDE) provides a forum for in-depth scientific discussions on assessment of pelagic stocks. For boarfish, limited information was available on catch, abundance, age and growth - elements that typically inform stock assessments. The scientists proposed using a biomass dynamic model, and ideas were discussed between assessment experts in WGWIDE (ICES, 2011b). Suggestions for improvements by peers stimulated further development of the model over the next two years (ICES, 2012b, 2013c). Peer reviewers highlighted the superiority of age-based models; however, this was not a viable option in the short term as there was no programme in place for sampling and analysis that could support an age-based assessment for boarfish. With the accumulating catch data, results from the recent dedicated boarfish acoustic surveys, and a number of other indices, WGWIDE was in 2013 able to perform an analytical assessment (ICES, 2013c). The time series of the parameters in the assessment model were still very short, however, and uncertainties were considered high.

ICES assessment working groups, such as WGWIDE, are not open to observers from the industry. The KFO and DPPO representatives were therefore following the developments in WGWIDE from the side-lines. They could, however, be observers in ICES Advice Drafting Groups where ICES Advice is formulated. This gave them a good understanding of the scientific basis for the catch advice which informs the European Commission's proposal for annual boarfish catch quotas.

\subsubsection{Development of a management strategy}

\subsubsection{A first interim management plan}

In October 2010, a communication from the European Commission temporarily brought the rapidly expanding and still unregulated boarfish fishery to a halt. EU Member States were informed that a technical regulation ${ }^{26}$ prevented fishing for boarfish with mesh sizes smaller than $100 \mathrm{~mm}$. The pelagic trawlers that target boarfish typically use 32-54 mm mesh sizes. Through an initiative led by an Irish Member of the European Parliament, an amendment was added to the regulation (European Union, 2011) to allow the boarfish fishery to continue. The

\footnotetext{
${ }^{26}$ Annex 1 of Regulation 850/1998.
} 
mesh size controversy triggered a speedy development of a first interim management plan for boarfish, catalysed by a coincidence: several of the key actors who had an interest in the boarfish fishery were at the time gathered to discuss other pelagic stocks. An interviewee recalled:

On the fringes of these meetings, time was available for scientists and industry stakeholders to consider the boarfish matter. The need for some kind of plan for precautionary management was discussed with industry by scientists. It wasn't hard to convince industry because they had already developed plans for horse mackerel and herring, and so they were keen. Fisheries administrators present were aware of the discussions. Though they did not get involved directly, they endorsed the initiative with the overall approach being: "Go away and come up with something. It needs to be precautionary; no nonsense!” (Interview, Scientist)

Guided by this informal mandate from the managers, a draft plan was quickly put together by an Irish scientist in collaboration with a representative of an Irish Producer Organisation. Their previous collaborations around management plans for other stocks gave them a common understanding about what needed doing. Only a few years of landing records and some preliminary life history information were available. Ideas from the FAO guidelines for new and developing fisheries (FAO, 1996) were combined with work done by ICES and the European Commission that were applicable under such data poor circumstances. The proposed plan also included a closed season to avoid by-catch of mackerel, and a closed area to protect the herring stock in the Celtic Sea, based on consultations with Irish fishermen.

The situation was urgent (the boarfish fishery had been closed), and the aim was to present the plan to the decision-makers before the European Council ${ }^{23}$ meeting in December 2010. The Council meeting would decide on quotas for boarfish for the first time. There would also be negotiations to divide the quota between EU Member States, and the Irish and Danish national delegations wished to present evidence of their industries' commitment towards a sustainable boarfish fishery. The interim management plan proposal and the ongoing collaborations with scientists were elements in a strategy to secure national shares of a boarfish quota.

The proposed interim $\operatorname{plan}^{27}$ was never formally implemented; however, the European Council $^{23}$ implicitly approved its TAC setting mechanism by cutting catches almost $75 \%$ compared to the previous year. The Council then agreed to allocate $67 \%$ of the 2011 boarfish quota to Ireland, 24\% to Denmark, 4\% to the UK, and 5\% to All Member States (European

\footnotetext{
${ }^{27}$ The proposed 2010 Interim plan can be found in IFFO (Marine Ingredients Organisation) 2012. Fisheries Assessment Report for boarfish, p. 12-13.

http://www.iffo.net/files/iffoweb/approved-raw-materials/whole-fish/boarfish-iffo-initial-assessment-uk-

denmark-fo.pdf.
} 
Council $^{23}, 2011$ ). The number of vessels involved in the boarfish fishery is small (see Section 4.1), and the Producer Organisation representatives have a direct dialogue with each of their members. When communicating the news about the dramatic reduction in fishing opportunities back to their constituencies, the KFO and DPPO representatives reminded the fishermen that the quota at 33,000 tonnes for 2011 should be seen as an alternative to a closed fishery, and highlighted the positive outcome of the quota sharing negotiations. They also stressed the importance of continued collaboration with scientists and of following up the interim plan with a proper long-term management plan. An interviewee commented on the importance of trust when gaining support for these joint actions:

I don't tell them how to fish at sea. If I did, they would tell me where to go. Likewise, they don't tell me how to manage the shore end of things, particularly in terms of how we are doing things. They expect me to be looking out for them in terms that we should be doing $\mathrm{x}, \mathrm{y}$ and $\mathrm{z}$. They want to be informed about it, right? And know about it. And they have use of it. But they do expect that I am not going to walk them into something. There is trust between us. (Interview, Industry representative)

\subsubsection{A long-term management plan}

In 2012, the first interim plan was followed-up by a first long-term management plan. The long-term management plan was designed by the same Irish scientist who had made the interim plan. Ideas and approaches were discussed with a representative from the KFO, who also consulted with other Irish and Danish Producer Organisations. The fishermen were kept informed through communications that explained the rationale behind giving the development of a long-term management plan for boarfish high priority:

KFO and Denmark's DPPO Propose Boarfish Management Plan: Most pelagic stocks now have a long-term management plan covering them. (...) Advantages of such plans include: taking the horse trading out of quota setting each year; agreeing a way of setting the TAC based on best scientific information; other management measures may be added; and accreditation bodies prefer that there is a plan in place. (...). It is in everybody's interest that a plan be developed. (KFO newsletter, July 2012)

It was clear to the ones involved that while a scientist did the development work, the ownership of the management plan resided with the industry. The scientist was invited to present the proposed plan to the Pelagic Advisory Council in July 2012. This group had only minor comments and supported the initiative to submit the plan to the European Commission as their recommendation (PRAC, 2012).

The plan proposed a six-tiered approach for setting TACs in various situations. This was an unusual and innovative design for a CFP-related management plan, and it had many similarities with the new framework for categorization of stocks in the context of ICES 
assessment and advice, which was also in development at the time (ICES, 2012a). The scientist who drafted the long-term management plan had taken inspiration from the FAO Guidelines for new and developing fisheries (FAO, 1996) and from harvest strategies designed for shark fisheries in Australia. The choice of TAC-setting rule would depend on the kind and quality of data available; the more information, the higher the tier. The highest tier corresponded to a situation when a full analytical stock assessment is available, while the lowest tier would be applicable in a situation with no data. Through its design, the proposed long-term management plan aimed to stimulate generation of data to support assessment of the stock and management of the new boarfish fishery.

The importance of having scientific data to support management of the new boarfish fishery was acknowledged by industry representatives when the collaborations with scientists were initiated in 2010. When asked (in the summer of 2014) to reflect on lessons learned from the boarfish experience, an industry representative (himself a fisherman) commented:

Definitely, we would look at going through the scientific route. Unless you have the scientific backup - I mean proper backup - there is no point in going to discuss and argue in Brussels saying "all the fishermen think there is plenty of fish out there". Forget that! Nobody has time for that. Some fishermen always say that. But if you have sound scientific evidence that is backed up by a reputable scientist and you have done your homework... One year is no good. You have done it over 3-4-5 years, and show trends. Then you have a case. If we ever get a new species again, which we probably won't in my lifetime anyway, I think we would do it in the same way. We handled a lot of species badly, but I like to think we handled this one well. (Interview, Fisherman, Industry representative)

The comment alludes to the strong position of scientific knowledge as basis for management decisions in European fisheries. The interviewee had been involved in fisheries for other pelagic species for many years and had followed related scientific and political developments closely. Investing in boarfish science was seen by this industry actor as a pathway through which he as a fisherman could contribute to the knowledge base for the new boarfish fishery.

\subsection{Discussion}

A knowledge base to support generation of a stock assessment and a long-term management plan for the boarfish fishery in the Northeast Atlantic was built within the time frame of only a few years (2010-2013). In this section, this rapid mobilisation of new knowledge is examined by first focussing on the actors involved, their stakes and the kinds of knowledge they brought forward. Processes of knowledge exchange are then discussed with attention to the role of the acoustic survey and the management plans as boundary objects. 


\subsubsection{Actors and stakes}

By starting to exploit boarfish opportunistically as a resource, and securing large shares of the EU catch quota, Irish and Danish fishermen established themselves as major stakeholders in the new commercial boarfish fishery in the Northeast Atlantic. The pelagic trawl sector, within which they operate, has been profitable for a number of years and this may have influenced the fishermen's decision to contribute financially to support scientific studies. At the time when decisions to invest in science to advance knowledge on boarfish needed to be made, the steadily increasing amounts of boarfish encountered on the fishing grounds fuelled an optimistic outlook about future large-scale harvesting possibilities. The fact that a small number of operators were involved in the fishery made it possible to involve practically everybody in deliberations around joint strategies, and to secure broad commitment. Deliberations among fishermen took place within each Producer Organisation, while coordination between the Producer Organisations was handled by their representatives. The stakes for each individual operator were high (the investment in science was a significant commitment). However, there were also possibly rewards for everybody in terms of quotas and profits in a sustainably managed boarfish fishery. The Producer Organisation representatives seem to have filled important roles as trusted facilitators in the deliberations to align fishermen's interests, which made joint actions possible.

The fisheries scientists at the Marine Institute also had stakes in the developing boarfish fishery. The mandate of their employer includes supporting sustainable development of Ireland's marine resources, and financial contributions from the industry gave welcome opportunities to initiate research efforts dedicated to advancing scientific knowledge on boarfish. Assisting the industry with the development of a management plan that would ensure a precautionary approach to exploitation of boarfish in Irish and EU waters was considered part of their regular work tasks.

The managers in DG MARE had stakes in ensuring that boarfish in EU waters would be managed sustainably; however, they were not directly involved in the collaborations studied here. Experiences from work with other stocks had shown that management measures proposed by the Pelagic Advisory Council were likely to have the industry's continued support (Coers et al., 2012), and the managers encouraged the industry's engagement with the boarfish management plans. 


\subsubsection{Novelty and forms of knowledge}

The general lack of knowledge about boarfish, which triggered the collaborative initiatives studied here, might in itself have facilitated knowledge exchange between the various groups of actors. Carlile draws attention to how powerful actors' reuse of common knowledge can prevent generation of new knowledge: the path dependency of existing knowledge becomes 'the curse of knowledge' (Carlile, 2002). In the setting studied here, put bluntly, nobody had any in-depth knowledge about boarfish, and everybody agreed that that was a problem. When the sudden increase in boarfish abundance on the fishing grounds posed a problem and triggered the need for immediate action, the stakeholders identified scientific knowledge as an essential part of the solution. Experiences from lobbying and negotiations with EU managers in Brussels had made the industry representatives aware of the power of scientific evidence in such settings.

The collaborations studied evolved opportunistically without any formal participatory research design in place. This sets the case analysed here apart from participatory studies that focus on how fishermen's knowledge can inform fisheries science (Hind, 2015) and fisheries management (Mackinson and Wilson, 2014; Mackinson et al., 2011). While the KFO and DPPO informally took on roles as joint coordinators of the collaborative efforts, they left it to the scientists to prioritise research tasks. The main tasks for the fishermen were to contribute with samples and funding. The scientists operated within their own domains and generated outputs tailored to scientific audiences. Clear separation of roles seems to have contributed to making the collaborations efficient, and tangible outcomes in the form of scientific publications were quickly produced.

The lack of involvement by managers limited the opportunities for taking bureaucratic knowledge into account when producing the management plans. The boarfish plans emerged during a period of consultations triggered by the European Commission's Green paper (European Commission, 2009a) in preparation for reform of the CFP in 2013. Although the scientists and industry representatives were knowledgeable about the regulatory system, and had gained relevant experiences from producing management plans for other pelagic stocks in EU waters, the shifting priorities and concerns of managers in DG MARE during this period could not easily be accommodated.

\subsubsection{Acoustic survey as boundary object}

The acoustic survey exemplifies how a boundary object works to connect actors from different domains through establishing a shared context. The scientists needed indices of 
abundance to assess the status of the boarfish stock. Access to acoustic survey data was considered essential for the development of a stock assessment model. Having a stock assessment model accepted by ICES would be beneficial in the context of future scientific advice on catch quotas. These connections motivated the Producer Organisation representatives to engage the boarfish fishermen, as well as other industry actors, to collectively mobilise funding to enable the initiation of a dedicated boarfish acoustic survey. The industry's repeated involvement in, and support of, the survey demonstrated to the scientists and managers their sincere commitment to work towards a sustainable boarfish fishery. At the international level, the need for survey data (and for age-based parameters) triggered questions around responsibility for securing appropriate time series of such data to support future assessments and scientific advice for boarfish as a new, commercially exploited species in EU waters.

\subsubsection{Management plans as boundary objects}

The two management plans that were created as part of the collaborations studied here were made without any specific mandate or dedicated group effort, which sets these processes apart from other initiatives where stakeholders and scientists have collaborated to make such plans (Hegland and Wilson, 2009; Stange et al., 2015). Two key individuals (a scientist and an industry representative) created the plans, and beyond their close collaboration there was little iteration between stakeholders, scientists and managers during the production process. The fact that the plans quickly gained support from other stakeholders signals that the authors were trusted as producers of relevant knowledge in this context. A small number of fishermen would be directly affected. They were operating within the same fleet segment, and the proposed measures did not trigger any major controversies around potential winners and losers. The opportunity for the fishermen to engage in direct dialogues within their Producer Organisations is likely to have facilitated the process of bringing the plans forward.

The first interim management plan was made in response to an urgent situation in which the future of the boarfish fishery was threatened. By proposing a short-term management strategy, which would imply a significant cut in catches, it signalled the industry's commitment to a precautionary approach to management of the new boarfish fishery. It also demonstrated the ability of the Irish and Danish Producer Organisations to negotiate and agree internally on a joint strategy for moving forward. The long-term management plan reconfirmed commitments that had been made by Ireland and Denmark through the interim plan. The fact that this plan was proposed to the European Commission by the Pelagic 
Advisory Council extended the commitment further to encompass the wider group of stakeholders with an interest in pelagic fisheries in Europe. It put emphasis on the importance of having a solid scientific knowledge base to underpin management decisions, and shifted focus from short-term to long-term.

\subsubsection{Knowledge exchange across boundaries}

Figure 4.3 illustrates resources that were at play in connecting actors in this study. Knowledge transfer was facilitated by a common vocabulary that was already established in previous collaborations regarding other pelagic stocks. With a clear separation of roles and tasks, there was no need for the stakeholders to become experts in the scientists' knowledge domains, and vice-versa. The acoustic survey helped connect fishermen and scientists by translating boarfish science into advisory tools that were highly relevant to the new fishery. Producer Organisation representatives facilitated deliberations between the scientists and the fishermen, as well as between fishermen within their own constituencies. The strong financial position of the fleet segment involved was a tangible resource in this case, as it enabled the fishermen to contribute with significant amounts of funding to support scientific studies. There was little interaction between actor groups during the making of the management plans; however, the plans seem to have been instrumental in generating support for longer-term strategies to achieve a sustainable boarfish fishery. This study did not shed light on the detailed negotiation processes within and between the Producer Organisations which enabled joint support of the plans; however, the sense of urgency that surrounded the making of the first interim plan is likely to have influenced the actors' ability to agree on joint actions. Introduced as a follow-up, issue novelty was reduced for the second plan. The fact that the long-term management plan was endorsed by the Pelagic Advisory Council suggests that there is broad support for precautionary long-term management strategies among European pelagic industry actors. 


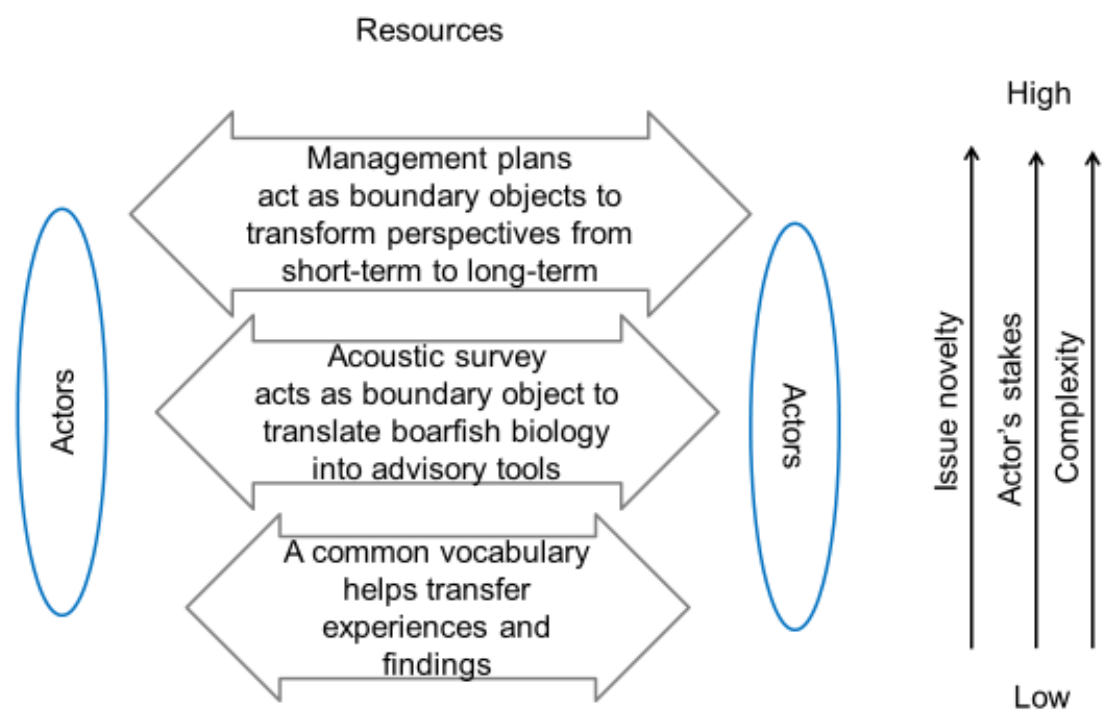

Figure 4.3 Resources that enable knowledge-sharing between actors

\subsection{Conclusions}

The conceptual framework applied in this study provided a lens which clarified how forms of knowledge were used in collaborations between fisheries scientists and representatives from the pelagic fishing industry in a joint effort to build a knowledge base for a new fishery. The setting explored in this study was characterised by lack of existing knowledge and an urgent need to fill knowledge gaps. Fishing industry representatives identified mobilisation of scientific knowledge as a priority, and there was little integration of other forms of knowledge. Funding provided by the industry enabled research initiatives which within a remarkably short time period (2010-2013) produced new scientific knowledge on boarfish maturity, aging, distribution, target strength, and abundance. A long-term management plan was designed to stimulate continued efforts to fill scientific knowledge gaps. Strategic choices made by the collaborative partners in this initiative highlight the information requirements for stocks that are managed under the CFP. The weight given to scientific knowledge in this context is evident. The findings illustrate that industry actors can fill important roles as facilitators in collaborative processes that aim to generate new scientific knowledge.

Knowledge exchange processes are difficult to study. Actors from different knowledge domains increasingly engage in collaborations to produce knowledge that is useful for fisheries management, and there is a need to better understand how different forms of 
knowledge interact. The case study presented here exemplifies how ideas from organisation management can be applied to investigate knowledge exchange in collaborations between actors who start out with different forms of knowledge. 
Chapter 5: Boundary spaces, objects and activities in mixed-actor knowledge production: Making fishery management plans in collaboration $^{28}$

\section{Paper III}

\footnotetext{
28 This paper is published as: Stange, K., Van Leeuwen, J., and Van Tatenhove, J. 2016. Boundary spaces, objects and activities in mixed-actor knowledge production: Making fisheries management plans in collaboration. Maritime Studies, 15:14. Numbering of sections, figures and tables has been edited to integrate this text as a thesis chapter.
} 


\begin{abstract}
This paper investigates knowledge production in collaborations where the actors have different knowledge and interests. Building on boundary object theory, a conceptual framework is developed to analyse knowledge exchange in two stakeholder-led collaborations to make fishery management plans. The framework introduces boundary spaces to conceptualise the dynamic interaction between objects and activities. Within boundary spaces, actors can share, transfer and translate their knowledge, and common understanding can emerge. The collaborations analysed aimed to produce management plans for the Nephrops (Nephrops norvegicus) fishery in the North Sea and the boarfish (Capros aper) fishery in the Northeast Atlantic. Several boundary spaces were identified in each collaboration. During the production phase, the emerging management plans took on multiple representations as boundary objects that facilitated knowledge exchange. Activities were essential, as these created entry points for different actors to become part of the boundary spaces where they could contribute to knowledge production. Fishing industry representatives in the North Sea Advisory Council and the Pelagic Advisory Council played key roles in initiating and coordinating activities. The case studies demonstrate that Advisory Councils take on proactive roles in initiatives that aim to expand the knowledge base for European fisheries management. Direct engagement was instrumental to create ownership of the problem addressed in the various collaborative settings that emerged during the management plan initiatives.
\end{abstract}

Keywords: knowledge production, knowledge exchange, boundaries, boundary objects, participation, stakeholders, fishery management, fisheries, Advisory Councils, cooperative research 


\subsection{Introduction}

A key challenge in environmental management is how different kinds of knowledge can be integrated into products that are useful for managers (Roux et al., 2006; Fazey et al., 2013; Raymond et al., 2010). European fishery management under the Common Fisheries Policy (CFP) has a legacy of being informed by science that focuses exclusively on biological aspects of fisheries (Hegland, 2006). Critical inquiries have highlighted, however, that knowledge contributions from a broad range of natural and social science disciplines as well as from stakeholders are needed to embrace the complexity of fishery management (Degnbol et al., 2006; Symes and Hoefnagel, 2010; Garcia and Charles, 2008; Hawkins, 2005; Schwach et al., 2007). CFP decision-making should, in accordance with good governance principles, be based on best available scientific advice and broad stakeholder involvement (EU, 2013). The two principles can be combined by involvement of stakeholders in research, here referred to as 'the scientific route' to knowledge integration. This scientific route was highlighted in the European Commission's Green Paper, which discussed how the CFP could be improved through reforms. Addressing the knowledge base for the CFP, the Green Paper asked: "How can we better promote stakeholder involvement in research projects, and incorporate stakeholder knowledge in research-based advice?" (European Commission, 2009a, p. 20-21).

Stakeholders can also contribute to the knowledge base of the CFP by submitting their recommendations to the European Commission through the Advisory Councils, here referred to as 'the stakeholder route' to knowledge integration. Established as Regional Advisory Councils (RACs) as part of the 2002 CFP reform, and as Advisory Councils following the 2013 reform $^{29}$ (Council, 2002, 2004; EU, 2013), these are heterogeneous stakeholder forums with $60 \%$ representation from the fishing industry and fishermen's organisations and $40 \%$ representation from other interest groups, including non-governmental organisations (NGOs). The Advisory Councils' role is to provide the European Commission and European Union (EU) member states with advice on issues related to fishery management. Linke et al. (2011) draw attention to challenges associated with incorporating the stakeholder knowledge provided by the Advisory Councils into management and policymaking as these bodies are typically consulted during the final stages of a governance process. Active involvement in earlier stages where knowledge is generated would be better aligned with the original

\footnotetext{
${ }^{29}$ The name change was introduced during the period studied. In this paper, these groups are generally referred to as Advisory Councils, while Regional Advisory Councils (RACs) is used when referring to documents published by these groups prior to the name change.
} 
motivation for the establishment of Advisory Councils, i.e. to "enable the Common Fisheries Policy to benefit from the knowledge and experience of the fishermen concerned and of other stakeholders and to take into account the diverse conditions throughout Community waters" (Council, 2002, p. 4).

Some Advisory Councils have moved beyond a reactive consultation role by taking initiatives to make long-term management plans. Such plans, also commonly referred to as multiannual plans, are used as tools by the EU bureaucracy to achieve the objectives of the CFP (EU, 2013; European Commission, 2014b). Stakeholder-driven initiatives to make such plans is a recent phenomenon in the EU. The first plan produced by an Advisory Council was a proposal regarding the western stock of Atlantic Horse mackerel (Trachurus trachurus) presented by the Pelagic Advisory Council (PELAC) in 2007 (PRAC, 2007; Hegland and Wilson, 2009). In 2012, the PELAC followed up with a plan for boarfish (Capros aper) in the Northeast Atlantic (PRAC, 2012a). A third Advisory Council plan was presented by the North Sea Advisory Council (NSAC) in 2015 as their advice concerning management of Nephrops (Nephrops norvegicus) in the North Sea (NSAC, 2015).

Advisory Council initiatives to produce management plans open up for integration of various forms of knowledge into the EU fishery management knowledge base via the stakeholder route. Knowledge exchange processes in such stakeholder-driven settings are largely unexplored. Knowledge exchange research on stakeholder engagement typically focuses on science-driven collaborations and the scientific route to knowledge integration (Fazey et al., 2013; Fazey et al., 2014). However, the Advisory Council initiatives are mixedactor collaborations that are not conducted as formal research projects. Insights about best practices from experiences with science-driven participatory research (Mackinson et al., 2011; Reed et al., 2014; Hegger et al., 2012) are thus not directly applicable.

In this paper, we apply and develop boundary object theory to investigate knowledge exchange processes in stakeholder-led initiatives to make management plans for EU fishery management. Building on previous research on boundary processes (Star and Griesemer, 1989; Star, 2010; Carlile, 2002, 2004; Nicolini et al., 2012) described in the next section, we ask: How do boundary objects, supported by boundary activities, create boundary spaces that facilitate knowledge exchange in stakeholder-led collaborations to make management plans? We address this question by analysing the initiatives to make long-term management plans for Nephrops and for boarfish, mentioned above. The two cases represent unique and recent examples of how stakeholders, who represent the fishing industry's interests, engage in activities with other stakeholders and with scientists in collaborations to produce tools for EU 
fishery management. The two cases complement each other by illustrating collaborations in different fisheries and stakeholder groups; the Nephrops case provide insights into an established demersal fishery and a collaborative process in the NSAC, while the boarfish case is set within the context of a new pelagic fishery and illustrates collaborations co-ordinated by interests in the PELAC. Our analysis focuses on the interplay between objects and activities, and on activities as entry points for various actors, with the aim of advancing understanding of knowledge production in stakeholder-led settings. The paper contributes to boundary object theory by presenting a theoretical understanding of knowledge exchange in stakeholder-led collaborations. In addition, the findings help fishery stakeholders, scientist and mangers understand the mechanisms and dynamics of developing long-term management plans in collaborative settings.

The next section introduces boundary object theory and the conceptual framework developed to analyse boundary processes and knowledge exchange. This is followed by a description of the methods used to collect and analyse empirical material for the two case studies. The Nephrops and boarfish cases are then presented and discussed, and in the final section conclusions are drawn.

\subsection{Theory on boundary processes in mixed-actor collaborations}

The metaphor of boundaries is applicable when analysing the dynamics between actors in collaborative knowledge production processes. Reflecting on the usefulness of boundary concepts in social science research, Lamont and Molnar (2002, p. 169) comment that "[i]f the notion of boundaries has become one of our most fertile thinking tools, it is in part because it captures a fundamental social process, that of relationality". Seminal contributions are Gieryn's concept of boundary work (Gieryn, 1983) and Star and Griesemer's concept of boundary objects (Star and Griesemer, 1989). The two concepts represent different interpretations of boundaries as a metaphor. While Gieryn's boundary work addresses demarcations, in particular between science and non-science and between scientific disciplines, Star and Griesemer's boundary objects address convergence, as in creating a common understanding between actors who wish to collaborate. As Riesch (2010, p. 455) puts it: "The groups that Star and Griesemer are concerned with here are not rivals that, as in Gieryn's schema need to protect their interest against outsiders, but rather different groups that may have different values, norms and aims, but nevertheless need to work together". Star 
and Griesemer were interested in how collaborations between diverse groups of actors involved in scientific work can succeed. They describe boundary objects as

objects which are both plastic enough to adapt to local needs and the constraints of the several parties employing them, yet robust enough to maintain a common identity across sites. They are weakly structured in common use, and become strongly structured in individual site use. They may be abstract or concrete. They have different meanings in different social worlds but their structure is common enough to more than one world to make them recognizable, a means of translation (Star and Griesemer, 1989, p. 393).

A clarification of Star and Griesemer's use of the words boundaries and objects in this context is appropriate. Susan Star explains: "Often, boundary implies something like edge or periphery, as in the boundary of a state or a tumour. Here, however, it is used to mean a shared space, where exactly that sense of here and there are confounded" (Star, 2010, p. 602603). An object, in Star's understanding, is "something people ... act toward and with. Its materiality derives from action, not from a sense of prefabricated stuff or "thing"-ness" (ibid, p. 603).

According to Carlile (2002), objects can perform as boundary objects in mixed-actor knowledge exchanges if they have certain characteristics: 1) they establish a shared syntax or language for individuals to represent their knowledge; 2) they provide concrete means for individuals to specify and learn about their differences and dependencies across a given boundary; and 3) they facilitate a process where individuals can jointly transform their knowledge. Carlile (2004) draws attention to that knowledge-sharing becomes increasingly challenging and complex if the actors in the collaboration have high stakes and if there is novelty involved. Boundary objects with characteristics tailored to the complexity and challenge at hand is therefore needed. Nicolini et al. (2012) highlight that boundary object theory is only one of several possibly useful lenses when seeking to understand the dynamics of mixed-actor collaborations. By using multiple theoretical approaches; theory on boundary objects, epistemic objects, cultural historical activity theory, and objects as infrastructure, they shed light on not only how, but also why and when objects may play a role in crossdisciplinary collaborations. They propose that objects can have several functions: 1) motivate collaboration; 2) facilitate work across different types of boundaries; and 3) provide infrastructure. This clarifies that a boundary object works for a reason; someone makes efforts that triggers activities which enable an object to perform as a boundary object in a particular setting and context. Activities thus become important when understanding the role of boundary objects in collaborations. We propose that the interplay between activities and 
boundary objects create 'boundary spaces' within which actors can share, transfer and translate their knowledge into joint knowledge. Without such activities, here referred to as 'boundary activities', the materiality of objects referred to by Star (2010) will not emerge.

These insights on boundary processes discussed above inspired us to develop a conceptual framework for analysing knowledge exchange in stakeholder-led, mixed-actor collaborations.

\section{Boundary space}

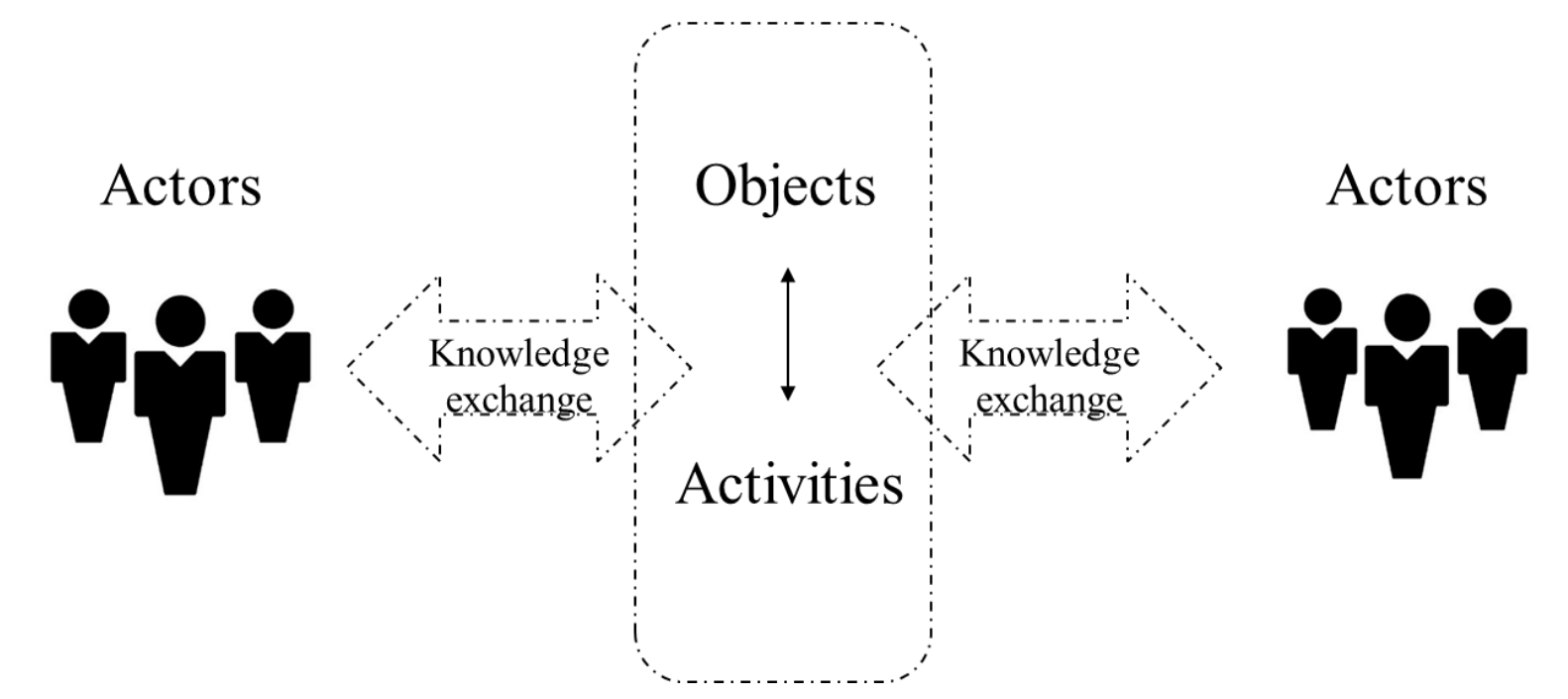

Figure 5.1 A conceptual framework for understanding knowledge exchange between actors facilitated through an interplay between objects and activities within boundary spaces.

The framework (Figure 5.1) addresses the dynamic interplay between objects, activities and actors. A boundary here refers to an abstract, shared space between collaborating actors with different knowledge. This 'boundary space' is where tacit knowledge becomes explicit and where actors are confronted with, and learn about, each other's interests and perspectives. Actors can be individuals or groups. In collaboration, they want to produce new knowledge, based on their own individual knowledge and interests. Objects become boundary objects when they play a role in connecting these actors and help establish a shared understanding between them. Objects can be both abstract and tangible. We introduce the concept of 'boundary activities' as activities that are instrumental in making objects function as boundary objects. Examples of boundary activities are face-to-face meetings, phone calls, workshops, field work, study visits, presentations, and decisions to initiate projects. These activities create entry points for actors to participate in a collaboration. They create ways to focus efforts around a certain shared idea, concept or product that can potentially be a boundary object. 
Activities are thus instrumental in making objects function as boundary objects in a specific context. Boundary activities and boundary objects are intrinsically interrelated in the sense that the objects trigger activities while the activities, in return, support the objects.

\subsection{Methods}

Knowledge exchange processes were investigated in two case studies of stakeholder-led collaborations; the Nephrops case and the boarfish case. The cases represent two out of three to us known examples where long-term management plans have been presented by Advisory Councils. A third collaboration to make a plan for western horse mackerel has previously been analysed from a participatory modelling perspective by Hegland and Wilson (2009). The collaborations studied here were recent or still ongoing, which made it possible to follow the developments in, or close to, real time. Qualitative empirical material was collected from documents, through semi-structured interviews, and from observations. The use of multiple methods gave opportunities for triangulation, i.e. to check and validate findings by combining evidence from multiple sources (Yin, 2009). The principal investigator participated as observer in eight NSAC meetings in 2012 and 2013, and in six PELAC meetings in 2014. Documents studied included minutes from NSAC meetings 2006-2015 and PELAC meetings 2006-2015. Other documents consulted were International Council for the Exploration of the Sea (ICES) Advice and Working Group (WG) reports related to Nephrops and boarfish, CFPrelated documents from the European Commission, and newsletters from fishermen's organisations. The documents were particularly useful to gain an overall understanding of the various actors' involvement with management plans, establish timelines, and identify potential informants for interviews. Semi-structured interviews $(n=37)$ were conducted between May 2012 and November 2014 with fishing industry stakeholders, including Advisory Council members and staff $(\mathrm{n}=17)$, scientists who had been involved in Nephrops or boarfish research or in the making of management plans $(n=14)$, and civil servants in the European Commission's Directorate-General for Maritime Affairs and Fisheries (DG MARE) $(n=6)$. The interviews were conducted face-to-face, and via telephone or Skype, and were with a few exceptions - recorded and transcribed.

Documents, interview transcripts and observer notes were assembled, labelled and structured using ATLAS.ti qualitative analysis software. The software aided retrieval and analysis of information from the combined pool of documents. Detailed narratives of the processes of making the Nephrops and boarfish management plans were created. The 
narratives described initiatives taken, actors involved in activities, and tangible output produced by the collaborations. Key informants were asked to review drafts of these narratives to help identify any errors and omissions. The narratives were used to analyse the role of objects, activities and actors with the conceptual framework presented in Figure 5.1 as a lens. Ideas and interpretations were tested and developed in dialogue between the co-authors in an iterative process through which the conceptual framework evolved.

\subsection{Nephrops case}

\subsubsection{Background}

Nephrops are crustaceans that live in burrows in soft sediment. In the North Sea, they are primarily caught by demersal (bottom) trawling within nine areas, called functional units. The functional units are considered to have separate stocks (ICES, 2013a). A catch quota (Total Allowable Catch, TAC) is currently set for all of the North Sea. ICES advises, however, that management of Nephrops should be at the functional unit level "to ensure that catch opportunities and effort are compatible and in line with the scale of the resources in each of the stocks defined by the functional units" (ICES, 2013a, p.2). How management at the functional unit level can best be arranged has been subject to debate between stakeholders, managers and scientists for several years. In 2006, the NSAC Demersal Working Group conceived the idea of producing a long-term management plan for Nephrops in the North Sea. The NSAC Executive Committee (ExCom) set work in motion, and in 2015 their proposal could be presented to the European Commission. Here, the dynamic interplay between objects, activities and actors is analysed to illuminate the knowledge exchange process from idea to proposal. An overview is presented in Table 5.1.

\subsubsection{The idea of a plan}

At the initial stage of the management plan process, the members of the NSAC Demersal Working Group played key roles. Several of them were at the time actively engaged in workshops and conferences where potential benefits of more holistic approaches to fishery management were discussed between stakeholders, scientists and managers (Pope et al., 2006; RACs, 2008; ICES, 2009b). They were inspired by these discussions, and eager to take ownership of a knowledge production process in which stakeholder input would be as important as contributions from scientists and managers. A template for a long-term management plan that would encompass biological, ecological, economic, social and 
institutional perspectives on fishery management (NSRAC-DWG, 2006) became the "scaffolding" around a management plan production process. The NSAC ExCom took action by deciding to establish a Nephrops Focus Group as a subset of the Demersal Working Group to bring the hands-on work with the plan forward. With this decision, a new set of actors became involved and another boundary space emerged.

Table 5.1 Boundary spaces and knowledge exchange in the Nephrops long-term management plan process

\begin{tabular}{|c|c|c|c|c|}
\hline $\begin{array}{l}\text { Boundary spaces } \\
\text { at stages in the } \\
\text { collaboration }\end{array}$ & Object & Actors & Activities & $\begin{array}{l}\text { Knowledge } \\
\text { exchange }\end{array}$ \\
\hline $\begin{array}{l}\text { Evolution of idea } \\
\text { to make a long- } \\
\text { term management } \\
\text { plan }\end{array}$ & $\begin{array}{l}\text { Long-term } \\
\text { management plan } \\
\text { as a template }\end{array}$ & NSAC members & $\begin{array}{l}\text { NSAC Demersal } \\
\text { Working Group } \\
\text { meetings (long } \\
\text { term); ExCom } \\
\text { decision. }\end{array}$ & $\begin{array}{l}\text { NSAC members } \\
\text { develop common } \\
\text { interest in taking } \\
\text { ownership of a } \\
\text { stakeholder- } \\
\text { driven, holistic } \\
\text { management plan } \\
\text { process }\end{array}$ \\
\hline $\begin{array}{l}\text { Production of } \\
\text { draft plans }\end{array}$ & $\begin{array}{l}\text { Long-term } \\
\text { management plan } \\
\text { as drafts }\end{array}$ & $\begin{array}{l}\text { NSAC members } \\
\text { and external } \\
\text { experts in the } \\
\text { Nephrops Focus } \\
\text { Group }\end{array}$ & $\begin{array}{l}\text { Nephrops Focus } \\
\text { Group meetings } \\
\text { (ad-hoc, long } \\
\text { term) }\end{array}$ & $\begin{array}{l}\text { Focus group } \\
\text { members learn } \\
\text { about each other's } \\
\text { concerns and } \\
\text { priorities; invited } \\
\text { experts contribute } \\
\text { with scientific } \\
\text { knowledge }\end{array}$ \\
\hline Port visits & $\begin{array}{l}\text { Long-term } \\
\text { management plan } \\
\text { idea and process } \\
\text { as a PowerPoint } \\
\text { presentation }\end{array}$ & $\begin{array}{l}\text { Nephrops Focus } \\
\text { Group members, } \\
\text { scientists and } \\
\text { fishermen }\end{array}$ & $\begin{array}{l}\text { Meetings in } \\
\text { fishing ports to } \\
\text { discuss } \\
\text { management plan } \\
\text { ideas and progress } \\
\text { (one time) }\end{array}$ & $\begin{array}{l}\text { Presentations and } \\
\text { responses; } \\
\text { difficult to reach } \\
\text { common } \\
\text { understanding in } \\
\text { "one-off" settings }\end{array}$ \\
\hline $\begin{array}{l}\text { Functional unit } \\
\text { plans }\end{array}$ & $\begin{array}{l}\text { Fishing plan for } \\
\text { the Farne Deeps }\end{array}$ & $\begin{array}{l}\text { Farne Deeps } \\
\text { Focus Group } \\
\text { members }\end{array}$ & $\begin{array}{l}\text { Farne Deeps } \\
\text { Focus Group } \\
\text { meetings; } \\
\text { scientific study. } \\
\text { (ad-hoc, short } \\
\text { term) }\end{array}$ & $\begin{array}{l}\text { Deliberations to } \\
\text { identify functional } \\
\text { unit-specific } \\
\text { management } \\
\text { options; scientific } \\
\text { study provides } \\
\text { analysis and } \\
\text { alternatives }\end{array}$ \\
\hline $\begin{array}{l}\text { Long-term } \\
\text { management plan } \\
\text { proposal }\end{array}$ & $\begin{array}{l}\text { Long-term } \\
\text { management plan } \\
\text { as a NSAC } \\
\text { proposal }\end{array}$ & $\begin{array}{l}\text { NSAC ExCom } \\
\text { members }\end{array}$ & $\begin{array}{l}\text { NSAC ExCom } \\
\text { decision }\end{array}$ & $\begin{array}{l}\text { NSAC-owned } \\
\text { plan holds } \\
\text { stakeholder } \\
\text { produced } \\
\text { knowledge }\end{array}$ \\
\hline
\end{tabular}




\subsubsection{Production of draft plans}

The Nephrops Focus Group consisted of NSAC members with strong interests in the Nephrops fishery. Their main activity was meetings; 16 Nephrops Focus Group meetings were held between May 2007 and September 2015. Face-to-face interaction over several years allowed the participants to learn from each other about perspectives and priorities within different segments of the fishing fleet. Group members with NGO affiliations brought forward conservation issues including discards, bycatch of vulnerable species, and impact of bottom trawling on the seabed. An activity which further shaped knowledge production within the Nephrops Focus Group was to invite scientists. This expansion in terms of actors involved gave opportunities for the Nephrops Focus Group members to gain new insights about Nephrops biology, recruitment mechanisms, stock assessments, and scientific advice provided by ICES. The scientists contributed with texts on fishery science-specific issues, such as reference points, for inclusion in the long-term management plan. Updated versions of the emerging plan were made available as tangible representations of how the work progressed. As such, the drafts provided a medium for making the participants' tacit knowledge explicit. Furthermore, they served in a boundary object capacity as "containers" for Nephrops-related information assembled and ideas discussed by the Nephrops Focus Group.

\subsubsection{Port visits}

Additional activities were initiated in 2010 to involve more actors in the management plan development process. A press release was sent out to invite fishermen to attend meetings:

In a ground-breaking initiative that could set a precedent for other stocks, the North Sea Regional Council [sic] is to hold a series of meetings with fishermen and other stakeholders in the main Nephrops ports. Chairman of the North Sea RAC ..., said: 'We have been working on a long-term management plan for Nephrops in the North Sea for two years. Now it is time to share our work with those in the fishery to test whether we have got things right and to see whether we have missed anything. Longterm management plans are the future and it is therefore extremely important that everyone involved in the Nephrops fishery contributes to its development [...]. (NFFO, 2010).

The port meetings created entry points for active Nephrops fishermen to contribute with their knowledge. In these meetings, PowerPoint slides presented by Nephrops Focus Group members set the stage by explaining the rationale behind the NSAC management plan initiative, present progress to date, and share ideas for ways forward. The responses from the fishermen signalled that there were strong and diverging interests and views between different 
operators and fleet segments. In this boundary space, lack of a shared language between the actors was a barrier to knowledge exchange. While the Nephrops Focus Group members and the scientists present were familiar with the scientific and bureaucratic jargon associated with stock assessments and management plans, this was not the case for the other participants. A one-off opportunity for face-to-face interaction, supported by the PowerPoint presentation, was insufficient for common understanding to develop. The feedback from the fishermen did, however, clarify to the NSAC that an overall plan for Nephrops management in the North Sea needed to take various local conditions and concerns into account. The next step was therefore to initiate more activities, this time with a local or regional focus.

\subsubsection{Functional unit management}

Based on feedback from the fishermen in the port meetings, and scientific advice from ICES that management of Nephrops should be at the functional unit level rather than on the overall North Sea level, the Nephrops Focus Group proceeded with the idea to make separate "fishing plans" for functional units. Initiatives to make functional unit fishing plans brought new actors into the overall process. Scientists were engaged to help draft a fishing plan for the Farne Deeps, the functional unit where management measures were most urgent. The scientists interviewed Nephrops fishermen and explored which objectives and management options that might be suitable for this particular area (Bailey et al., 2012). The response from fishermen to the scientists' enquiries to participate in the study was low, but for the fishermen who chose to engage, the initiative provided entry points for contributing with their knowledge and concerns. A quote from the Farne Deeps study highlights differences in interests and perspectives between the local fishermen and the more distant operators:

There was a stark difference of opinion between fishers registered at ports in North East England and those from elsewhere. The main concern of those registered at ports close to the grounds was that the twin rig gears preferred by many visiting skippers were damaging the seabed and taking too much from the fishery. ... There was a strong call from many of the local fleet to ban twin rigging on the Farne Deeps Nephrops grounds. In contrast, those using twin rig gear were of the opinion that claims of seabed damage were unfounded and that bottom contact by heavy weights used by twin rig gear was minimal if it was set up correctly. (Bailey et al., 2012, p. ii).

The Nephrops Focus Group established a Farne Deeps sub-group to discuss possible alternatives to reduce fishing pressure. This initiative reduced the number of actors involved in this boundary space to only a few individuals. After considering effort controls, gear restrictions, spatial measures, and "of which no more than x tonnes" quota-restricting clauses, 
the Farne Deeps sub-group found the quota-restricting clauses most promising (NSRACNFG, 2012). However, this conclusion triggered questions from industry stakeholders about who would then be eligible to take the functional unit-specific quota in the Farne Deeps (NSAC-NFG, 2014). Exploratory calculations on how such a clause would be materialised in the form of quota allocations to fishermen under the existing management regime highlighted problems related to creating winners and losers. Diverging views on appropriate management measures in the Farne Deeps among fishing industry representatives, who wished to protect the business interests of their constituencies, could not be resolved by arranging yet more Farne Deeps sub-group or Nephrops Focus Group meetings. The NSAC finally settled for including a provisional fishing plan for the Farne Deeps as an annex to the overall management plan for the North Sea Nephrops fishery. The annex highlighted the “...of which no more than ..." provision as a potentially good solution for the Farne Deeps, while also drawing attention to possible consequences of imposing such quota-restricting measures:

... all parties accept that in the event of a significant reduction in Nephrops fishing opportunities for operators in the Farne Deeps fishery, quota availability would become a serious issue for locally based vessels dependent on this single fishery. The administrations involved would need to work with the POs (producer organisations) to find the best outcome for those who have a record of fishing in the area and to safeguard the interests of the locally based fleet for the duration of any required quota reductions. (NSAC, 2015, p. 38).

The challenges encountered when trying to reach consensus on management measures for the Farne Deeps functional unit clarified how far such a constellation of actors as the Farne Deeps sub-group, the Nephrops Focus Group, and ultimately the NSAC, could take a collaborative mixed-actor knowledge production process before encountering politically sensitive issues and handing it over to managers for further work and decision-making (Stange et al., 2015).

\subsubsection{A Nephrops long-term management plan proposal}

In February 2015, nine years after the decision to make a management plan was taken by the NSAC ExCom, a 43-page long document A Long Term Management Plan for North Sea Nephrops was submitted to DG MARE as NSAC's advice (NSAC, 2015). A provisional fishing plan for the Farne Deeps was included in an annex. Another annex, written by scientists, proposed a new reference point for identifying precautionary levels of Nephrops stocks. Actors involved at this stage were the NSAC's ExCom as the formal owner and producer of the plan. Introductory statements explained the plan's somewhat unusual length and format: 
Because this is the first plan that has been prepared in this way, with the full involvement of stakeholders, the plan is rather longer [sic] and more detailed than a conventional Management Plan. The plan includes information on how the management conclusions were reached, and how the plan has progressively evolved. Later versions are expected to be more concise. (NSAC, 2015, p. 3).

With this, the NSAC communicated that it had been as important the them to develop a plan with ideas and elements that the fishermen could support as to deliver a product that would fit smoothly into the existing management framework.

\subsubsection{Nephrops case summary}

Producing a long-term management plan for the Nephrops fishery became a lengthy learningby-doing exercise for the NSAC. The process was open and transparent. Stakeholders, scientists and managers with an interest in Nephrops science and management were invited to contribute to the hands-on knowledge production process by engaging in the Nephrops Focus Group. Several boundary spaces emerged within which actors could exchange knowledge. Draft versions of the long-term management plan served as objects through which this exchange took place. Boundary activities were manifested in the form of numerous group meetings, port visits and an interview study. These activities provided entry points for participation in the knowledge production process; however, direct engagement by active fishermen and managers was limited. It seemed an overly ambitious undertaking to produce a long-term management plan with a holistic approach to management based on broad input from stakeholders with different knowledge and interests. Still, a tangible output was produced and delivered through the stakeholder route. The proposal for a long-term management plan presented to DG MARE represents a milestone for the NSAC as stakeholder contributors to the knowledge base for EU fishery management.

\subsection{Boarfish case}

\subsubsection{Background}

Boarfish is a small pelagic species that is being caught in increasing amounts on the shelf edge south and west of Ireland. Some consider it a nuisance by-catch species, while others target it as a resource for the fishmeal industry. In 2013, boarfish was added to the list of stocks handled by the PELAC (EU, 2013, Annex III). In the PELAC, a majority of the boarfish fishermen's interests is represented through Killybegs Fishermen's Organisation (KFO) and Danish Pelagic Producers Organisation (DPPO). Development of a long-term 
management plan for the boarfish fishery in the Northeast Atlantic was part of collaborations in 2010-2012 between KFO, DPPO and fishery scientists (Stange, 2016). Here, knowledge exchange processes during these collaborations are described with focus on the interplay between objects, activities and actors. An overview of the boundary spaces that emerged is shown in Table 5.2.

Table 5.2 Boundary spaces and knowledge exchange in the boarfish long-term management plan process

\begin{tabular}{|c|c|c|c|c|}
\hline $\begin{array}{l}\text { Boundary spaces } \\
\text { at stages in the } \\
\text { collaboration }\end{array}$ & Object & Actors & Activities & $\begin{array}{l}\text { Knowledge } \\
\text { exchange }\end{array}$ \\
\hline $\begin{array}{l}\text { Science-industry } \\
\text { research } \\
\text { initiatives }\end{array}$ & $\begin{array}{l}\text { Problematic } \\
\text { knowledge gaps } \\
\text { in a rapidly } \\
\text { developing } \\
\text { fishery }\end{array}$ & $\begin{array}{l}\text { Fishermen's } \\
\text { organisation } \\
\text { representatives } \\
\text { (KFO and DPPO); } \\
\text { Scientists (Marine } \\
\text { Institute and } \\
\text { DTU-Aqua); } \\
\text { Boarfish } \\
\text { fishermen }\end{array}$ & $\begin{array}{l}\text { Mobilisation of } \\
\text { funding for } \\
\text { scientific studies; } \\
\text { sampling } \\
\text { program, acoustic } \\
\text { survey, age and } \\
\text { maturity studies }\end{array}$ & $\begin{array}{l}\text { New scientific } \\
\text { knowledge } \\
\text { produced; } \\
\text { fishermen develop } \\
\text { understanding } \\
\text { about the role of } \\
\text { scientific data in } \\
\text { stock assessment } \\
\text { and management }\end{array}$ \\
\hline $\begin{array}{l}\text { Interim plan } \\
\text { proposal } \\
\text { development }\end{array}$ & $\begin{array}{l}\text { Interim plan } \\
\text { proposal as idea }\end{array}$ & $\begin{array}{l}\text { Fishermen's } \\
\text { organisation } \\
\text { representatives } \\
\text { (KFO and DPPO); } \\
\text { Scientist (Marine } \\
\text { Institute) }\end{array}$ & $\begin{array}{l}\text { Deliberations } \\
\text { (one-on-one) }\end{array}$ & $\begin{array}{l}\text { Common interest } \\
\text { identified }\end{array}$ \\
\hline $\begin{array}{l}\text { Long-term } \\
\text { management plan } \\
\text { proposal } \\
\text { development }\end{array}$ & $\begin{array}{l}\text { Long-term } \\
\text { management plan } \\
\text { as idea }\end{array}$ & $\begin{array}{l}\text { Fishermen's } \\
\text { organisation } \\
\text { representatives } \\
\text { (KFO and DPPO); } \\
\text { Scientist (Marine } \\
\text { Institute); } \\
\text { PELAC WG II } \\
\text { members }\end{array}$ & $\begin{array}{l}\text { Deliberations } \\
\text { (one-on-one); } \\
\text { PELAC WG II } \\
\text { presentation }\end{array}$ & $\begin{array}{l}\text { Common ground } \\
\text { established, } \\
\text { facilitated by } \\
\text { industry } \\
\text { representatives }\end{array}$ \\
\hline $\begin{array}{l}\text { Long-term } \\
\text { management plan } \\
\text { proposal }\end{array}$ & $\begin{array}{l}\text { Long-term } \\
\text { management plan } \\
\text { as proposal }\end{array}$ & $\begin{array}{l}\text { PELAC ExCom } \\
\text { members }\end{array}$ & $\begin{array}{l}\text { PELAC ExCom } \\
\text { decision }\end{array}$ & $\begin{array}{l}\text { PELAC owned } \\
\text { plan holds } \\
\text { stakeholder } \\
\text { produced } \\
\text { knowledge }\end{array}$ \\
\hline
\end{tabular}




\subsubsection{Science-industry collaborations}

In 2010, representatives for the fishermen saw a need for the industry to contribute to expand scientific knowledge about boarfish, as explained by the KFO Chief Executive in a newsletter editorial:

The KFO has embarked on a scientific study of boarfish with the contracting of (name) to carry the necessary scientific work. Very little is known about boarfish and in light of development of the fishery by the RSW (refrigerated seawater) pelagic vessels, the KFO considered it was necessary to have the relevant biological information. Such information is central to devising rational management arrangements that will ensure the long term sustainable future for this fishery. This is a new developing fishery, which has the potential to become a significant economic Irish fishery. Investment in the science at an early stage is paramount to that development. (KFO, 2010, p. 4).

Funding for scientific studies on boarfish was made available through contributions from fishermen who had boarfish quotas, as well as from the land-based processing industry. Coordination and deliberations within the producer organisations were essential to mobilise the funding. An interviewee explained:

If the members (of the producer organisation) believe that this is the right thing to do, there is never an issue with money. If they don't believe in it, you will never get beyond that first talk. (Interview, Industry representative).

The funding from the industry enabled fishery scientists at the Marine Institute in Ireland and at the Danish Technical University DTU-Aqua to quickly initiate studies on maturity and age verification of boarfish (Farrell et al., 2012; Hussy et al., 2012). Funding also made it possible to arrange annual acoustic surveys to generate abundance data (O’Donnell et al., 2011) and to investigate boarfish-specific acoustic signals (Fässler et al., 2013). The scientific studies provided opportunities for the fishermen to be directly involved in the research undertaken, not only as financers, but also as suppliers of boarfish samples. These activities created entry points for the fishermen to engage in a boundary space where a shared understanding about scientific components to support management of the new boarfish fishery could evolve. Results that emerged from the scientific studies were regularly communicated back to the fishermen in KFO meetings and newsletters, along with explanations of how scientific knowledge on boarfish life history and abundance fit into the contexts of stock assessment, scientific advice, and management decisions. The scientists also published their findings in scientific journals, and brought their new insights on boarfish to the ICES' Working Group for Widely Distributed Stocks (WGWIDE) where it was used to underpin stock assessments and scientific advice (ICES, 2012b). The scientific studies facilitated knowledge exchange 
between industry actors and scientists around elements that were relevant for decision-making on boarfish quota and management.

\subsubsection{An interim management plan}

In parallel with the science-industry collaborations, a first interim management plan for boarfish was developed in 2010 as an Irish-Danish initiative. The initiative was triggered by a mesh size regulation that temporarily closed the boarfish fishery. At the time, industry representatives, scientists and managers were assembled to discuss other pelagic stocks, and they took the opportunity to engage in informal one-on-one discussions around the urgent boarfish situation. A scientist and a representative for a producer organisation, who could draw on experiences from previous collaborations around management plans, developed an interim boarfish management plan proposal within a time frame of only a few weeks. An interviewee explained the role of the scientists in this kind of setting:

My role was to act as a technical advisor to the industry. That doesn't mean that I, or the institute where I work, endorsed those plans. We provided a technical service. We tried to develop something that represented their value system. It was clear to the industry that if they wanted to get a plan accepted, it had to have my value system in it. But ultimately, it is their plan. ... By the time the boarfish plan came along, we had experiences with other plans that had failed because they weren't precautionary. So that learning curve had already been established and we didn't need to go through that phase again. (Interview, Scientist)

The key actors who were involved in this boundary space had a history of working together. Among previous collaborations was the development of a management plan for horse mackerel (Hegland and Wilson, 2009; Clarke et al., 2007). The boarfish interim plan proposal was a 2-page document which emphasised the need for taking a precautionary approach, given the very limited knowledge about this species. A specific TAC-setting rule was proposed, and this element made the plan directly applicable as a tool for managers. The proposal also included measures to avoid by-catch of unwanted species. The interim plan filled a role as a boundary object by facilitating a transformation of thinking for the industry actors from short-term gains to longer term strategies (Stange, 2016). To the fishermen, the interim plan implied a dramatic reduction of catch opportunities, at least in the short term. However, it also served as a stimulus to collaborate with scientists. Filling scientific knowledge gaps was urgent to avoid closure of the fishery and could possibly lead to better catch opportunities in the longer term. The interim plan also served as a medium through which the Irish and Danish industry actors could signal their commitment to sustainable management of the rapidly expanding boarfish fishery. 


\subsubsection{A long-term management plan proposal}

In 2012, Irish and Danish industry representatives wished to follow up the interim plan initiative with a proper long-term management plan for boarfish that could be endorsed by the PELAC and used as a tool by DG MARE. At this stage, boarfish was not yet among the species formally handled by the PELAC. There was, however, an understanding between the PELAC and the European Commission that boarfish would be added to the PELAC list of species with the 2013 reform of the CFP. With the inclusion of the PELAC as actor, the boundary space widened and the process became more formal and structured. However, the development work was done outside the PELAC by the same key actors who had been involved in the interim plan process. With only a small number of people involved, one-onone communication co-ordinated by the producer organisation representatives was efficient for bringing the process forward. The long-term management plan for boarfish was introduced to the PELAC's WG II in July 2012 in the form of a PowerPoint presentation (Clarke, 2012). The meeting minutes reflect how the design of the plan could be interpreted as linking level of knowledge with more and less restrictive quota-setting mechanisms:

... the more information is available the more generous the TAC can be set whereas the less information is available the higher the uncertainty becomes and therefore the more restricted the TAC would have to be. (PRAC, 2012b, p. 12)

The design of the plan thus created incentives for continued collaboration between the scientists and the industry to further expand the scientific knowledge base for boarfish management. The few members of the PELAC WG II who had high stakes in the boarfish fishery had been involved during the drafting phase of the plan, and were already familiar with its content when it was presented to the PELAC. Other PELAC members had little interest in the boarfish fishery. With a few edits, including a change of ownership in the preamble from KFO and DFFO to the PELAC, the plan was brought forward for endorsement by the PELAC ExCom (PRAC, 2012b).

The PELAC submitted their Draft management plan for Boarfish, Caperos aper as their recommendation to DG MARE in August 2012 (PRAC, 2012a). This recommendation was a 5-page long document designed to meet the managers' needs when making decisions about TAC in a new fishery with a small, but growing, scientific knowledge base. Put forward through the formal channel established for delivering stakeholder advice to the EU fisheries management system, i.e. through an AC, the boarfish plan got a "wrapping" as stakeholder 
produced knowledge. In this boundary space the PELAC ExCom members were the main actors, while the scientists were no longer involved.

\subsubsection{Boarfish case summary}

The analysis highlights that the mixed-actor collaborative process that led towards a longterm management plan proposal for the boarfish fishery in the Northeast Atlantic had two distinct components; one was the production of boarfish-specific scientific knowledge, and another was the making of a long-term management plan that could be proposed through the PELAC as their stakeholder advice to the European Commission. In between, an interim plan helped draw stakeholders', managers' and scientists' attention to the implications of the lack of knowledge on which to build management decisions, and the urgency in building a knowledge base to support this new fishery. Through all stages, representatives for the fishermen co-ordinated initiatives and activities that provided entry points for participation and engagement by various actors. The initial stages were fairly closed and involved only a few, well informed individuals who trusted each other and could work efficiently together. The setting changed from the point when the PELAC took ownership of the long-term management plan. Additional actors then entered the boundary space, and the producer organisation representatives followed up on boarfish matters in roles as PELAC members. The widening of context did not trigger any controversies. This indicates that interests were aligned, or that contested issues had been worked through in the preparation phase, during which activities were co-ordinated by PELAC members in roles as representatives of producer organisations.

\subsection{Conclusions}

This paper has described and analysed how proposals for long-term management plans for the Nephrops fishery in the North Sea and the boarfish fishery in the Northeast Atlantic evolved through collaborations in which fishing industry representatives in the NSAC and PELAC played key roles. The paper contributes to boundary object theory by presenting a theoretical understanding of knowledge exchange in stakeholder-led collaborations. In addition, the findings help fisheries stakeholders, scientist and mangers understand the mechanisms and dynamics of developing long-term management plans in collaborative settings. The Nephrops case involved a large number of actors who needed to understand each other and establish ways of working together. The boarfish case involved only a few actors, and several of them 
had experiences from previous collaborations. The conceptual framework added dimensions to traditional boundary object theory that were helpful for understanding knowledge exchange in both settings. The analysis focused on the interplay between objects and activities at the boundary between actors, and on how this interplay created spaces for knowledge exchange.

In both cases, management plans were boundary objects in a capacity of motivating the collaborations. Additional boundary objects with different capacities emerged during the course of the collaborations. For example; a management plan template provided "scaffolding" to guide the work with the Nephrops plan on from idea to action. In this capacity, the template served as a translational device between actors who needed to develop a common understanding of what a long-term management plan should contain. A more complex boundary process was illustrated in the boarfish case, where an interim management plan was instrumental in transforming boarfish fishermen's priorities from short-term gains to longer-term precautionary harvesting strategies.

The conceptual framework highlighted the importance of activities as entry point for actors' engagement. In the Nephrops case, Nephrops Focus Group meetings were key activities. These meetings provided a forum for knowledge-sharing between stakeholders and scientists as well as between different stakeholder interests. Over time, a common understanding evolved around key issues and challenges. Initiatives to address specific problems triggered new activities, which brought different sets of actors into the collaboration. In the boarfish case, scientific studies created entry points for direct engagement by fishermen in roles as sample providers and financers. These activities created leverage for fruitful knowledge exchange, and a common understanding around the need for management measures for the new boarfish fishery developed.

Analysing the collaborations as a progression of boundary spaces was useful for pinpointing challenges encountered and strategies chosen to address them. For example; when contested issues are encountered, opening up another boundary space with new actors and objects can be a strategy for bringing the process forward. This was illustrated in the Nephrops case when diverging views triggered the need for another boundary space where a tailored functional unit management solution could be elaborated. In the boarfish case, the creation of a small boundary space with only a few well informed individuals was an efficient way of getting an interim plan produced quickly. These examples demonstrate that multiple boundary spaces evolve during a collaborative knowledge production process, and that inclusion of new actors and exclusion of others are elements in such processes. 
The stakeholder-led collaborations analysed were characterised by ad hoc ways of working. Individuals with a strong interest in the issues took initiatives to get collaborative processes started. They used their networks to get others involved, and took on roles as facilitators. These individuals also acted in roles as representatives of fishermen, and were thus not without stakes themselves. In the boarfish case, the absence of formalities seemed to make the collaborations efficient. As long as there was agreement within and between the producer organisations where the interests of a majority of the boarfish fishermen were represented, decisions could be made quickly and new activities were initiated on short notice. The Nephrops process encountered a number of more complex problems which required significant time and efforts to identify ways forward. The approach to problem-solving practiced by the Nephrops Focus Group made the development of a long-term management plan for Nephrops an inclusive "bottom-up" process, in line with the NSAC's original intensions.

The Nephrops and boarfish long-term management plan proposals were submitted as Advisory Council recommendations to the European Commission. This route represents a formally established channel for stakeholder input, and the tangible outcome from the mixedactor collaborations in the form of management plan proposals could thus be recognised as stakeholder knowledge contributions to the EU fishery management knowledge base. The boarfish case illustrated that a dual strategy was used by the pelagic industry actors. Their engagement as funders of scientific studies on boarfish resulted in knowledge contributions through the scientific route as well, e.g. in the form of scientific publications and data to underpin ICES stock assessments.

The management plan proposals illustrate Advisory Councils' ability and willingness to take on pro-active roles as producers of knowledge for EU fishery management. The plans produced were different in terms of their form and content. The Nephrops plan was long and descriptive, while the boarfish plan was short with focus on harvest control strategies. It is beyond the scope of this study to evaluate the utility of the two proposals for EU fishery management. It is notable, however, that managers were literally absent from the boundary spaces during the production of the plans. Including managers in the knowledge exchange process would increase possibilities for producing plans that take managers' current priorities and needs into account. This could, however, make the process more complex and timeconsuming. 


\section{Chapter 6: What hat are you wearing? On the multiple roles of fishery scientists in the ICES community ${ }^{30}$}

\section{Paper IV}

${ }^{30}$ This paper has been published as: Dankel, D. J., Stange, K., and Nielsen, K. N. 2016. What hat are you wearing? On the multiple roles of fishery scientists in the ICES community. ICES Journal of Marine Science, 73 : 209-216. Numbering of sections has been edited to integrate this text as a thesis chapter. 


\begin{abstract}
Trends towards a more participatory agenda in policy-relevant science imply that the roles and work tasks of scientists become more multifaceted. In Europe, the increased use of multiannual plans creates a need for fishery scientists to contribute with their expertise in a wide variety of situations. We identify and characterize four roles for scientists as developers, reviewers, judges, and messengers in arenas where management plans are produced and evaluated. Using examples of producing and evaluating management plans for pelagic fish stocks in Europe, we present different scientific roles and how they may intertwine. The examples illustrate that fishery scientists increasingly interact with advisory councils and industry stakeholders when performing roles as developers and messengers. The roles as reviewers and judges are typically affiliated with evaluation processes carried out under the auspices of the marine science and advisory organization International Council for the Exploration of the Sea (ICES). While it may be difficult to separate the roles in practice, we argue that it must be emphasized to be aware of their different requirements to ensure that scientific credibility is not compromised. By asking the question "What hat are you wearing?", we encourage individual fishery scientists, their employers, and ICES as a network organization of expertise to reflect on roles, affiliations, mandates, and possible consequences of wearing different "hats".
\end{abstract}

Keywords: common fisheries policy, credibility, fishery management, fishery science, institutions, legitimacy, science-policy interface, stakeholder participation, transparency 


\subsection{Introduction}

The role of science in society is changing and, therefore, so is the role of scientific institutions (Gibbons et al., 1994; Latour, 1998; Latour, 1999; Nowotny et al., 2001; Van der Sluijs et al., 2008; Gluckman, 2014). Individual scientists are affected by this change. Formal and informal conventions have developed through a history to shape expectations about how a scientist should act. According to Robert Merton's classical "ethos of science” (Merton, 1996), good science is guided by the principles of universalism, communism, disinterestedness, and organized scepticism. These norms correspond to a view that science is at its best when it is not disturbed - or "corrupted" - by external influences, and reflects the ideal of science as an "independent republic" (Polanyi, 1962). If it ever was, however, science is no longer pursued in isolated academic "ivory towers". More open and diverse forms of knowledge production have emerged, captured by the concepts "mandated science" (Jasanoff, 1990), "Mode 2 science" (Gibbons et al., 1994; Gibbons, 2000), and "Post-Normal Science" (Funtowicz and Ravetz, 1993). In contrast to viewing science as a value-free, curiosity-driven, and an independent pursuit of knowledge, these concepts refer to types of scientific knowledge production that result from a closer interaction with public and private interests in society. Such interests have an increasingly important role in defining what is to be researched and how research is carried out. The development can be noted through, for example, the consolidated role of research funding agencies (Rip, 1994), privately funded and prioritized research (Rabeharisoa and Callon, 2002), and the active merging of different types of knowledge from a wider pool of experts, including citizens and stakeholders, as denoted by the term "participatory research" (Cornwall and Jewkes, 1995). These trends lead to the formation of new operational spaces where societal and scientific problems are framed and defined, and solutions negotiated (Metze, 2010).

In this Food for Thought article, we draw attention to implications of these societal trends towards more diverse forms of knowledge production in the context of fishery scientists and the International Council for the Exploration of the Sea (ICES). ICES is an international organization that develops science and advice to support the sustainable use of the oceans (www.ices.dk). ICES provides scientific advice to its 20 member countries and to client commissions and plays a key role in the science-policy landscape in Europe [see Stange et al. (2012) for a description of the ICES organizational structure and function]. 


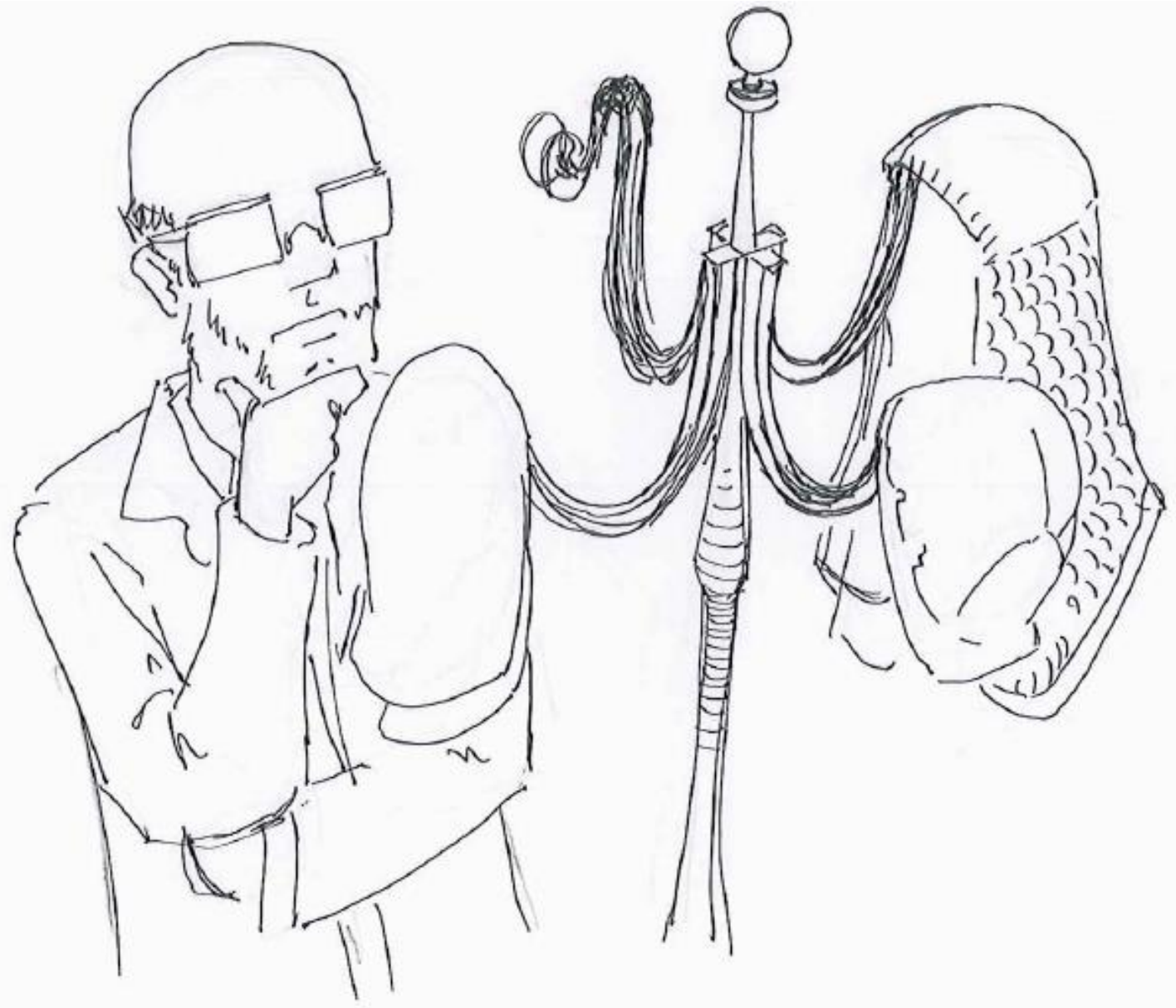

Figure 6.1 The individual on the left is pondering the plurality of roles that can confront scientists who are working on policy-relevant science. On the right is a hat stand. Each hat represents a metaphor for the roles themselves. In our definition, roles are dictated by the combination of mandates, affiliations, and work tasks that come together to create different hats. In this illustration, we see depictions of a developer's construction hat, a judge's wig, and a messenger's cap as representations of three of the roles we describe in this article. Illustration by J. Mariano Collantes Alegre.

We use the development of management plans for pelagic fish stocks in Europe to illustrate how individual scientists and ICES get involved in various roles as such plans proceed from idea towards implementation. We identify and describe four roles: the developer, the reviewer, the judge, and the messenger. Our interest in this topic emerged within the ICES Working Group on Marine Systems (WGMARS) when this group was tasked with analysing management strategy evaluations and management procedures. WGMARS' investigations shed light on the diversity of practices in such contexts regarding stakeholder participation, quality assurance, and documentation of procedures. In this article, we focus on the multiple roles taken on by individual scientists in work related to developing and evaluating management plans and draw attention to possible tensions and conflict of interest that might 
occur. The word "hat" is used here as a metaphor for many different possible combinations of roles, tasks, affiliations, and mandates a scientist might have (Figure 6.1). The hat metaphor is commonly heard when fishery scientists in Europe request, state, or communicate a clarification of the role an individual takes on when engaging in a debate or a collaboration, raising the question "What hat are you wearing?" or making statements such as "I am wearing the hat of ...", followed by the scientist's institutional affiliation, sometimes combined with further specification of a mandate or a task.

Our aim with this article is twofold. First, we argue that it must be emphasized that institutions, such as ICES, which deliver scientific advice for policy, are aware of, and reflect on, how their operations are affected by societal changes that influence how science is produced and used in support of planning or policy-making. It must be emphasized that it is not the trend towards more participatory knowledge production per se that causes potential tensions or conflict of interest for scientists in various roles. It is, for example, always good practice for scientists to be transparent about their funding sources and never good practice to ask scientists to review their own work. These issues need to be addressed in all scientific processes and are not unique to participatory research efforts or to the making of management plans. Our second aim is to highlight and acknowledge the efforts of fishery scientists in the ICES community who have explored new territory by responding to calls for participatory knowledge production. Their experiences are valuable and can inspire others who are challenged to take on similar tasks.

Data to inform this Food for Thought article were obtained through interviews, document review, and observations in Pelagic Advisory Council meetings during 2014. Interviews ( $\mathrm{n}=$ 10) were conducted between November 2013 and December 2014 with scientists who had hands-on experience with the production of fishery management plans for pelagic stocks in European waters. Interviewees were asked to tell their story how the plans evolved and to reflect on their own roles. ICES expert group reports [ICES Expert Group reports are available at http://www.ices.dk (accessed 6 October 2015).] and minutes from meetings of the Pelagic Advisory Council [minutes from meetings of the Pelagic Advisory Council are available at http://www.pelagicac.org/ (accessed 6 October 2015).] provided further information on timelines and key issues.

We proceed as follows. In the section on "Roles in making management plans", roles of scientists within the context of developing and evaluating fishery management plans in Europe are described. The section on "Case descriptions" introduces two case studies of scientists involved in the development of such plans and highlights dilemmas and tensions 
that might occur. In the "Discussion" section, we discuss how roles develop and implications of the multiple and shifting roles for scientific knowledge production. We conclude in the "Food for further thought" section with some questions and recommendations to stimulate further reflection and discussion within the ICES community.

\subsection{Roles in making management plans}

Multiannual plans were introduced in the 2002 reform of the European Common Fisheries Policy (CFP) to move towards longer time perspectives on management. The desired characteristics of such plans were outlined:

... multi-annual plans should establish targets for sustainable exploitation of the stocks concerned, contain harvesting rules laying down the manner in which annual catch and/or fishing effort limits are to be calculated and provide for other specific management measures, taking account also of the effect on other species. (Council, 2002, p. L358/59)

Overviews compiled by the ICES Workshop on Guidelines for Management Strategy Evaluations (ICES, 2013d) highlight that a diversity of actors and practices are involved in the production and evaluation of elements that form parts of such plans. Developing quotasetting mechanisms - specifically; harvest control rules - became the key component of the plans developed to the extent that harvest control rules and management plans are sometimes used as synonyms. In its 2013 reformed version (EU, 2013), the CFP again promotes the use of multiannual plans as a management tool to meet overall policy objectives:

Multiannual plans shall be adopted as a priority, based on scientific, technical and economic advice, and shall contain conservation measures to restore and maintain fish stocks above levels capable of producing maximum sustainable yield. (Article 9-1)

Furthermore, regarding the content of such plans,

A multiannual plan shall include: a) the scope, in terms of stocks, fishery and the area to which the multiannual plan shall be applied; b) objectives ... c) quantifiable targets ... d) clear time-frames to reach the quantifiable targets; e) conservation reference points ... f) objectives for conservation and technical measures; g) safeguards to ensure that quantifiable targets are met, as well as remedial action, where needed .... (Article 10-1)

These developments will have implications on how future requests for science and advice related to management plans are formulated as well as on the associated work tasks to be carried out by scientists. Based on scientists' experiences with plans produced before the 
reform, we here identify and describe four roles that they take on when producing and evaluating management plans: the developer, the reviewer, the judge, and the messenger.

The principal task for the developer is to make a plan that meets the client's needs and that also adheres to the general objectives of fishery management (e.g. the CFP). The role of the developer is thus akin to that of an engineer who provides technology development services to clients while ensuring that legal requirements or product standards are met. The call to engage in development work can reach the scientist via ICES, triggered by a client request to ICES from, for example, the European Commission or an ICES member country. The request can also come to the scientist directly from stakeholder groups such as the Advisory Councils or individual fishing industry organizations. An interviewee who assisted the Pelagic Advisory Council with developing a management plan for Western horse mackerel (Trachurus trachurus) in 2007 (Clarke et al., 2007; Hegland and Wilson, 2009) explained his role in this context:

They (the industry) said: 'This is what we want. Would you help us write it?' So, what they asked us to do was to provide some translation of their needs into the normal language of fisheries science. .... While we (the scientists) didn't have any specific objectives with regards to the yield of the (western horse mackerel) plan, we would have represented the minimum criteria that needed to be adhered to with regards to the sustainability of any fishery which would be prosecuted on the stock. So, we had a kind of an ancillary role in setting the objectives. (Interview, Scientist A)

Scientists' reflections illustrate that the work tasks associated with the developer's role are not limited to developing a quota-setting mechanism. In this case, multiple iterations between scientists and stakeholders were needed to formulate objectives that guided the more technical aspects of the development work.

The second role is the reviewer. As a reviewer, the scientist is asked to critically examine and comment on work done by others. The well-known procedure for quality assurance within science, that is peer review, can be seen as a general model for this role (Bornmann, 2011). Various peer-review practices apply within the ICES advisory system, depending on whether the request concerns recurring or non-recurring advice. ICES also provides review services for research conducted outside ICES. This involves selecting qualified experts without a vested interest to provide reviews (ICES, 2015, p. 3). Given that management plans are developed in a variety of ways, there is not one standardized review procedure that applies to such plans within the ICES system.

The third role is the judge. The judge is typically called upon in response to a specific request from a client (i.e. a fishery management authority such as the European Commission). 
The judge is asked - in our examples under the institutional capacity of ICES - to assess whether a management plan is consistent with the management objectives defined by the client. The outcome is exemplified in this generic formulation of ICES advice as a response to such a request: "ICES has evaluated the plan and concludes that it is in accordance with the precautionary approach and the ICES maximum sustainable yield (MSY) framework". [See Lassen et al. (2014) for a historical overview of how the precautionary approach and the MSY framework have been integrated into the ICES advisory context.]

The fourth role is the messenger. As a messenger, the scientist needs to disseminate, clarify, or give a detailed account of scientific advice. For example, the scientist can be tasked with explaining to the European Commission or to an Advisory Council why a management plan is deemed precautionary or not by ICES. An interviewee reflected on how the work task of the messenger in interaction with stakeholders has evolved favourably over the last 15 years:

Presenting fisheries advice in the late 1990s to the fishing industry was not a pleasant experience. It is completely different today. [You do not dread it. ...]. We have come a long ways. (Interview, Scientist B)

A Memorandum of Understanding (MoU) between ICES and the European Commission specifies that recurrent advice from ICES will be presented to the Advisory Councils by ICES staff or scientists. [AGREEMENT In the form of a MoU between the European Union and the International Council for the Exploration of the Sea (p. 11). http://www.ices.dk/exploreus/Documents/Cooperation\%20agreements/EU/2015_EU_ICES_ MOU_web.pdf (accessed 6 October 2015).] In this context, the idealized role for the messenger is similar to that of diplomat who is instructed to deliver an official message to representatives of a foreign government. It is neither up to the messenger to change details of the decision nor to communicate agreement or disagreement with it. The role of the messenger is simply to communicate decisions made elsewhere, to explain underlying reasons, and to respond to questions (in so far this does not undermine the intent of the message being communicated). In reality, however, the messenger sometimes gets entangled in political processes that override the simple mandate of disseminating the outcome of scientific work. An interviewee recalled how an invitation to present a management plan proposal developed by an ICES Working Group to an international meeting ended up not going through:

The [non-EU country] chairman refused to accept the presentation on the management plan, because [the Chair] wanted to make a public statement that they were not having 
the (European) Commission telling them what to do. This was the first time I had actually hit such a public political problem. It was a bit of a shock. (Interview, Scientist B)

This scientist's experience may serve as a reminder that production and dissemination of science for advice at the science-policy interface may become entangled in political agendas.

\subsection{Case descriptions}

In this section, two case studies are presented to highlight the diversity of roles of fishery scientists at work producing and evaluating management plans and to illustrate roles taken on by ICES. The Northeast Atlantic (NEA) mackerel (Scomber scombrus) case exemplifies a situation where ICES receives a request from a client to provide advice on long-term management strategies for a stock that is shared between the EU and coastal states. The North Sea horse mackerel case illustrates the involvement of fishery scientists and ICES in a setting where industry stakeholders take an initiative to make fishery management plans.

\subsubsection{NEA mackerel}

The fishery for mackerel in the NEA is a highly valuable for a number of European countries. It is a shared stock between EU and non-EU coastal states, and management decisions about the size and distribution of quotas need to be negotiated between the competent authorities. The sharing arrangement is disputed and has triggered long-lasting conflicts. A request from the European Commission to ICES in 2007 regarding this stock illustrates a situation where several roles were called for:

ICES is requested to identify multi-annual plans of the following form, and assuming that egg surveys of mackerel continue on a tri-annual basis: [detailed description of the criteria]. ICES is asked to identify combinations of values for [parameters] that would assure management of the mackerel stock that would conform to the precautionary approach i.e. a low risk of stock depletion, stable catches and sustained high yield. [...]. ICES are also invited to suggest other approaches to the multi-annual management of mackerel on its own initiative. (ICES, 2008a, p.1)

An ICES ad hoc expert group was established to deal with this request (ICES, 2008b). Several of the scientists engaged to carry out the work had recently been involved in the ICES Study Group on Management Strategies (SGMAS) 2006-2008, and were eager to put the outcomes to use. The SGMAS had highlighted the importance of interaction between scientists, stakeholders, and managers at an early stage in a development process "to get some understanding of needs and preferences, and communicate possibilities, limitations and 
tradeoffs" (ICES, 2007, p. 31). However, there were no established routines within ICES on how to organize a participatory process in such a setting, and this added another learning-bydoing aspect to the challenge at hand. At the outset of the NEA mackerel plan development work, stakeholders and managers were invited to discuss priorities and options with the scientists. The developers then proceeded to explore a number of strategies, using simulations. They acknowledged the need to keep the roles of developing and evaluating management strategies separate and emphasized in their report how far they as developers had been able to take the process:

This document describes the technical basis and the results from the simulations in order that they may be evaluated by ACOM (the ICES Advisory Committee), and provide an answer to the EU request. (ICES, 2008a, p. 2)

They also highlighted that development work needs to be guided by objectives:

It should be recognized that these simulations, while they may form the basis for a putative management plan, do not in themselves constitute such plan. If a management plan is to be developed, it will require a clarification of objectives, and a full consideration of review period, performance monitoring, and actions to be taken in exceptional circumstances. This will require further interaction with stakeholders. (ICES, 2008a, p. 2)

In reply to the request, ACOM acted as a judge and informed the European Commission that "any of the types of harvest control rules (developed) would be consistent with the precautionary approach if the appropriate parameters were incorporated within the harvest control rule" (ICES, 2008a, p.1). Following the 2008 development work, a management plan was negotiated and agreed between the EU, Norway, and the Faroe Islands. However, this plan was never formally applied because of disputes between the three coastal states and Iceland and Greenland around access to the NEA mackerel stock. In 2014, the three coastal states issued another request to ICES to evaluate potential elements of a new management plan for this stock. A workshop was organized by the ICES Secretariat to deal with this request (ICES, 2014b). Scientists assigned roles as co-chairs used their network to identify potential participants who could provide relevant information. An interviewee commented:

We deliberatively chose also people who had been involved with the evaluation of the current management plan to be in the group. We don't need to reinvent the wheel, because they did a lot of work on this already. (There were) really good people doing it the last time. (Interview, Scientist C)

This pragmatic approach to getting people with the desired competence to contribute to the workshop is not sensitive to any possible vested interests among the participants. Two scientists attended the workshop with explicit roles as reviewers. Their mandate is spelled out 
in the annex to the report produced: "The process of the review of this type in ICES, is that: i) the reviewers attend the workshop, ii) reviewers comments are taken on board during the process; and iii) the report reflects the work of the experts and the implementation of the reviewers' recommendations" (ICES, 2014b, p. 118). This review procedure makes the roles of developers and reviewers somewhat blurred as the contributions made by the reviewers are not known to anyone who was not present. Stakeholders with industry affiliations from EU countries also attended the workshop. Some of them had attended previous meetings with similar agenda items as scientists with ICES or national research institute affiliations, exemplifying the need for all participants to clarify their "hats" and to declare any possible conflict of interest.

\subsubsection{North Sea horse mackerel}

In 2013, an industry stakeholder organization in the fishery for horse mackerel in the North Sea asked a national research institute to develop a multiannual management plan to ensure sustainable exploitation of this stock. The industry's interest in a management plan was triggered by the fact that ICES was implementing a new approach to advice for "data limited" stocks (ICES, 2012a). With only landings data available to inform advice, ICES considered North Sea horse mackerel a Category 5 (data limited) stock, a status which would imply a $20 \%$ reduction in advice on total allowable catch as part of the ICES Data Limited Stock approach. In addition to having a management plan developed, the industry organization was, therefore, also eager to enhance availability of data and fill knowledge gaps in ways that would allow the stock to move up the ICES stock category "ladder" (Coers and Miller, 2014).

The industry-science collaboration acquired funding, and a small project group was assembled. The group was chaired by a representative of the fishery industry organization acting as the client, while two national scientists led the scientific work as developers. One of them was, at the time, chair of the ICES Working Group on Widely Distributed Stocks (WGWIDE), a role which had made this scientist familiar with the history and intricacies of the stock in the context of ICES science and advice. The other scientist had an extensive network among the industry stakeholders. During the development stage, both scientists described in our interviews that they felt they had "national scientist hats" on. However, the engagement with WGWIDE gave one of them a sense of having dual affiliations, representing both their national institute and ICES.

In April 2013, a kick-off meeting was arranged to discuss availability and interpretation of data. Industry stakeholders, including skippers and fleet managers, were invited, as were 
scientific experts from other European countries. The national institute scientists then proceeded with exploratory development work. Progress reports were presented to the Pelagic Advisory Council in October 2013 and again in February 2014 with the scientists as developers with national institute affiliations. The exploratory work had been challenging and many question marks remained. The industry was eager to make progress towards a finished plan, and the idea was put forward to have ICES evaluate the proposal produced by the industry-science collaboration. The owner of the initiative was the industry organization.

However, neither the industry organization nor the Pelagic Advisory Council is entitled to send requests to ICES directly; all requests must go via the European Commission or via an ICES member country. Therefore, the request to evaluate the proposed plan for North Sea horse mackerel was submitted to ICES by the member country's ministry. In response to the evaluation request, the ICES Secretariat organized a workshop to review and evaluate the proposed plan (ICES, 2014c). Two independent reviewers were recruited, and the two developers were assigned roles as co-chairs. The workshop was held at the developers' home institute. Issues regarding broader participation in the ad hoc workshop had not been discussed between the ICES Secretariat and the chairs before the meeting. One of the developers reflected on roles and work tasks for ICES and for the assigned chairs in this context:

I did not feel responsible for organizing the participatory process. I assumed throughout the preparations of this meeting that they (the ICES Secretariat) had extended the invitations to the stakeholders. [...]. Then I found out maybe four or five days before the meeting that this hadn't happened. So I basically stepped out of my role as an invited expert to ICES, or as invited Chair, by inviting the industry organization, saying: 'Hey, this meeting is going on. I'm sure that it is intended to be an open meeting. You can participate! Are you coming?'. (Interview, Scientist, D)

In the workshop, the two invited scientists served as both reviewers and judges. However, because the results from the exploratory analyses showed that the proposed management plan would not meet precautionary criteria, the meeting turned into a discussion among peers on alternative, more appropriate management approaches, using the technical background document as a basis. Based on the reviewers' feedback, the developers completed the technical document, including a number of recommendations for management of the stock in the short term. The outcome of the workshop was then discussed in an ICES Advice Drafting Group meeting in which the task was to formulate a reply to the request from the ICES member country. One of the developers was called in as an expert in this group of judges. Asked to reflect on the multiple roles and work tasks, the scientist commented: 
I don't think we wanted to be the people doing the work and the people reviewing it, but we did in a way end up being that. I was a participant in the Advice Drafting Group. I didn't actively push particular perspectives, because the data was speaking for itself and I was obviously in agreement with (the Advice Drafting Group Chair) and other people about what we should be saying. (Interview, Scientist E)

An update with focus on the industry-science project work was presented to the Pelagic Advisory Council in July 2014, again with the scientist as a developer wearing a "national institute hat". The review and evaluation process going on within ICES was not mentioned during the presentation. Instead, the focus of the message was on the bad news: no precautionary harvest control rule could be suggested. An interviewee commented on being a developer in this situation:

You can change how you look at a management plan or a rule, but you are still maintaining the same scientific guideline of what is precautionary. You are just trying to find - within that precautionary space - what is the most acceptable thing for the stakeholders and play around with that. Unfortunately, that precautionary space was very small. I really would have been a lot happier if the stock had been doing well. I think it would have been a really nice exercise, but it didn't quite work out that way. (Interview, Scientist, E)

The scientist's reflection highlights that there is not always an acceptable science-based solution to be found to the problem at hand; the exploratory modelling work could not produce any precautionary harvest control rules that were acceptable to the reviewers and judges. The developer could thus not deliver the outcome that the industry had hoped for when they initiated the industry-science collaboration. At this point, the industry-science project had come to an end; however, the process of assessing the status of the North Sea horse mackerel stock and advising on catches continued within the ICES advisory system. When ICES (2015) catch advice for this stock was to be presented to the Pelagic Advisory Council in October 2014, one of the developers was offered to take on yet another role - that of the messenger. The scientist declined:

I didn't want to! (laughter) It seemed like I was just wearing too many hats there. I had already presented to them a couple of times - told them what we were doing and what we had looked at. And then I didn't want to come back and say: 'This is the advice'. I felt it would have more gravitas with the group if somebody from ICES was there - an official ICES person - to present the results. (Interview, Scientist, E)

The scientist had already worked on the North Sea horse mackerel issue as a developer. The scientist engaged in the issue again together with the reviewers in the review workshop, and together with the judges in the Advice Drafting Group. When offered the role of the messenger, this scientist encountered all four roles we have previously described. ICES 
advice on catches for North Sea horse mackerel for 2015 ended up being presented to the Pelagic Advisory Council by one of the ICES ACOM vice chairs, who in this situation was a messenger with an ICES affiliation.

\subsection{Discussion}

The two cases presented in the section on "Case descriptions" give glimpses into how the work of scientists is influenced as fishing industry stakeholders and the Advisory Councils increasingly engage in knowledge production processes aimed at underpinning fisheries management decisions in Europe. The cases also show how management plan evaluation requests to ICES trigger a need for clear procedures and clarification of mandates associated with various roles.

When acting in roles as developers in the cases described here, scientists encountered settings where they needed to communicate efficiently with non-scientific audiences when discussing objectives, priorities, and trade-offs. When development work is financed by the fishing industry, the industry's stakes increase, and it is understandable if they express disappointment if their goals cannot be met. One can speculate that it is more personally satisfying for a scientist to deliver outputs that meet the goals set and that can be put to use in the process towards implementation of sustainable management measures. Scientists, however, are expected to be "disinterested" from a Mertonian view of the role of science and not let their work be influenced by any pressure to arrive at a particular conclusion. In the interest of scientific credibility, it thus becomes crucial that the process is transparent and allows review of the steps that achieved the results.

The role of the reviewer is also present in the cases described in this article, although somewhat blurred. When the role of ICES is to evaluate a management plan, the evaluation processes sometimes involve development, review, and judging elements. ICES review procedures have evolved during the period studied here, and some different practices are being explored. The fact that the developers in the North Sea horse mackerel case were assigned roles as chairs of the workshop where the development work was evaluated raises questions as to the extent this review process can be considered "independent", and whether the review is "internal" or "external". A review group may at times find itself in a situation where different interpretations are asserted and contested by different individuals. The maintenance of external credibility of the scientific work thus warrants a more formalized procedure set-up to establish the independence of the review process. In Europe, a practical 
limitation to establishing an independent review process relates to the fact that the pool of fishery scientists with competence to carry out the work task called for in the settings described above is small. Only a limited number of scientists have in-depth knowledge of particular biological operating models, data sources, methods, and stocks. The interconnectedness of fishery scientists contributes to a lack of competent "independent" alternatives (Finlayson, 1994). This dilemma highlights the need for strategic planning in ICES Member Countries. It also highlights the need for scientists to reflect on their role, interests, and stakes when participating in settings where their own work is up for evaluation, and when acting as a reviewer in a group of peers.

The work task for the judge in the context of evaluating management plans depends on the evaluation criteria. In the examples described above, the focus was on judging whether a management plan - or more specifically, a harvest control rule - could be considered precautionary or not. The process of producing management plans for stocks and fisheries in Europe is not standardized. To date, plans have focused on single stocks, and harvest control rules have been central components. Future management plans in Europe are likely to have other key components, reflecting the objectives of the recently reformed CFP, the legal requirements of co-decision procedures, and the resulting priorities of managers in the European Commission (EC, 2014b). With changing management priories, operationalization by ICES of the criteria to be evaluated scientifically will need to adapt as well. The role of the judge will still be needed, but the work to be carried out is likely to become more diverse.

The role of the messenger has evolved in terms of the work task involved. There are probably several factors that contribute to the positive development regarding interactions between scientists and stakeholders. ICES has attempted to become a more open organization. For example, observers are now welcome to workshops within the ICES advisory process. [How to join the advisory process as stakeholder observer: http://www.ices.dk/community/advisory-process/Pages/How-to-join-the-advisoryprocess.aspx (accessed 6 October 2015).] "Opening the box" training courses organized by ICES have made stock assessment and fisheries advice more accessible for non-scientific audiences, including fishing industry stakeholders, NGOs, managers, and policy-makers. Meetings between ICES and the Advisory Councils [so-called MIRAC (before RAC's name change) and MIACO meetings] have been arranged annually since 2006 as a high-level forum for interaction and exchange. Several of the industry representatives who hold seats on the Advisory Councils have been involved in projects and collaborations with fishery scientists and have become familiar with the intricacies of the science that underpins ICES advice. As a 
result of increased interactions between industry representatives, fishery scientists, and the ICES advisory process, the presentation of official ICES advice no longer comes out of a "black box". The reasons why the advice looks like it does are often already known to the stakeholder representatives whose constituencies will be most affected by the advice in question. Discussions in settings where the scientist is in a messenger role can, therefore, focus on clarifications, as well as be opportunities for expressing frustrations, or sometimes agreement, with the advice provided.

\subsection{Food for further thought}

The trend towards a more participatory agenda in European fisheries management and towards a more prevalent use of multiannual plans implies that the roles and work tasks of fishery scientists in Europe will become more multifaceted. Our examples from the production of management plans for pelagic fish stocks illustrate that the various roles intertwine at several points. To stimulate further reflection, we ask what is the role of scientists in arenas where the general objectives outlined in the CFP need to be translated into specific, operational management tools? In what ways does the setting change if the development work is financed by the industry? Whose responsibility is it to organize and facilitate a participatory process when ICES receives a request to develop or evaluate a management plan? How can transparency and scientific credibility be ensured when scientists get involved in processes where their own work is evaluated? The scientists who contributed with their experiences in this study have been actively involved in participatory processes with industry stakeholders, some on multiple occasions. These engagements had led them to reflect on their own various roles and affiliations. They expressed sensitivity to the presence of different mandates as well as to the requirements and expectations associated with them.

The responsibility to ensure that different scientific roles are acted out in an adequate and transparent manner resides at a top level as well as at an individual level. While institutions frame, guide and supervise individual actions, individuals are responsible for that their own actions are in accordance with established norms. Accordingly, we suggest two main types of approaches to address the issue of tensions and overlaps between different roles: (i) increased formalization of procedures of roles and mandates and (ii) enhanced reflective capacity and role communication. The following approaches are generic in their applicability outside the scientific advisory institution of ICES and even outside the field of fisheries science. 


\subsubsection{Increased formalization}

With a basis in Mertonian norms of science, this approach seeks to organize for an independent and credible scientific process, sheltered from vested interests and political bias. Concretely, the approach sets out to eliminate the potential for role overlaps and conflicts of interest through institutional and organizational change. For example, this could imply that a scientist who has acted as a developer in relation to a management plan cannot be accepted as a reviewer or a judge in relation to the same plan. Pushed to its limits, this approach might imply that a researcher can only hold one role relative to a given development or advisory process. Furthermore, the possibility for the industry, or other non-governmental parties, to fund research in support of a management plan should be welcomed as an element in a participatory agenda, but must be associated with a transparent and independent review process. As we indicated previously, however, there are practical concerns that constrain the extent to which the strategy of formalization can be pursued as a means to maintain transparency in the advisory process. Importantly, there are resource constraints as the pool of fishery scientists with the required skills in a given area is limited, which creates pressure for individuals to take on multiple roles. This fact underscores the necessity of the transparent dialogue with clients of science and advice and the adoption of methods of responsible research and innovation in the following point.

\subsubsection{Enhanced reflective capacity and role communication}

This approach has a different normative basis which recognizes that advisory science, in the context of post-normal science in particular (Dankel et al., 2012), is embedded in value judgments. Strictly speaking, this implies that science cannot be fully "disinterested" and "independent". This perspective implies that transparency and scientific legitimacy in the context of policy-relevant science cannot alone be met through formalization, as described above. In Europe and elsewhere, a shift from centralized fisheries management to more inclusive forms of governance has led to new types of engagement with science. [Participatory research, fishery-dependent research, and industry-contracted research (The cross-cutting Responsible Research and Innovation (RRI) platform of the EU Framework Program for Research and Innovation "Horizon 2020"; Owen et al., 2012; Von Schomberg, 2013) are part and parcel of the effort to align science and society to help earn trust and aid the utmost credibility, legitimacy, and transparency of science and advice.] Taken together, there are many roles to be filled by a limited number of qualified experts. Maintaining the legitimacy and credibility of fisheries science in the context of a multiplicity of roles will 
benefit from continued and perhaps even enhanced awareness and communication about roles. We, therefore, suggest a reflexive review of ICES procedures in all areas of working group and committee membership. Concrete codes of conduct that guide individual scientists to identify situations when their credibility is compromised are also recommended.

ICES is a unique institution of continued high relevance for marine science and centralized advice across European countries. Our involvement within ICES in the Working Group on Marine Systems (WGMARS) has helped us identify the institutional and individual tensions of dynamic and overlapping roles, and we fulfil our mandate to explore these themes with the food for thought we provide here. It is our hope that the ICES community will engage in further discussions on how institutional practices can provide the optimal field for its network of scientists. By continuing to ask the question "What hat are you wearing?", we also encourage others outside of ICES to reflect on their roles, affiliations, mandates, and associated consequences of wearing different "hats" when participating at the science-policy interface. 
Chapter 7: Conclusions 


\subsection{Introduction}

In this final chapter, I summarize and synthesize the findings from the research presented in Chapters 3-6 and discuss their implications. The main topic addressed in this thesis is how knowledge is produced and used in collaborations where stakeholders take the lead and engage others in developing EU fishery-management plans. This issue is important for several reasons. Knowledge systems must be "opened up," so that sustainable fisheries can be achieved with support from a broad knowledge base. Scientists routinely contribute to the EU fishery-management knowledge base, e.g. via ICES and STECF; however, it is not clear how knowledge contributions from stakeholders can be integrated. Advisory Councils and multiannual plans were two elements introduced with the 2002 CFP reform. One aspect of this research, therefore, has been to study Advisory Councils as knowledge producers in the context of management-plan development and to shed light on how these new elements affect EU fishery management in practice. We also need to improve our understanding of how actors, who join collaborations with different knowledge and interests, can develop a common understanding of complex fishery-management issues. A second aspect of this research, therefore, has been to apply and develop boundary-object theory to explain the dynamic interaction between actors and how they collaborate to produce new knowledge.

Two stakeholder-led initiatives that resulted in the presentation of long-term, managementplan proposals to DG MARE via Advisory Councils were investigated in depth: the NSAC development of a long-term management plan for the North Sea Nephrops fishery (Chapters 3 and 5, here referred to as the Nephrops case); and the PELAC development of a long-term management plan for boarfish in the Northeast Atlantic (Chapters 4 and 5, here referred to as the boarfish case). Two additional management-plan processes were described in Chapter 6: an initiative taken by pelagic-industry actors to explore the possibilities of developing a management plan for North Sea horse mackerel; and deliberations of a plan for Northeast Atlantic mackerel. Chapter 6 examined the multiple roles played by fishery scientists and the diversity of settings within which management plans are produced and evaluated.

The research question posed was: How is knowledge used and produced in stakeholder-led collaborations to make management plans for EU fishery management?

Three subquestions guided the research:

- How do boundary processes and boundary objects explain knowledge-production processes in stakeholder-led collaborations to make management plans for EU fishery management? 
- How does stakeholder-led development of management plans provide arenas for bringing the knowledge and interests of different actors together?

- How are stakeholders, scientists, and managers involved in stakeholder-led collaborations to make management plans for EU fishery management, and what roles do they play in these knowledge-production processes?

In Section 7.2, I synthesize and discuss findings from the empirical studies to provide answers to these questions. In Section 7.3, I reflect on the contributions of this thesis to research on EU fishery management and on knowledge exchange. In Section 7.4, I reflect on the research approach. Finally, in Section 7.5, I present ideas for further research.

\subsection{Synthesis of results}

\subsubsection{Conceptual frameworks for understanding mixed-actor knowledge production}

One aim of this research was to contribute to our understanding of knowledge production in settings where actors with different knowledge and interests collaborate. Traditional boundary-object theory introduced by Star and Griesemer (1989) served as a starting point for approaching collaborative knowledge production analytically. In the research presented in this thesis, attention was given to the knowledge-production aspects of mixed-actor collaborations, using management-plan development as the setting of interest. Although boundary-object theory can be useful for understanding collaborations, additional tools were needed to analyse the knowledge-production process. A framework introduced by Carlile (2004) was therefore useful to this study. In Carlile's framework, boundary objects are seen as one of several potential resources in interactions between actors who are engaged in collaborative knowledge production. Chapter 3 introduced this framework and explored how it could be used to understand knowledge production in a stakeholder-led collaboration to make a long-term management plan for the North Sea Nephrops fishery.

The Carlile-inspired analytical approach was useful to understanding knowledge production in the Nephrops case (Chapter 3). It confirmed that the interactions between stakeholders in the Nephrops Focus Group took place at several levels of complexity. This insight emerged through attention to three knowledge-generating processes: transfer, translation, and negotiation. The analytical approach was also useful for identifying resources that can help collaborating actors overcome their differences in the face of challenging issues. The findings demonstrated that the emerging long-term management plan was in itself a resource; the drafts had boundary-object characteristics. The drafts allowed the members of the Nephrops Focus Group to make their tacit knowledge explicit, and they developed a 
common understanding of complex, management-related issues. Furthermore, the findings revealed that the collaborating actors struggled to arrive at a common view of the preferred management measure at a functional-unit level, exemplified by the complex management situation in the Farne Deeps. An important theory-driven insight from the Nephrops case study is that knowledge transformation cannot occur if the resources available do not match the complexity of the collaborative setting.

In Chapter 4, the Carlile-inspired framework was applied to the case study of collaborations between pelagic fishing industry actors and fishery scientists, which aimed to produce a knowledge base for a new boarfish fishery in the Northeast Atlantic. In this case, the analytical approach was particularly useful in demonstrating how several boundary objects with various characteristics emerged during the collaborations. The two boarfish management-plan proposals that emerged - an interim plan and a long-term management plan - served as boundary objects to facilitate communication between actor groups. Notably, the first interim plan proposal was instrumental in transforming knowledge. Other boundary objects - an acoustic survey and a sampling programme - emerged in the science-industry collaboration that took place parallel with the management-plan developments. These boundary objects served as resources supporting the overall collaborative process of building a knowledge base for boarfish. A theory-driven insight from the boarfish case (Chapter 4) is that resources facilitating knowledge exchange can assume many different forms. Boundary objects exemplify such resources. In addition to the boundary objects mentioned, a sense of urgency became a resource at a critical moment when the pelagic fishing industry stakeholders needed to agree on presenting an interim management plan. Another example of a resource was the financial support mobilized by industry stakeholders to allow fishery scientists to quickly begin filling scientific knowledge gaps related to boarfish biology.

Another finding of the boarfish study presented in Chapter 4 was that coordination efforts made by producer-organization representatives were of paramount importance to how the collaborations evolved. The study revealed that many activities were initiated by fisher representatives in the boarfish fishery, for whom the stakes were high. This finding triggered my curiosity about how these coordinating efforts were instrumental in connecting actors and driving the collaborative processes. A conceptual framework was needed to investigate this further. In an iterative development process, the layered-complexity and issue-novelty aspects of Carliles' framework were re-considered, and activities and boundary objects were brought to the fore. The result was a modified conceptual framework to analyse the interaction between actors, objects, and activities. The modified boundary spaces conceptual framework 
was presented in Chapter 5 (Figure 5.1). Chapter 5 also included a first application in an analysis of knowledge-exchange processes in the Nephrops and boarfish cases. Taken together, the cases provided a rich, empirical context for exploring the utility of the modified framework. The boundary spaces framework (Figure 5.1) provided a lens through which to analyse additional layers of the collaborations previously analysed in Chapters 3 and 4 . The findings in Chapter 5 pointed to the importance of entry points for various actors to become directly involved in the collaborative knowledge-production processes. Furthermore, the findings demonstrated that direct engagement was instrumental to creating ownership of the problem addressed in the various collaborative settings that emerged during the long-term, management-plan initiatives. Ownership of the problem thus appears to be a key issue in producing constructive and efficient collaborations. Chapter 5's analysis demonstrated the importance of activities in this context.

\subsubsection{Management-plan development as arenas for knowledge exchange}

The findings discussed in Section 7.2.1 revealed that management plans can be boundary objects. In this section, the discussion addresses management-plan development processes as arenas where different actors come together to produce knowledge relevant to the CFP. A Mode 2, agora-inspired analytical perspective on management-plan development as an arena for knowledge exchange generated insights into how different actors' knowledge interacts, as discussed below. Arenas are settings where actors with different knowledge and interests meet and mix. Knowledge exchange is an overarching term that includes sharing, generation, and coproduction of knowledge (Fazey et al., 2013).

The different approaches in the NSAC and PELAC initiatives to make management plans serve as a first entry point for discussing the findings in light of knowledge mixing and production. In the Nephrops case (Chapters 3 and 5), the process of developing the plan appeared to be as important as the tangible outcome. By allowing the process to take several years, and by providing a forum for interaction between different actors and interests in the form of Nephrops Focus Group meetings, the development of a long-term, Nephrops management plan became an arena for mixed-actor knowledge generation. The setting allowed the members of the Nephrops Focus Group to reflect, learn, and develop an understanding of complex issues situated outside their own area of expertise. For example, industry representatives learned from NGO representatives about conservation concerns, and developed insights into how these concerns could or should be addressed in the management plan. They also learned from scientists about Nephrops biology and ways to assess the status 
of stocks in the North Sea. Integrating the scientific knowledge into the management plan was difficult, however. Part of the problem was that it remained unclear which specific problem the scientists were supposed to help the stakeholders solve with their scientific contributions. Mixing between forms of knowledge was primarily manifested as opportunities for learning within the Nephrops Focus Group. The tangible output from the collaboration, i.e. the final, long-term, management-plan proposal, presented the outcome from the Nephrops Focus Group's effort in the bulk text, while the specific scientific contribution was attached as an appendix. In Figure 7, the watering can metaphor introduced in Section 1.4 (Figure 1.3) is modified to illustrate tangible outcomes from the Nephrops and boarfish collaborations. A watering-can cartoon visualization of the NSAC's long-term management plan as a tangible output from the collaborations is shown in Figure 7.1b. When I discuss the role of scientists in Section 7.3.2 and in my general reflections in Section 7.4, I will return to this demarcation between stakeholder contributions and scientific contributions.

In the pelagic industry's initiatives to make management plans for boarfish (Chapters 4 and 5) and North Sea horse mackerel (Chapter 6), the problem to be addressed in the plans was more specific. These collaborations aimed at producing management tools that could be applied directly by DG MARE as part of their annual quota-setting routine. The process of plan production, therefore, concentrated on finding management strategies in the form of harvest control rules that would meet formal policy requirements. Knowledge contributions from scientists were essential to achieving this goal. Chapter 6 highlighted scientists' reflections on their role as advisors when helping industry representatives translate their needs into scientific language. This same issue of translating stakeholder needs into fishery science and management language was also highlighted by scientists who were engaged in developing management plans for boarfish (Chapter 4). For scientists to help with such translation, the stakeholders must have a clear idea of their needs. By the time the boarfish plan emerged on the pelagic industry stakeholders' agenda, their needs and priorities had been considered and articulated as management plan objectives: e.g. management plans should be tools to achieve high and stable yield (Coers et al., 2012). The boarfish case demonstrated that actors from the pelagic industry saw their plan's scientific content as a strength. Integration of stakeholder and scientific contributions was done with the final "wrapping," as the long-term, boarfish management plan was presented as a PELAC stakeholder contribution. However, its content was scientific. A watering-can cartoon visualization of the PELAC's long-term management plan for boarfish is shown in Figure 7.1(c). 
(a)

Stakeholder input to science (participatory research)

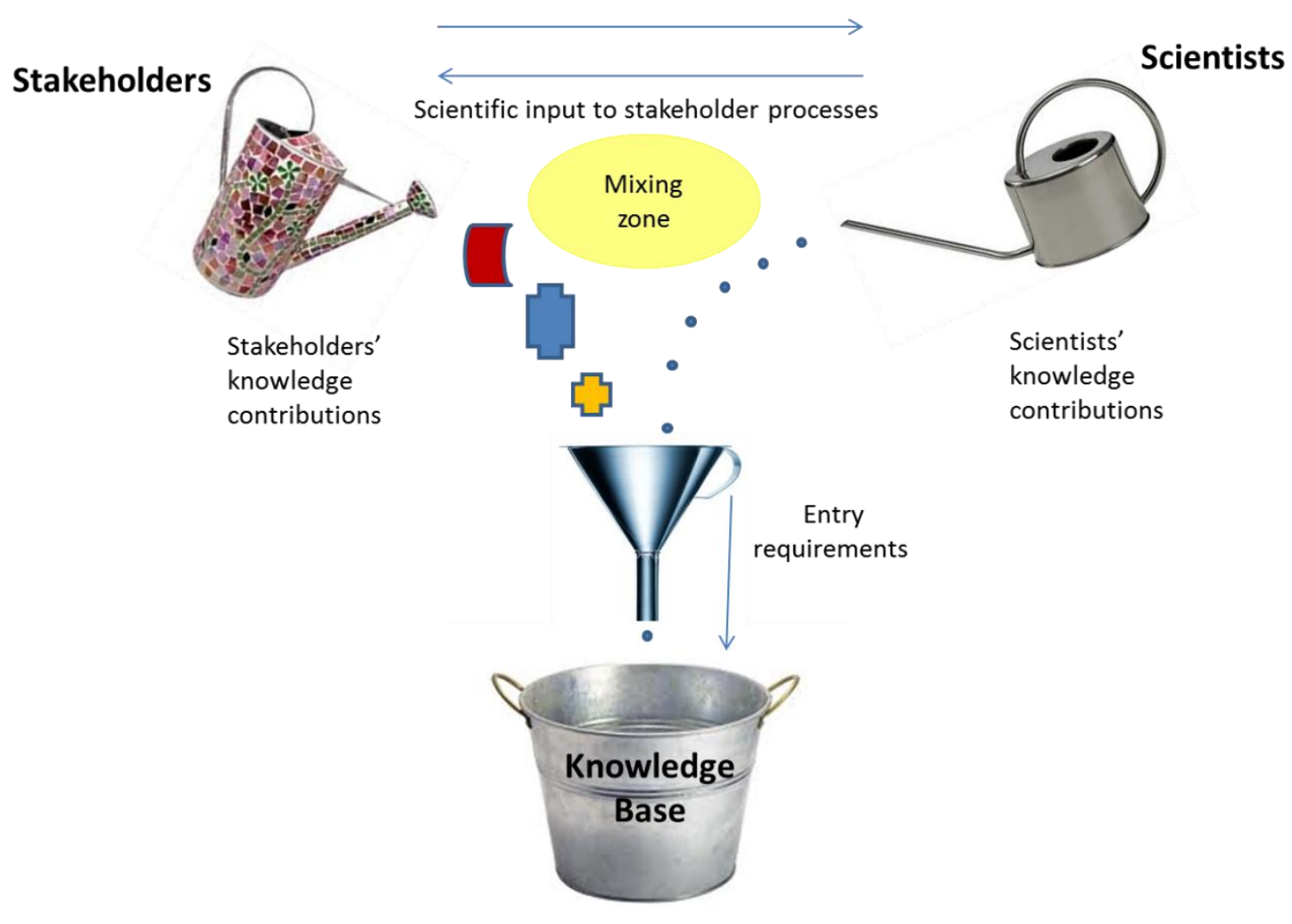

(b)

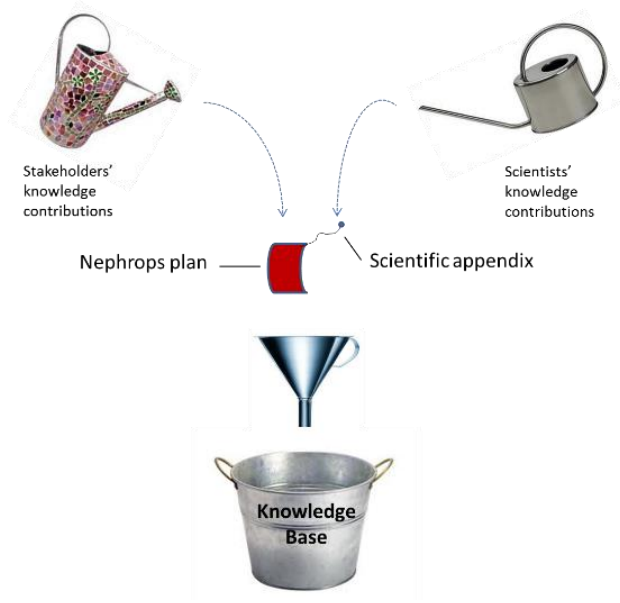

(c)
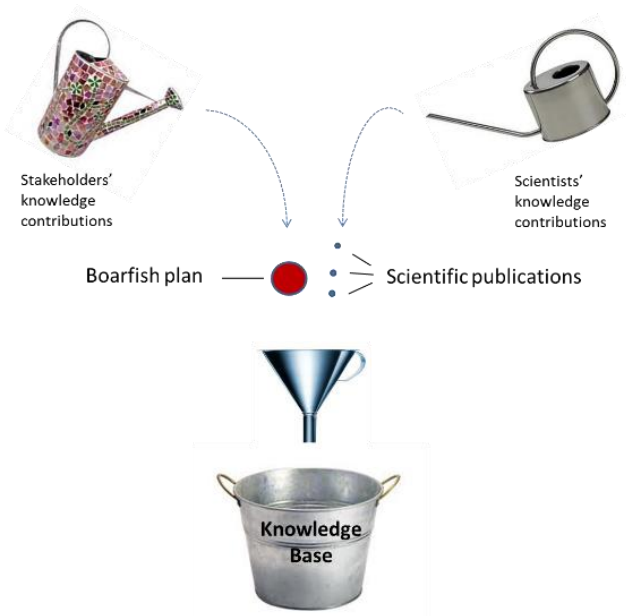

Figure 7.1 Watering-can cartoon visualizing output from the Nephrops and boarfish collaborations. (a) Overview of contributions, processes, and mixing zone where knowledge interacts (see also Figure 1.3); (b) Visualization of the long-term, Nephrops management plan. The plan itself is produced by an Advisory Council and is recognised as a stakeholder contribution. The plan's content reflects stakeholder interests and priorities. Its format deviate from traditional plans produced by DG MARE. Scientific knowledge is attached to the plan as an appendix; (c) Visualization of the long-term, boarfish management plan. The plan is produced by an Advisory Council and is recognised as a stakeholder contribution. The plan is "scientific" in its content and format. In addition to the management plan, the boarfish collaborations produced scientific outputs, recognised as distinct scientific contributions. 
The boarfish case also presented examples of output from mixed-actor collaborations delivered through the scientific route. The results from research initiated as part of the science-industry collaborations around boarfish were published in scientific journals. Results were also brought to ICES working groups and became part of the scientific knowledge base that supports boarfish stock assessment and scientific advice. Figure 7.1c illustrates these outcomes as scientific-knowledge contributions that are well aligned with the requirements for entering the EU fishery-management knowledge base. The boarfish case thus demonstrated that a dual strategy was used by the actors in the boarfish-related collaborations; they contributed their knowledge through the stakeholder route in the form of a PELAC management-plan proposal, and through the scientific route in the form of scientific papers and ICES advice.

\subsubsection{Actors and roles in management-plan collaborations}

Three groups of actors were central to this research: stakeholders, scientists, and managers. This categorization reflects terminology commonly used in EU fishery management. The three actor groups all have reasons to be engaged in management-plan processes: Managers use plans as tools, scientists contribute scientific components, and stakeholders are affected by them. The plans that have been formally adopted to date have been developed on the initiative of managers in DG MARE. The case studies presented in this thesis demonstrate that stakeholders who represent fishing-industry interests now take initiatives to develop such plans. The establishment of Advisory Councils was a prerequisite for the stakeholders to act in roles as management-plan producers; this CFP development provided both a forum for stakeholder deliberation and a channel for delivery of their recommendations. The analysis of knowledge exchange in management-plan processes presented in Chapters 3-6 gives useful insights into additional aspects of roles assumed by the various actors, as discussed below.

Chapter 5's analysis clarified how the collaborations in making the Nephrops and boarfish plans proceeded through several stages. Multiple boundary spaces, each with a different set of actors, emerged during the course of these collaborations. For the stakeholders, the role as owner of the initiatives meant being in control of those included in the collaborative knowledge-production process. In the Nephrops case, the members of the Nephrops Focus Group acted as gatekeepers to the boundary spaces during the development process. Through their active choices and actions, actors with the desired competences became part of their 
deliberations. Lack of funding initially prevented scientist involvement; however, an opportunity for the NSAC to engage in a participatory research project gave access to scientific expertise that was highly relevant. The network established during the participatory research project turned out to be useful in the longer term, because some of the scientists continued to support the Nephrops Focus Group with their advice after the project ended. The scientists then carried out work as part of their regular tasks as government marine institute employees. This informal collaborative arrangement meant that the Nephrops Focus Group in their gatekeeper role - were not in a position to put any pressure on the scientists to deliver. Progress with the scientific components of the Nephrops plan was thus sensitive to the scientists' priorities and other commitments. In the boarfish case, the boundary space where the long-term management plan emerged was very small; one fishery scientist and one producer-organization representative were the key actors. They in turn used their networks to engage others as they deemed appropriate. The boarfish case demonstrated that several different funding mechanisms were triggered to involve scientists. The scientist who did most of the hands-on work developing the interim plan, as well as the long-term, management-plan proposal, acted in an advisory role as an employee of a national marine research institute. This implies that boarfish management was given high priority at that institute. At the same time, boarfish-specific scientific studies were made possible with external funding from the industry. The case demonstrates a constructive relationship between scientists and industry actors in which both parties take ownership of the tasks of filling knowledge gaps and building a knowledge base to support management of boarfish.

The North Sea horse mackerel case (Chapter 6) provided additional perspectives on the implications for scientists of funding in stakeholder-initiated, management-plan initiatives. The case illustrates the current cost-recovery, project-oriented reality for many scientists employed by national marine research institutes. In the North Sea horse mackerel case, a research institute and a pelagic-industry producer organization collaborated to get research funding. This initiative allowed the fishery scientists to devote time to meetings and modelling work on North Sea horse mackerel. The external funding also influenced project formalities such as deadlines and deliverables. When the task to be completed by the scientists turned out to be more challenging than expected, they found themselves under pressure. The project ended before they could deliver any "good news" to the industry project partners. The case illustrates the need for clear allocation of roles and the importance of communication about responsibilities and expectations in such mixed-actor collaborative initiatives. 
Managers represent an important actor group in most management-plan contexts. Interestingly, managers were absent from the stakeholder-led collaborations studied in this research. The empirical material provides some answers to why the managers were not directly involved in the collaborations. In the Nephrops case, there was an explicit ambition to make a plan that was different from the previous DG MARE plans. The NSAC plan should represent, first and foremost, the knowledge and interests of the stakeholders, i.e. the Nephrops fishers. Tailoring the content to managers' current needs was simply not a priority, at least not until the very end of the development process. Managers were regularly invited to attend Nephrops Focus Group meetings, and the occasional participation by managers allowed some exchange of management-related knowledge. However, during the 2013 CFP reform process, DG MARE representatives were themselves unsure about the future of management plans. As a result, they could not provide clear guidance to the Nephrops Focus Group on the desired management-plans content. In the boarfish case, the managers signalled at an early stage that they preferred to receive proposals developed by the stakeholder without their own direct involvement (Chapter 4). That the boarfish plan emerged through the dedicated efforts of only a few individuals, i.e. without any designated group or project context, also meant that no obvious entry points existed for managers to become directly involved in the development process. In all case studies, the lack of manager involvement limited the opportunities for considering manager knowledge and current needs in the collaborative knowledge-production processes.

\subsection{Reflections on the contribution of this research}

The research presented in this thesis is a social science study, methodologically anchored in sociology. The topic and findings are relevant to several current strains of research within environmental social science and sociology of science. In this section, I will highlight issues that are debated in the scientific literature of these fields and reflect on how this thesis contributes to that debate.

\subsubsection{New actors and instruments in EU fishery management}

By analysing the NSAC and PELAC's roles as knowledge producers, this thesis contributes new insights to a strain of governance literature that concentrates on stakeholder participation in EU fishery management. Advisory Councils were added to the governance structure of EU fisheries a decade ago, and studies of their role and function have started to emerge, e.g. 
Linke et al., 2011; Coers et al., 2012; Ounanian and Hegland, 2012; Linke and Jentoft, 2014; Linke and Bruckmeier, 2015. Linke et al. (2011) used the BSAC as an example when analysing the Advisory Councils' role in the context of stakeholder participation in EU fishery governance. They found the deliberations within the BSAC to be characterized by the opposing views of the fishing industry and NGO representatives, and noted that the BSAC often formulated their recommendations as separate majority and minority statements rather than as consensus advice. The open tension sometimes displayed between members has triggered questions about the BSAC's ability to operate efficiently (Stohr and Chabay, 2010; Linke and Jentoft, 2013). The NSAC identified cultivation of better cooperation between industry and non-industry interests as a key struggle as well as a critical success factor (Ounanian and Hegland, 2012). In the NSAC Nephrops-plan initiative analysed in this thesis, NGO representatives were actively involved from the start of the management-plan process, and specific conservation measures were included in the NSAC's management-plan proposal as a result of deliberations between NGO and industry representatives in the Nephrops Focus Group. The boarfish case illustrated another situation, because the NGOs were not involved during the preparatory phase of the boarfish long-term management plan. When the boarfish proposal was brought to the PELAC for deliberation and endorsement, PELAC representatives, including NGOs, made only minor comments. In general, the PELAC sees their ability to work on a basis of consensus as a strength (Coers et al., 2012). Their Working Group and ExCom Chairs put great effort into mediating between diverging interests during and between - meetings to avoid adding minority statements to their recommendations. In the cases analysed in this thesis, the NSAC and the PELAC demonstrated a professional working atmosphere at meetings and a constructive problem-solving attitude when encountering contested issues. These contrasting observations from the BSAC, NSAC, and PELAC illustrate the value of studying several different Advisory Councils and the importance of learning about their differences. The findings in this thesis demonstrate that, although the Advisory Councils are similar in their formal structure and mandate, their ways of working are different. Generalizations about Advisory Councils' role and function should thus be made with caution.

Multi-annual plans as a new element in EU fishery management represent another entry point when reflecting on this thesis' contributions to the governance literature. Since the 2013 CFP reform, such plans are a prioritized tool. Various actors' experiences with them are relevant to understanding attitudes and actions. To my knowledge, the western horse mackerel study presented by Hegland and Wilson (2009), and the cases presented in this thesis (Stange 
et al., 2015; Stange, 2016; Stange et al.,2016), are the only analyses published about processes where Advisory Councils take ownership of producing long-term, management-plan proposals. These studies provide unique insights into a new phenomenon in EU fishery governance, in which Advisory Councils take on tasks beyond their traditional reactive, consultative role. The consultative role has sometimes been a frustrating one: The feeling of possessing relevant information, but not being listened to, is a reoccurring topic in the analysis of stakeholder-manager relations, as illustrated in the context of developing and implementing a recovery plan for cod in the North Sea (Wilson, 2009a; Kraak et al., 2013). In another example, Linke and Jentoft (2014) analysed the BSAC's experiences as advisors to the European Commission on a management-plan proposal for Baltic Sea salmon. The process was complex, involving several overlapping policies and deeply conflicting perspectives among the policy-makers in the European Commission, their scientific advisors in ICES, and the stakeholders in the BSAC. The process was eventually abandoned. Penas (2016) assigned the European Commission's withdrawal of the Baltic salmon-plan proposal to political circumstances, because it got entangled in the inter-institutional disagreement between the Council and the European Parliament (see Section 1.2.1). According to Linke and Jentoft (2014), the experience with the Baltic salmon plan left the BSAC deeply frustrated; they felt that their stakeholder contributions had not been taken into account and all of their effort and work with the plan had been in vain. The cases analysed in this research demonstrate that management plans as recommendations from Advisory Councils can be instrumental in improving relations between stakeholders and managers. Before RACs were established, relations between these actors were strained. Proposals presented by the European Commission would typically be met with criticism from the industry, whereas the industry did not themselves contribute alternative proposals (Lado, 2016, p. 253). The energy and optimism that was visible in the boarfish case (Chapters 4 and 5) might be explained by the pelagic industry's previous positive experiences with the western horse mackerel plan. Although that plan was never formally adopted - because this too got entangled in the interinstitutional deadlock - it was welcomed and used as a quota-setting tool by the European Commission (Lado, 2016). PELAC efforts with the western horse mackerel plan were portrayed as a success story in the DG MARE newsletter (European Commission, 2009c), with reference to the ambition of increasing participation in EU fishery management. The Nephrops case (Chapter 3) also illustrated a positive attitude from the European Commission to NSAC's then on-going efforts to produce a long-term management plan. The findings in this thesis point to the importance of a well-functioning, two-way dialogue between the 
Advisory Councils and the European Commission, and the importance of providing constructive feedback on Advisory Council contributions so that their efforts remain meaningful.

Engagement in producing management plans through Advisory Councils has provided entry points for the industry to take ownership of fishery-management dilemmas. With ownership comes a willingness to actively contribute to finding solutions to these dilemmas. However, the lack of manager involvement in the development processes provided limited opportunities to consider current management needs and tailor the content of the plans accordingly. This research did not specifically address the saliency of the output produced by the collaborations, i.e. the management-plan proposals, as management tools. It is interesting, however, that the proposals presented by the NSAC and PELAC were strikingly different in their structure and content, as illustrated in Figure 7.1b and 7.1c. The Nephrops plan was long and descriptive, and did not specify any quantitative mechanism for quota setting. The boarfish plan was short, and included a table with a tiered harvest control rule that managers could apply directly when proposing quotas. As discussed in Chapter 6 the high priority given to multi-annual plans in the reformed 2013 CFP demonstrates the importance of understanding roles and processes associated with these management tools.

\subsubsection{Scientific knowledge and other forms of knowledge}

This research contributes to the sociology of science literature by analysing management-plan development as an arena for mixed-actor knowledge production. In the Introduction, I mentioned Mode 2 and Post Normal Science as concepts relevant to the challenge of "opening up" knowledge systems. In Chapter 6, these concepts were revisited in framing the challenge of producing credible science for EU fishery management. Understanding how scientific knowledge interacts with non-scientific knowledge is particularly relevant to producing scientific advice that underpins management decisions (Wilson, 2009b). Studies that analyse the differences between scientific knowledge and fishers' knowledge (e.g. Soto, 2006; Nursey-Bray et al., 2014) are useful to understanding the challenge of integration. Holm (2003) discussed how "raw" fishers' knowledge may be useful if "purified" and transformed into forms that are fit for purpose in a fishery advisory science context. Such transformation takes place in an arena where Mode 1 and Mode 2 science ideals are valued for their strengths, while the shortcomings of both modes are acknowledged and debated. Perhaps today's European fishery advisory science is halfway between these two ideal types, expressed by Msomphora (2016) as "Mode 1,5." Such an in-between setting, where actors 
promote traditional linear science while arguing the value of their non-scientific knowledge, was described by Carter (2013). Her study of Advisory Councils' awareness of different forms of knowledge indicated that, although industry representatives portray themselves as having relevant, non-scientific knowledge that should be taken into account, they simultaneously support the traditional Mode 1 type paradigm. The research presented here contributes to this debate by demonstrating how stakeholders look for and test ways of presenting their knowledge in content and format that are relevant to managers. The NSAC's - and particularly the PELAC's - mixed-actor collaborations were able to produce management plans because they integrated scientific-knowledge contributions, so making their output more salient as management tools (Figure 7.1b and 7.1c). This research thus demonstrates that the knowledge purification and transformation mentioned by Holm (2003) go both ways: Stakeholder knowledge must be transformed to be fit for purpose if the output is to be recognized as science, and scientific knowledge must be transformed to be fit for purpose if the output is to be recognized as stakeholder-produced knowledge.

This thesis also contributes illustrations of the broad range of knowledge held by actors that, in EU fishery-management contexts, are routinely collectively referred to as stakeholders. Advisory Council members have diverse educational backgrounds and work experiences. Many of them have in-depth understanding of complex scientific issues and management dilemmas. Categorizing their knowledge as "stakeholder knowledge" is, I would argue, of limited utility when aiming to understand knowledge exchange. An in-depth understanding of Advisory Councils' contributions to knowledge production requires an examination of the specific knowledge-exchange settings, as exemplified in the case studies presented here.

Another body of literature within sociology of science for which this thesis is relevant addresses fishers' knowledge within various contexts of stakeholder participation. A recent review by Hind (2015) demonstrated how research on fishers' knowledge has, since the 1980s, evolved through different stages. Hind found that focus and perspectives have shifted between different disciplines: from initial natural history studies to ethnography, followed by applied social science studies, and on to quantitative biology. He suggests that we might now be at the onset of a fifth wave where the interests of applied social science and quantitative biology meet. At this intersection, qualitative knowledge can be integrated into quantitative fishery science. In response to Hind's review, Stephenson et al. (2016) point to additional and related strains of literature that analyse fisher participation in knowledge production in a wider context. They emphasize that scientific studies that take a participatory or collaborative 
research approach are often interdisciplinary, and that results of interest to fishery science and management are found in a wide range of journals - i.e. beyond those that focus on fisheries. Chapters 4 and 6 are illustrative examples of social science studies of collaborations between fishery stakeholders and scientists that are published in journals with a traditional fisheryresearch profile. Chapters 3 and 5 exemplify publications on similar topics in journals with a social science profile. Promoting understanding between scholars from natural science and social science disciplines is important to "opening up" knowledge systems, as is access to information (Cash et al., 2003; Garcia and Charles, 2008; Cornell et al., 2013). The articles presented here as Chapters 3-6 are "open access," which means that they are freely accessible without the restriction of journal subscription fees. Open access makes the findings from this research available to all interested audiences. This includes stakeholders, scientists, and managers who are not employed by academic institutions or research institutes, e.g. members of Advisory Councils and policy officers in DG MARE.

\subsubsection{Boundary-object theory and knowledge exchange}

The setting explored in this research, i.e. mixed-actor production of fishery-management plans, has some similarities with the natural history museum setting where the boundaryobject concept originally emerged (Star and Griesemer, 1989), as well as the industrialproduction setting studied by Carlile (2002, 2004); it involved individuals with different kinds of knowledge and interests, and with a common overarching goal and need to collaborate. Beyond these similarities, the settings analysed are strikingly different. The disciplinary anchoring is also different; Star and Griesemer's work is situated within STS, whereas Carlile's work belongs within organization and management studies. The broad utility of the boundary-object concept is demonstrated by the high citation scores for Star and Griesemer's 1989 publication distributed over a range of social science disciplines (Lamont and Molnar, 2002). Carlile contributed by fruitfully combining STS and organization management thinking, and his works on boundary objects (Carlile, 2002) and knowledge management at boundaries (Carlile, 2004) are also highly cited $^{31}$. Recent applications of boundary-object theory include analyses to understand collaborations and controversies within a range of different natural-resource management contexts, e.g. Turnhout, 2009; Wilson, 2009a; Clark et al., 2010; and Floor et al., 2016. This thesis contributes to the rich body of boundary-object literature by adding current knowledge-exchange perspectives to analyses of mixed-actor

${ }^{31}$ Carlile (2002): 796; Carlile (2004): 593. Data "times cited", from Web of Science Core Collection 28 October 2016. 
collaborations. Knowledge exchange is emerging as an interdisciplinary area of research that may facilitate the "opening up" of knowledge systems (Fazey et al., 2013). The boundary spaces conceptual framework developed, presented, and tested as part of this research (Chapter 5) is a tangible contribution to our understanding of knowledge exchange. The conceptual framework adds dimensions to traditional boundary object theory that were helpful for understanding knowledge exchange in the collaborations analysed. The analysis focused on the interplay between objects and activities at the boundary between actors, and on how this interplay created spaces for knowledge exchange. Specifically, the case studies analysed demonstrate the importance of activities in mixed-actor, knowledge-production processes. The findings align with other recent studies, e.g. Roux et al., 2006; Cvitanovic et al., 2015a; and Cvitanovic et al., 2015b, that point to the value of applying knowledge-exchange perspectives to the understanding of knowledge transfer between diverse groups of actors in marine science and management.

\subsection{Reflections on the research approach}

This research aimed to advance our understanding of how knowledge is used and produced in collaborations where actors have different knowledge and interests. Development of longterm management plans for EU fishery management was the setting within which the phenomenon of collaborative knowledge production was investigated. As discussed in Section 2.1, the choice of the case study as a research method was appropriate, given the research question posed, the investigator's (my) lack of influence over the events, and the contemporary nature of the phenomenon studied. The contemporary dimension in this research had wide-ranging implications. The goal was to study collaborative development processes in real time. This, in turn, was motivated by the use of Carlile's conceptual framework for understanding knowledge exchange at boundaries between actors (Carlile 2002, 2004). Analysing the dynamics of knowledge exchange requires in-depth investigation supported by rich empirical material. Carlile's ethnographic studies were carried out on location, in a factory, over several months. In the research conducted for this thesis, the lack of a geographical location for the phenomenon of interest created logistical challenges. The development of management plans for European fishery management is not standardized. The diversity of approaches used to make them is in itself an interesting aspect of such plans, as discussed in Chapter 6. In general, on-site studies of interaction between actors during management-plan development would require the researcher's presence at meetings at various 
European locations over extended periods. Management-plan development processes can take several years, as illustrated in the Nephrops case (Chapters 3 and 5). The ad hoc and opportunistic aspects of the boarfish interim plan development (Chapters 4 and 5) illustrated that good planning is sometimes not enough to ensure presence when and where managementplan ideas emerge. The management-plan processes of interest in this study were stakeholderdriven and did not follow a typical research-project trajectory, i.e. with start and end dates, and prescheduled meeting activities. These circumstances contributed to the challenge of being in the right place at the right time to allow collection of data with the richness required for the analysis of knowledge production. In light of these challenges, the opportunity to participate as an observer in two of the Nephrops Focus Group meetings was particularly valuable. These on-site, real-time, data-collection events allowed a deeper analysis and understanding of the knowledge-exchange processes in the Nephrops case than in the other cases. The month-long stay at the Scottish Fishermen's Federation's offices in Aberdeen, with accompanying visits to Nephrops fishing ports, added further richness to the Nephrops case study. In the boarfish case, the absence of meeting activities dedicated to the boarfish management-plan process point to the lack of "site" for participant observation. Some of the interviews for the boarfish case were done on site in Killybegs and Galway, Ireland, to get as close as possible to the action, given the limitations of data collection described. In both cases, participation in NSAC and PELAC meetings was valuable to understanding the issues and observing interaction between Advisory Council members. These events, however, were somewhat removed from hands-on development work with the management plans. Access to interviewees who had in-depth knowledge of the processes of interest compensated to some extent for the limited opportunities to collect data on site, as did access to detailed meeting minutes. In sum, the research strategy allowed insights to be gained about the dynamics of mixed-actor collaborations in making management plans, but could only to a limited degree reveal the essence of knowledge production during these collaborations. Once again, I lean on Carlile's statement that "collecting data about knowledge has proven difficult" (Carlile, 2002, p. 446).

Returning to the issue of external validity mentioned in Section 2.5, some analytical generalizations can be made, based on the findings in this research. They demonstrate that the framework introduced by Carlile (2004) could be applied successfully to case studies of collaborations in fishery-management-plan production to reveal the complexity embedded in such collaborations (Chapters 3 and 4). The "thick descriptions" provided in the Nephrops and boarfish case studies, including detailed narratives of how the management plans evolved, 
provide guidance to other researchers when evaluating the applicability of the theoretical approach in Chapters 3 and 4 to other studies and settings. The boundary spaces conceptual framework developed as part of this research (Chapter 5) allowed analytical focus on the dynamic interaction between activities and objects in collaborative processes. The knowledgeproduction aspects of collaborations were considered in this research; however, the boundary spaces framework is applicable to studies of mixed-actor collaborations with other explicit goals. For example, it can be useful in identifying the actors who - by taking initiatives that generate activities - play key roles in collaborations. Furthermore, the boundary spaces framework can be applicable to understanding the nature and function of boundary objects in mixed-actor settings.

\subsection{Ideas for further research}

In this final section, I will put forward ideas for future research. The first two address the understanding of knowledge in fishery management, while the third addresses knowledge production in general.

The conceptual framework presented in Chapter 5 was used on two collaborations that produced management plans. The study was not specifically designed to contrast the cases; however, the findings illuminated several interesting differences between the two settings investigated. The boundary spaces framework was therefore found useful in investigating the interaction between actors in these knowledge-production processes. As a next step, the framework could be used in a variety of settings to test its broader utility for understanding knowledge exchange. One setting of interest is the production and use of knowledge in certification programmes. Certification programmes have emerged as an important element within environmental governance, including governance of wild capture fisheries (Gulbrandsen, 2010). Consumers and non-state certification bodies are key actors in certification programmes. Scientists also play roles: as knowledge providers. The use and interpretation of scientific knowledge to underpin certification schemes, however, are sometimes contested. This tension is evident in a current debate regarding the status of fish stocks in the Northeast Atlantic (Froese and Proelss, 2012; Agnew et al., 2013; Opitz et al., 2016). Analyses of knowledge-generating processes that focus on objects, actors, and activities, i.e. using the boundary spaces conceptual framework presented in Chapter 5, would add useful perspectives to our understanding of such controversies. 
Another topic for further exploration is how the content of management plans produced by Advisory Councils is added to the EU fishery-management knowledge base. How and to what extent ideas presented by stakeholders are incorporated into management tools is of interest in "opening up" knowledge systems. This thesis followed two management-plan proposals from conception to their presentation to the European Commission. The research was conducted during a period when an inter-institutional deadlock between the European Parliament and the Council prevented management-plan proposals from advancing through the system. During this period, there was no incentive for DG MARE policy officers to take action on the Advisory Council recommendations and develop the proposals into EU regulations. This barrier is removed, and management-plan development is again on DG MARE's agenda. Investigations of uptake dynamics would require a policy-analysis approach. Alternatively, ideas presented by Roux et al. (2006) on bridging the science-management divide could be applied.

A third topic for further research relates to the never-ending pursuit of understanding the nature of knowledge. I join a long line of sociology of knowledge scholars when stating that the concept of knowledge is multifaceted and complex. The research presented here was inspired by others who have already confronted the challenges of sharing and managing knowledge, in particular the works of Star and Griesemer (1989) and of Carlile (2002, 2004). The work was carried out as part of a research project that concentrated on collaborations between fishers and scientists. Issues related to EU fishery management were prioritized. In another research context with collaborative focus on knowledge creation per se, scholars with specific competence in learning and knowledge acquisition could add valuable perspectives. The work of du Chatenier et al. (2010) on collaborative knowledge creation exemplified approaches that could trigger interesting research questions. The concept of knowledge exchange is now used by scholars interested in knowledge production for natural-resource management (Fazey et al., 2013; Cvitanovic et al., 2015b). The knowledge-exchange literature points to the value of studying knowledge from multiple perspectives: Many disciplines and competences are needed in our pursuit of understanding knowledge exchange. Fruitful collaboration between scientists from different disciplines is thus one important element of "opening up" knowledge systems. 


\section{References}

Agnew, D. J., Gutierrez, N. L., Stern-Pirlot, A., Smith, A. D. M., Zimmermann, C., and Sainsbury, K. 2013. Rebuttal to Froese and Proelss "Evaluation and legal assessment of certified seafood". Marine Policy, 38: 551-553.

Anon 2014. Task Force agreement on multiannual plans. http://www.europarl.europa.eu/meetdocs/2009_2014/documents/pech/dv/taskfor/taskf orce.pdf.

Bailey, M. C., Polunin, N. V., and Hawkins, A. D. 2012. A sustainable fishing plan for the Farne Deeps Nephrops fishery. Report to the Marine Management Organisation May 2012. Newcastle University.

Bernard, H. R. 2006. Research methods in anthropology: qualitative and quantitative approaches, AltaMira Press, Lanham, MD.

Bjørkan, M. 2011. Fishing for advice. The case of the Norwegian Reference Fleet. PhD thesis. Norwegian College of Fisheries, University of Troms $\varnothing$.

Bornmann, L. 2011. Scientific peer review. Annual Review of Information Science and Technology, 45: 199-245.

Carlile, P. R. 2002. A pragmatic view of knowledge and boundaries: Boundary objects in new product development. Organization Science, 13: 442-455.

Carlile, P. R. 2004. Transferring, translating, and transforming: An integrative framework for managing knowledge across boundaries. Organization Science, 15: 555-568.

Carter, C. A. 2013. Constructing sustainability in EU fisheries: Re-drawing the boundary between science and politics? Environmental Science \& Policy, 30: 26-35.

Cash, D. W., Clark, W. C., Alcock, F., Dickson, N., Eckley, N., and Jäger, J. 2002. Salience, credibility, legitimacy and boundaries: Linking research, assessment and decision making, John F. Kennedy School of Government, Harvard University.

Cash, D. W., Clark, W. C., Alcock, F., Dickson, N. M., Eckley, N., Guston, D. H., Jager, J., et al. 2003. Knowledge systems for sustainable development. Proceedings of the National Academy of Sciences of the United States of America, 100: 8086-8091.

Clark, W. C., Tomich, T. P., Van Noordwijk, M., Dickson, N. M., Catacutan, D., Guston, D., and McNie, E. 2010. Toward a general theory of boundary work: Insights from the CGIAR's natural resource management programs. CID Working Paper No. 199. Center for International Development, Harvard University. Cambridge, MA: Harvard University, July 2010.

Clarke, M. 2012. Draft interim management plan for boarfish. Presentation to the Pelagic Regional Advisory Council, Working Group II, 11 July 2012.

Clarke, M., Van Balsfoort, G., Coers, A., Campbell, A., Dickey-Collas, M., Egan, A., Ghiglia, M., et al. 2007. A new scientific initiative with the Pelagic RAC to develop a management plan for western horse mackerel. ICES Annual Science Conference, Helsinki. ICES CM 2007/O:20. International Council for the Exploration of the Sea.

Coad, J. O., Hüssy, K., Farrell, E., and Clarke, M. 2014. The recent population expansion of boarfish, Capros aper (Linnaeus, 1758): interactions of climate, growth and recruitment. Journal of Applied Ichthyology, 30: 463-471.

Coers, A., and Miller, D. 2014. Evaluation of a multi-annual plan including an index based HCR for North Sea horse mackerel. Report number C097/14. IMARES Wageningen UR.

Coers, A., Raakjaer, J., and Olesen, C. 2012. Stakeholder participation in the management of North East Atlantic pelagic fish stocks: The future role of the Pelagic Regional Advisory Council in a reformed CFP. Marine Policy, 36: 689-695.

Coffey, A., and Atkinson, P. 1996. Making sense of qualitative data: complementary research strategies, Sage, Thousand Oaks, Calif. 
Collins, H., and Evans, R. 2008. Rethinking expertise, University of Chicago Press.

Cornell, S., Berkhout, F., Tuinstra, W., Tabara, J. D., Jager, J., Chabay, I., de Wit, B., et al. 2013. Opening up knowledge systems for better responses to global environmental change. Environmental Science \& Policy, 28: 60-70.

Cornwall, A., and Jewkes, R. 1995. What is participatory research? Social Science \& Medicine, 41: 1667-1676.

Council 2002. (Council of the European Union). Council Regulation (EC) No 2371/2002 of 20 December 2002 on the conservation and sustainable exploitation of fisheries resources under the Common Fisheries Policy.

Council 2004. (Council of the European Union). Council Decision of 19 July 2004, establishing Regional Advisory Councils under the Common Fisheries Policy (2004/585/EC). Official Journal of the European Union, L256/17, 3.8.2004.

Council 2011. (Council of the European Union). Council Regulation (EU) No 57/2011 of 18 January 2011 fixing for 2011 the fishing opportunities for certain fish stocks and groups of fish stocks, applicable in EU waters and, for EU vessels, in certain non-EU waters. Official Journal of the European Union, L24, 27.1.2011.

Cvitanovic, C., Hobday, A. J., Kerkhoff, L., and Marshall, N. A. 2015a. Overcoming barriers to knowledge exchange for adaptive resource management; the perspectives of Australian marine scientists. Marine Policy, 52: 38-44.

Cvitanovic, C., Hobday, A. J., Van Kerkhoff, L., Wilson, S. K., Dobbs, K., and Marshall, N. A. 2015b. Improving knowledge exchange among scientists and decisionmakers to facilitate the adaptive governance of marine resources: A review of knowledge and research needs. Ocean \& Coastal Management, 112: 25-35.

Dankel, D. J., Aps, R., Padda, G., Rockmann, C., Van der Sluijs, J. P., Wilson, D. C., and Degnbol, P. 2012. Advice under uncertainty in the marine system. ICES Journal of Marine Science, 69: 3-7.

Daw, T. 2008. How fishers count: engaging with fishers' knowledge in fisheries science and management. $\mathrm{PhD}$ Thesis. Newcastle University.

Daw, T., and Gray, T. 2005. Fisheries science and sustainability in international policy: a study of failure in the European Union's Common Fisheries Policy. Marine Policy, 29: 189-197.

Degnbol, P., Gislason, H., Hanna, S., Jentoft, S., Nielsen, J. R., Sverdrup-Jensen, S., and Wilson, D. C. 2006. Painting the floor with a hammer: Technical fixes in fisheries management. Marine Policy, 30: 534-543.

Dorner, H., Graham, N., Bianchi, G., Bjordal, A., Frederiksen, M., Karp, W. A., Kennelly, S. J., et al. 2015. From cooperative data collection to full collaboration and comanagement: a synthesis of the 2014 ICES symposium on fishery-dependent information Introduction. ICES Journal of Marine Science, 72: 1133-1139.

Dreyer, M., and Renn, O. 2011. Participatory approaches to modelling for improved learning and decision-making in natural resource governance: an editorial. Environmental Policy and Governance, 21: 379-385.

du Chatenier, E., Verstegen, J., Biemans, H. J. A., Mulder, M., and Omta, O. 2010. Identification of competencies for professionals in open innovation teams. $R$ \& $D$ Management, 40: 271-280.

ECJ 2015. (Court of Justice). Judgment of the Court (Grand Chamber) of 1 December 2015. European Parliament and European Commission v Council of the European Union. Actions for annulment - Regulation (EU) No 1243/2012 - Choice of legal basis Article 43(2) and (3) TFEU - Policy decision — Long-term plan for cod stocks. Joined Cases C-124/13 and C-125/13

Edelenbos, J., Van Buuren, A., and Van Schie, N. 2011. Co-producing knowledge: joint knowledge production between experts, bureaucrats and stakeholders in Dutch water 
management projects. Environmental Science \& Policy, 14: 675-684.

Eliasen, S. Q., Hegland, T. J., and Raakjaer, J. 2015. Decentralising: The implementation of regionalisation and co-management under the post-2013 Common Fisheries Policy. Marine Policy, 62: 224-232.

Etzkowitz, H., and Leydesdorff, L. 2000. The dynamics of innovation: from national systems and "Mode 2" to a triple helix of university-industry-government relations. Research Policy, 29: 109-123.

EU 2011. Regulation (EU) No 579/2011 of The European Parliament and of the Council of 8 June 2011 amending Council Regulation (EC) No 850/98 for the conservation of fishery resources through technical measures for the protection of juveniles of marine organisms and Council Regulation (EC) No 1288/2009 establishing transitional technical measures from 1 January 2010 to 30 June 2011. Official Journal of the European Union, L 165/1, 24.6.2011.

EU 2013. Regulation (EU) No 1380/2013 of the European Parliament and of the Council of 11 December 2013 on the Common Fisheries Policy, amending Council Regulations (EC) No 1954/2003 and (EC) No 1224/2009 and repealing Council Regulations (EC) No 2371/2002 and (EC) No 639/2004 and Council Decision 2004/585/EC. Official Journal of the European Union, L 354/22, 28.12.2013.

EU 2016. Regulation (EU) 2016/1139 of the European Parliament and of the Council of 6 July 2016 establishing a multiannual plan for the stocks of cod, herring and sprat in the Baltic Sea and the fisheries exploiting those stocks, amending Council Regulation (EC) No 2187/2005 and repealing Council Regulation (EC) No 1098/2007. Official Journal of the European Union, L 191/1, 15.7.2016.

European Commission 2009a. Green Paper. Reform of the Common Fisheries Policy. Brussels, COM (2009) 163.

European Commission 2009b. Proposal for a Council Regulation establishing a multi-annual plan for the western stock of Atlantic horse mackerel and the fisheries exploiting that stock. COM (2009) 189 final.

European Commission 2009c. Participation - a Regional Advisory Council initiates a multiannual plan. In Fisheries and aquaculture in Europe, No 44, August 2009, p. 10-11. European Commission.

European Commission 2014a. Commission Delegated Regulation (EU) No ...... Laying down detailed rules on the functioning of the Advisory Councils under the Common Fisheries Policy. Brussels: EC 7012 final.

European Commission 2014b. Communication from the Commission to the European Parliament and the Council - Concerning a consultation on fishing opportunities for 2015 under the Common Fisheries Policy. COM (2014) 388 final.

FAO 1996. Precautionary approach to capture fisheries and species introductions. Elaborated by the Technical Consultation on the Precautionary Approach to Capture Fisheries (Including Species Introductions). Lysekil, Sweden, 6-13 June 1995. FAO Technical Guidelines for Responsible Fisheries. No. 2. Rome, FAO. 1996. 54p.

Farrell, E. D., Hussy, K., Coad, J. O., Clausen, L. W., and Clarke, M. W. 2012. Oocyte development and maturity classification of boarfish (Capros aper) in the Northeast Atlantic. ICES Journal of Marine Science, 69: 498-507.

Fazey, I., Bunse, L., Msika, J., Pinke, M., Preedy, K., Evely, A. C., Lambert, E., et al. 2014. Evaluating knowledge exchange in interdisciplinary and multi-stakeholder research. Global Environmental Change-Human and Policy Dimensions, 25: 204-220.

Fazey, I., Evely, A. C., Reed, M. S., Stringer, L. C., Kruijsen, J., White, P. C. L., Newsham, A., et al. 2013. Knowledge exchange: a review and research agenda for environmental management. Environmental Conservation, 40: 19-36.

Finlayson, A. C. 1994. Fishing for truth: a sociological analysis of northern cod stock 
assessments from 1977 to 1990, Institute of social and economic research, Memorial University of Newfoundland St. John's, Newfoundland.

Fitzpatrick, M. 2014. From boom and bust to local stewardship: A governance benchmark for Celtic Sea fisheries management. In Social issues in sustainable fisheries management, pp. 43-63. Ed. by J. Urquhart, T. G. Acott, D. Symes, and M. Zhao. Springer, Dordrecht.

Floor, J. R., Van Koppen, C. S. A., and Van Tatenhove, J. P. M. 2016. Uncertainties in the assessment of "significant effect" on the Dutch Natura 2000 Wadden Sea site - The mussel seed fishery and powerboat race controversies. Environmental Science \& Policy, 55: 380-392.

Folke, C., Hahn, T., Olsson, P., and Norberg, J. 2005. Adaptive governance of socialecological systems. Annual Review of Environment and Resources, 30: 441-473.

Froese, R., and Proelss, A. 2012. Evaluation and legal assessment of certified seafood. Marine Policy, 36: 1284-1289.

Funtowicz, S. O., and Ravetz, J. R. 1993. Science for the post-normal age. Futures, 25: 739755.

Fässler, S. M. M., O’Donnell, C., and Jech, J. M. 2013. Boarfish (Capros aper) target strength modelled from magnetic resonance imaging (MRI) scans of its swimbladder. ICES Journal of Marine Science, 70: 1451-1459.

Garcia, S. M., and Charles, A. T. 2008. Fishery systems and linkages: Implications for science and governance. Ocean and Coastal Management, 51: 505-527.

Garrett, A., MacMullen, P., and Symes, D. 2012. Fisheries as learning systems: Interactive learning as the basis for improved decision making. Fisheries Research, 127: 182-187.

Gibbons, M. 1999. Science's new social contract with society. Nature, 402: C81-C84.

Gibbons, M. 2000. Mode 2 society and the emergence of context-sensitive science. Science and Public Policy, 27: 159-163.

Gibbons, M., Limoges, C., and Nowotny, H. 1994. The new production of knowledge: The dynamics of science and research in contemporary societies, Sage, London.

Gieryn, T. F. 1983. Boundary-work and the demarcation of science from non-science: Strains and interests in professional ideologies of scientists. American Sociological Review, 48: 781-795.

Gluckman, P. 2014. The art of science advice to government. Nature, 507: 163-165.

Graham, N., Grainger, R., Karp, W. A., MacLennan, D. N., MacMullen, P., and Nedreaas, K. 2011. An introduction to the proceedings and a synthesis of the 2010 ICES Symposium on Fishery-Dependent Information. ICES Journal of Marine Science, 68: 1593-1597.

Gray, T., Hatchard, J., Daw, T., and Stead, S. 2008. New cod war of words: 'Cod is God' versus 'sod the cod' - Two opposed discourses on the North Sea Cod Recovery Programme. Fisheries Research, 93: 1-7.

Gulbrandsen, L. H. 2010. Transnational environmental governance: the emergence and effects of the certification of forests and fisheries, Edward Elgar Publishing.

Guston, D. H. 1999. Stabilizing the boundary between US politics and science: The role of the Office of Technology Transfer as a boundary organization. Social Studies of Science, 29: 87-111.

Hauge, K. H., Nielsen, K. N., and Korsbrekke, K. 2007. Limits to transparency - exploring conceptual and operational aspects of the ICES framework for providing precautionary fisheries management advice. ICES Journal of Marine Science, 64: 738743.

Hawkins, T. 2005. The role of partnerships in the governance of fisheries within the European Union. In Participation in fisheries governance, pp. 65-83. Ed. by T. S. Gray. Springer, Dordrecht. 
Hegger, D., Lamers, M., Van Zeijl-Rozema, A., and Dieperink, C. 2012. Conceptualising joint knowledge production in regional climate change adaptation projects: success conditions and levers for action. Environmental Science \& Policy, 18: 52-65.

Hegland, T. J. 2006. Fisheries policy-making: production and use of knowledge. In The knowledge base for fisheries management, pp. 219-237. Ed. by L. Motos, and D. C. Wilson. Elsevier, Amsterdam.

Hegland, T. J. 2012. Fishing for change in EU governance: Excursions into the evolution of the Common Fisheries Policy. PhD Thesis. Aalborg University.

Hegland, T. J., and Wilson, D. C. 2009. Participatory modelling in EU fisheries management: Western Horse Mackerel and the Pelagic RAC. Maritime Studies, 8: 75-96.

Hessels, L. K., and Van Lente, H. 2008. Re-thinking new knowledge production: A literature review and a research agenda. Research Policy, 37: 740-760.

Hind, E. J. 2015. A review of the past, the present, and the future of fishers' knowledge research: a challenge to established fisheries science. ICES Journal of Marine Science, 72: 341-358.

Hoefnagel, E., Burnett, A., and Wilson, D. C. 2006. The knowledge base of co-management. In The knowledge base for fisheries management, pp. 85-108. Ed. by L. Motos, and D. Wilson. Pergamon.

Holm, P. 2003. Crossing the border: On the relationship between science and fishermen's knowledge in a resource management context. Maritime Studies, 2: 5-33.

Holm, P., and Nielsen, K. N. 2004. The TAC Machine. In Report of the Working Group on Fishery Systems (WGFS Annual Report), pp. 40-51. ICES, Copenhagen.

Holmes, S. J., Bailey, N., Campbell, N., Catarino, R., Barratt, K., Gibb, A., and Fernandes, P. G. 2011. Using fishery-dependent data to inform the development and operation of a co-management initiative to reduce cod mortality and cut discards. ICES Journal of Marine Science, 68: 1679-1688.

Hunt, J., and Shackley, S. 1999. Reconceiving science and policy: Academic, fiducial and bureaucratic knowledge. Minerva, 37: 141-164.

Hussy, K., Coad, J. O., Farrell, E. D., Clausen, L. A. W., and Clarke, M. W. 2012a. Age verification of boarfish (Capros aper) in the Northeast Atlantic. ICES Journal of Marine Science, 69: 34-40.

Hussy, K., Coad, J. O., Farrell, E. D., Clausen, L. W., and Clarke, M. W. 2012b. Sexual dimorphism in size, age, maturation, and growth characteristics of boarfish (Capros aper) in the Northeast Atlantic. ICES Journal of Marine Science, 69: 1729-1735.

ICES 2006. Report of the Review Group on Fisheries Surveys of North Sea Stocks (RGFS). ICES CM 2006/ACFM:38. International Council for the Exploration of the Sea, Copenhagen.

ICES 2007. Report of the Study Group on Management Strategies (SGMAS). ICES CM 2007/ACFM:04. 59 pp. International Council for the Exploration of the Sea, Copenhagen.

ICES 2008a. ICES Advice 2008. Book 9. Section 9.3.2.1. European Commission (EC) request on evaluation of management plan for NEA mackerel. International Council for the Exploration of the Sea, Copenhagen.

ICES 2008b. Report of the Working Group on NEA Mackerel Long-Term Management Scientific Evaluations (NEAMACKLTM). ICES CM 2008/ACOM:54. 229 pp. International Council for the Exploration of the Sea, Copenhagen.

ICES 2009a. ICES Advice 2009, Book 6. Nephrops in Subarea IV (North Sea). International Council for the Exploration of the Sea, Copenhagen.

ICES 2009b. Report of the ICES-STECF Workshop on Fishery Management Plan Development and Evaluation (WKOMSE). ICES CM 2009/ACOM:27. 22 pp. International Council for the Exploration of the Sea, Copenhagen. 
ICES 2011a. ICES Advice 2011, Book 9, Section 9.4.22. Boarfish in the Northeast Atlantic. Advice for 2012. International Council for the Exploration of the Sea, Copenhagen.

ICES 2011b. Report of the Working Group on Widely Distributed Stocks (WGWIDE). ICES CM 2011/ACOM:15. International Council for the Exploration of the Sea, Copenhagen.

ICES 2012a. General context of ICES advice. ICES Advice 2012, Book 1. Section 1.2. International Council for the Exploration of the Sea, Copenhagen.

ICES 2012b. Report of the Working Group on Widely Distributed Stocks (WGWIDE). ICES CM 2012/ACOM:15. International Council for the Exploration of the Sea, Copenhagen.

ICES 2013a. ICES Advice 2013, Book 6. Nephrops in Subarea IV (North Sea). International Council for the Exploration of the Sea, Copenhagen.

ICES 2013b. Interim Report of the Working Group on Maritime Systems (WGMARS), 4-8 November 2013, Stockholm, Sweden. ICES CM 2013/SSGSUE:06. 30 pp. International Council for the Exploration of the Sea, Copenhagen.

ICES 2013c. Report of the Working Group on Widely Distributed Stocks (WGWIDE). ICES CM 2013/ACOM:15. International Council for the Exploration of the Sea, Copenhagen.

ICES 2013d. Report of the Workshop on Guidelines for Management Strategy Evaluations (WKGMSE). ICES CM 2013/ACOM 39. 122 pp. International Council for the Exploration of the Sea, Copenhagen.

ICES 2014a. ICES Advice 2014, Book 9, Section 9.3.6. Boarfish in the Northeast Atlantic. Advice for 2015. International Council for the Exploration of the Sea, Copenhagen.

ICES 2014b. Report of the EU Workshop on the NEA Mackerel Long-term Management Plan (WKMACLTMP). ICES CM 2014/ACOM:63. 120 pp. International Council for the Exploration of the Sea, Copenhagen.

ICES 2014c. Workshop on North Sea horse mackerel management plan (WKHOMMP), 1718 June 2014, IJmuiden, the Netherlands. ICES CM 2014/ACOM:55. 23 pp. International Council for the Exploration of the Sea, Copenhagen.

ICES 2015. ICES Advice basis. ICES Advice 2015, Book 1. International Council for the Exploration of the Sea, Copenhagen.

Jacobsen, R. B., Wilson, D. C. K., and Ramirez-Monsalve, P. 2012. Empowerment and regulation - dilemmas in participatory fisheries science. Fish and Fisheries, 13: 291302 .

Jasanoff, S. 1990. The fifth branch: Science advisers as policymakers, Harvard University Press.

Jasanoff, S. 2004. States of knowledge: the co-production of science and social order, Psychology Press.

Jentoft, S. 2000. Legitimacy and disappointment in fisheries management. Marine Policy, 24: 141-148.

Jentoft, S., and Chuenpagdee, R. 2009. Fisheries and coastal governance as a wicked problem. Marine Policy, 33: 553-560.

Johnson, M. P., Lordan, C., and Power, A. M. 2013. Habitat and ecology of Nephrops norvegicus. In Ecology and biology of Nephrops Norvegicus, pp. 27-63. Ed. by M. L. Johnson, and M. P. Johnson. Elsevier Academic Press Inc, San Diego.

KFO 2010. (Killybegs Fishermen's Organisation). KFO news. April 2010, Issue 37.

Kotter, J. P. 1995. Leading change. Why transformation efforts fail. Harvard Business Review, 73: 59-67.

Kraak, S. B. M., Bailey, N., Cardinale, M., Darby, C., De Oliveira, J. A. A., Eero, M., Graham, N., et al. 2013. Lessons for fisheries management from the EU cod recovery 
plan. Marine Policy, 37: 200-213.

Kuhn, T. S. 1962. The structure of scientific revolutions, University of Chicago press.

Kvale, S., and Brinkmann, S. 2009. InterViews: learning the craft of qualitative research interviewing, Sage Publications, Los Angeles.

Lado, E. P. 2016. The Common Fisheries Policy: The quest for sustainability, WileyBlackwell. 392 pp.

Lamont, M., and Molnar, V. 2002. The study of boundaries in the social sciences. Annual Review of Sociology, 28: 167-195.

Large, P. A., Hammer, C., Bergstad, O. A., Gordon, J. D. M., and Lorance, P. 2003. Deepwater fisheries of the Northeast Atlantic: II. Assessment and management approaches. Journal of Northwest Atlantic Fishery Science, 31: 151-163.

Lassen, H., Kelly, C., and Sissenwine, M. 2014. ICES advisory framework 1977-2012: from F-max to precautionary approach and beyond. ICES Journal of Marine Science, 71: 166-172.

Latour, B. 1998. From the world of science to the world of research? Science, 280: 208-209.

Latour, B. 1999. Pandora's hope: essays on the reality of science studies, Harvard University Press.

Levin, S., Xepapadeas, T., Crepin, A. S., Norberg, J., De Zeeuw, A., Folke, C., Hughes, T., et al. 2013. Social-ecological systems as complex adaptive systems: modeling and policy implications. Environment and Development Economics, 18: 111-132.

Linke, S., and Bruckmeier, K. 2015. Co-management in fisheries - Experiences and changing approaches in Europe. Ocean \& Coastal Management, 104: 170-181.

Linke, S., Dreyer, M., and Sellke, P. 2011. The Regional Advisory Councils: What is Their Potential to Incorporate Stakeholder Knowledge into Fisheries Governance? Ambio, 40: 133-143.

Linke, S., and Jentoft, S. 2013. A communicative turnaround: Shifting the burden of proof in European fisheries governance. Marine Policy, 38: 337-345.

Linke, S., and Jentoft, S. 2014. Exploring the phronetic dimension of stakeholders' knowledge in EU fisheries governance. Marine Policy, 47: 153-161.

Ludwig, D. 2001. The era of management is over. Ecosystems, 4: 758-764.

Mackinson, S., Wilson, D. C., Galiay, P., and Deas, B. 2011. Engaging stakeholders in fisheries and marine research. Marine Policy, 35: 18-24.

Mackinson, S., and Wilson, D. C. K. 2014. Building bridges among scientists and fishermen with participatory action research. In Social issues in sustainable fisheries management, pp. 121-139. Ed. by J. Urquhart, T. G. Acott, D. Symes, and M. Zhao. Springer, Dordrecht.

McNie, E. C. 2007. Reconciling the supply of scientific information with user demands: an analysis of the problem and review of the literature. Environmental Science \& Policy, 10: $17-38$.

Merton, R. K. 1996. On social structure and science, University of Chicago Press.

Metze, T. 2010. Innovation Ltd.: boundary work in deliberative governance in land use planning, Eburon Academic Publishers, Delft.

Miles, M. B., and Huberman, A. M. 1994. Qualitative data analysis: an expanded sourcebook, Sage, Thousand Oaks, CA.

Msomphora, M. R. 2016. The role of science in fisheries management in Europe: from Mode 1 to Mode 2. Maritime Studies, 15:3.

Napier, I. R. 2012. Fishers' North Sea Stock Survey 2012. NAFC Marine Centre. Shetland. Napier, I. R. 2014. Fishers' North Sea Stock Survey 2014. NAFC Marine Centre. Shetland.

NFFO 2010. Nephrops: Taking it to the Ports. In: FiskerForum 13 June 2010.

Nicolini, D., Mengis, J., and Swan, J. 2012. Understanding the Role of Objects in CrossDisciplinary Collaboration. Organization Science, 23: 612-629. 
Nonaka, I. 1994. A dynamic theory of organizational knowledge creation. Organization science, 5: 14-37.

Nowotny, H., Scott, P., and Gibbons, M. 2001. Re-thinking science: knowledge and the public in an age of uncertainty, SciELO Argentina.

Nowotny, H., Scott, P., and Gibbons, M. 2003. 'Mode 2' revisited: The new production of knowledge - Introduction. Minerva, 41: 179-194.

NSAC 2015. A Long Term Management Plan for North Sea Nephrops. North Sea Advisory Council.

NSAC-NFG 2014. North Sea Advisory Council, Nephrops Focus Group. Meeting of the Nephrops Focus Group, 11 November 2014, Brussels, Belgium.

NSRAC-DWG 2006. North Sea Regional Advisory Council, Demersal Working Group. Template for a Long-term Management Plan. Produced from the Edinburgh Workshop. Paper for Den Helder WG. May 14, 2006.

NSRAC-NFG 2012. North Sea Regional Advisory Council, Nephrops Focus Group. Meeting of the Nephrops Farne Deeps Focus Group, 13 November 2012, Aberdeen, Scotland.

Nursey-Bray, M. J., Vince, J., Scott, M., Haward, M., O’Toole, K., Smith, T., Harvey, N., et al. 2014. Science into policy? Discourse, coastal management and knowledge. Environmental Science \& Policy, 38: 107-119.

O’Brien, L., Marzano, M., and White, R. M. 2013. 'Participatory interdisciplinarity': Towards the integration of disciplinary diversity with stakeholder engagement for new models of knowledge production. Science and Public Policy, 40: 51-61.

O’Donnell, C., Farrell, E., Nolan, C., and Campbell, A. 2012a. Boarfish acoustic survey cruise report. 09 July-26 July, 2012. FSS Survey Series: 2012/03.

O'Donnell, C., Farrell, E., Saunders, R., and Campbell, A. 2012b. The abundance of boarfish (Capros aper) along the western shelf estimated using hydro-acoustics. Irish Fisheries Investigations No. 23, Marine Institute 2012.

O'Donnell 1, C., Farrell, E., Nolan, C., and Campbell, A. 2013. Boarfish acoustic survey cruise report 10 July - 31 July, 2013. FEAS Survey Series;2013/03.

O’Donnell 1, C., Farrell, E. D., Saunders, R. A., and Campbell, A. 2011. Boarfish acoustic survey cruise report, 07 July-28 July, 2011. FSS Survey Series: 2011/03. Marine Institute, Galway, Ireland.

Opitz, S., Hoffmann, J., Quaas, M., Matz-Luck, N., Binohlan, C., and Froese, R. 2016. Assessment of MSC-certified fish stocks in the Northeast Atlantic. Marine Policy, 71: $10-14$.

Ounanian, K., and Hegland, T. J. 2012. The Regional Advisory Councils' current capacities and unforeseen benefits. Maritime Studies, 11:10.

Owen, R., Macnaghten, P., and Stilgoe, J. 2012. Responsible research and innovation: From science in society to science for society, with society. Science and Public Policy, 39: 751-760.

Pastoors, M. A. 2016. Stakeholder participation in the development of management strategies: a European perspective. In Management Science in Fisheries: An introduction to simulation-based methods, pp. 411-424. Ed. by T. T. Edwards, and D. J. Dankel. Routledge, London and New York.

Patton, M. Q. 2015. Qualitative research \& evaluation methods: integrating theory and practice, SAGE Publications, Inc, Thousand Oaks, California.

Polanyi, M. 1962. The republic of science: Its political and economic theory. Minerva, 1: 5473.

Pope, J., Hawkins, A. D., Tingley, D., Mardle, S., and Cattermoul, N. 2006. Long-term management of North Sea fisheries. A report to DEFRA and the North Sea Regional Advisory Council.

PRAC. 2007. (Pelagic Regional Advisory Council). Management plan for western horse 
mackerel. http://www.pelagic-ac.org/media/pdf/20070725\%20Management\%20Plan\% 20Horse\%20Mackerel\%20July\%202007.pdf

PRAC 2012a. (Pelagic Regional Advisory Council). Long-term management plan for boarfish. Letter to DGMARE 14 August 2012.

PRAC 2012b. (Pelagic Regional Advisory Council). Minutes of Working Group II, 11 July 2012. Amsterdam.

Rabeharisoa, V., and Callon, M. 2002. The involvement of patients' associations in research. International Social Science Journal, 54: 57-63.

RACs 2008. Joint RACs meeting on Long Term Management Plans - 11-12 September 2008, Nantes, France.

Raymond, C. M., Fazey, I., Reed, M. S., Stringer, L. C., Robinson, G. M., and Evely, A. C. 2010. Integrating local and scientific knowledge for environmental management. Journal of Environmental Management, 91: 1766-1777.

Reed, M. S. 2008. Stakeholder participation for environmental management: A literature review. Biological Conservation, 141: 2417-2431.

Reed, M. S., Stringer, L. C., Fazey, I., Evely, A. C., and Kruijsen, J. H. J. 2014. Five principles for the practice of knowledge exchange in environmental management. Journal of Environmental Management, 146: 337-345.

Riesch, H. 2010. Theorizing boundary work as representation and identity. Journal for the Theory of Social Behaviour, 40: 452-+.

Rip, A. 1994. The republic of science in the 1990s. Higher Education, 28: 3-23.

Roux, D. J., Rogers, K. H., Biggs, H. C., Ashton, P. J., and Sergeant, A. 2006. Bridging the science-management divide: Moving from unidirectional knowledge transfer to knowledge interfacing and sharing. Ecology and Society, 11: 4.

Röckmann, C., Ulrich, C., Dreyer, M., Bell, E., Borodzicz, E., Haapasaari, P., Hauge, K. H., et al. 2012. The added value of participatory modelling in fisheries management what has been learnt? Marine Policy, 36: 1072-1085.

Röckmann, C., Van Leeuwen, J., Goldsborough, D., Kraan, M., and Piet, G. 2015. The interaction triangle as a tool for understanding stakeholder interactions in marine ecosystem based management. Marine Policy, 52: 155-162.

Schomberg, R. von 2013. A vision of responsible innovation. In Responsible Innovation, pp. 51-74. Ed. by R. Owen, M. Heintz, and J. Bessant. Wiley, London.

Schwach, V., Bailly, D., Christensen, A. S., Delaney, A. E., Degnbol, P., Van Densen, W. L. T., Holm, P., et al. 2007. Policy and knowledge in fisheries management: a policy brief. ICES Journal of Marine Science, 64: 798-803.

Seijger, C., Dewulf, G., Otter, H., and Van Tatenhoue, J. 2013. Understanding interactive knowledge development in coastal projects. Environmental Science \& Policy, 29: 103114.

Simmonds, E. J., Doring, R., Daniel, P., and Angot, V. 2011. The role of fisheries data in the development evaluation and impact assessment in support of European fisheries plans. ICES Journal of Marine Science, 68: 1689-1698.

Sissenwine, M., and Symes, D. 2007. Reflections on the common fisheries policy - report to the General Directorate for Fisheries and Maritime Affairs of the European Commission. 75 pp.

Soto, C. G. 2006. Socio-cultural barriers to applying fishers' knowledge in fisheries management: An evaluation of literature cases. PhD Thesis. School of Resource and Environmental Management-Simon Fraser University.

Stange, K. 2016. Building a knowledge base for management of a new fishery: Boarfish (Capros aper) in the Northeast Atlantic. Fisheries Research, 174: 94-102.

Stange, K., Olsson, P., and Österblom, H. 2012. Managing organizational change in an international scientific network: A study of ICES reform processes. Marine Policy, 36: 
681-688.

Stange, K., Van Leeuwen, J., and Van Tatenhove, J. 2016. Boundary spaces, objects and activities in mixed-actor knowledge production: Making fisheries management plans in collaboration. Maritime Studies, 15:14.

Stange, K., Van Tatenhove, J., and Van Leeuwen, J. 2015. Stakeholder-led knowledge production: Development of a long-term management plan for North Sea Nephrops fisheries. Science and Public Policy, 42: 501-513.

Star, S. L. 2010. This is not a boundary object: Reflections on the origin of a concept. Science Technology \& Human Values, 35: 601-617.

Star, S. L., and Griesemer, J. R. 1989. Institutional ecology, 'translations' and boundary objects: Amateurs and professionals in Berkley's Museum of Vertebrate Zoology, 1907-39. Social Studies of Science, 19: 387-420.

STECF 2014. (Scientific, Technical and Economic Committee for Fisheries). The 2014 Annual economic report on the EU fishing fleet (STECF-14-16). Publications Office of the European Union, Luxembourg, EUR 26901 EN, JRC 92507, 363 pp.

Stephenson, R. L., Paul, S., Pastoors, M. A., Kraan, M., Holm, P., Wiber, M., Mackinson, S., et al. 2016. Integrating fishers' knowledge research in science and management. ICES Journal of Marine Science, 73: 1459-1465.

Stohr, C., and Chabay, I. 2010. Science and participation in governance of the Baltic Sea fisheries. Environmental Policy and Governance, 20: 350-363.

Symes, D., and Hoefnagel, E. 2010. Fisheries policy, research and the social sciences in Europe: Challenges for the 21st century. Marine Policy, 34: 268-275.

Talwar, S., Wiek, A., and Robinson, J. 2011. User engagement in sustainability research. Science and Public Policy, 38: 379-390.

Thornton, T. F., and Scheer, A. M. 2012. Collaborative engagement of local and traditional knowledge and science in marine environments: A review. Ecology and Society, 17: 25.

Tsoukas, H. 2009. A dialogical approach to the creation of new knowledge in organizations. Organization Science, 20: 941-957.

Turnhout, E. 2009. The effectiveness of boundary objects: the case of ecological indicators. Science and public policy, 36: 403-412.

Van de Ven, A. H., and Johnson, P. E. 2006. Knowledge for theory and practice. Academy of Management Review, 31: 802-821.

Van der Sluijs, J. P., Petersen, A. C., Janssen, P. H. M., Risbey, J. S., and Ravetz, J. R. 2008. Exploring the quality of evidence for complex and contested policy decisions. Environmental Research Letters, 3: 9.

Verweij, M. C., Van Densen, W. L. T., and Mol, A. J. P. 2010. The tower of Babel: Different perceptions and controversies on change and status of North Sea fish stocks in multistakeholder settings. Marine Policy, 34: 522-533.

White, E., Minto, C., Nolan, C. P., King, E., Mullins, E., and Clarke, M. 2011. First estimates of age, growth, and maturity of boarfish (Capros aper): a species newly exploited in the Northeast Atlantic. ICES Journal of Marine Science, 68: 61-66.

Williams, P. 2002. The competent boundary spanner. Public Administration, 80: 103-124.

Wilson, D. 2009a. Stakeholder participation in recovery plans. Deliverable No. 30 of the Understanding the Mechanisms of Stock Recovery (UNCOVER) Project. EU 6th Framework Project No. 022717 (SSP 8).

Wilson, D. C. 2009b. The paradoxes of transparency: science and the ecosystem approach to fisheries management in Europe, Amsterdam Univ Press.

Yin, R. K. 2009. Case study research: design and methods, SAGE, London.

Zeiss, R., and Groenewegen, P. 2009. Engaging boundary objects in OMS and STS? Exploring the subtleties of layered engagement. Organization, 16: 81-100. 


\section{Appendix 1: List of meetings, workshops and conferences}

\begin{tabular}{|c|c|}
\hline Date & Meetings attended as observer \\
\hline 2011-11-16 & GAP2 Herring Case Kick-off, DTU Aqua, Copenhagen \\
\hline 2012-01-23 & MIRAC 2012, The Hague. Annual meeting with ICES and RACs \\
\hline 2012-02-22 & NSRAC DWG, Amsterdam \\
\hline 2012-04-27 & GAP2 Herring Case, DK Ministry, Copenhagen \\
\hline 2012-07-10 & NSRAC DWG, Mixed Fisheries Focus Group, Amsterdam \\
\hline 2012-09-13 & NSRAC DWG, Amsterdam \\
\hline 2013-02-21 & NSAC DWG, Amsterdam \\
\hline 2013-03-05_06 & SFF Sub-Committees, Aberdeen \\
\hline 2013-04-02_03 & SFF ExCom, Edinburgh \\
\hline 2013-04-04 & NSAC Nephrops Focus Group, London \\
\hline 2013-04-05 & NSAC DWG, Cod management, London \\
\hline 2013-04-10 & $\begin{array}{l}\text { The Fisheries Management and Conservation Group (FMAC). Elgin, } \\
\text { Scotland }\end{array}$ \\
\hline 2013-04-22 & Marine Scotland stakeholder deliberations on MPAs, Lerwick, Shetland \\
\hline 2013-07-19 & NSAC Nephrops Focus Group, London \\
\hline 2014-01-15 & MIACO 2014, Copenhagen. Annual meeting with ICES and ACs \\
\hline 2014-02-04 & PELAC ExCom, WG I and WG II, The Hague \\
\hline 2014-02-05 & PELAC Discard meeting, The Hague \\
\hline 2014-02-06 & MyFish-PELAC MSY workshop, The Hague \\
\hline 2014-02-27 & EC Mixed Fisheries workshop, Brussels \\
\hline 2014-07-09 & PELAC WG I and WG II \\
\hline 2014-07-10 & PELAC ExCOM \\
\hline 2014-10-01 & PELAC WG I and WG II \\
\hline 2014-10-02 & PELAC ExCOM \\
\hline
\end{tabular}


Date

2012-07-05

2013-02-07

2013-02-25_26

2013-11-29_12-04

2014-02-26

2014-12-01_05

2015-02-24_26

\section{Date}

2012-05-08_12

2012-10-17_20

2013-06-25

2013-06-26_28

2013-12-10

2014-03-03_06

2014-09-17_19

2015-09-21_25

\section{Workshops}

GAP2 Management plan workshop, Brussels (co-organiser, presentation)

GAP2 Policy workshop, Choggia, IT. (co-organiser)

COMFISH North Sea mixed fisheries, Hurtigruten (participant and observer)

ICES WGMARS, Stockholm (participant)

GAP2 Regionalisation workshop, Brussels (participant and observer)

ICES WGMARS, Copenhagen (participant)

GAP2 final symposium, Barcelona (participant and poster presentation)

\section{Conferences}

World Fisheries Congress, Edinburgh (attending)

4S\&EASST Conference, Copenhagen (oral presentation)

MARE Policy Day, Amsterdam (attending)

MARE Conference, Amsterdam (session chair, oral presentation)

$1^{\text {st }}$ WUR PhD Symposium (panel co-organiser and oral presentation)

Fisheries Dependent Information symposium, FAO, Rome (oral presentation)

EASST Conference, Torun, Poland (oral presentation)

ICES Annual Science Conference, Copenhagen (oral presentation) 


\title{
Appendix 2: Interview guide. (Supplement 1 to Paper III)
}

\author{
Interview guide, Boarfish case: From idea to a Long Term Management Plan (LTMP)
}

\section{Introduction}

Background and purpose of study: The focus of my research is on how different actors and forms of knowledge contribute to the knowledge base of European fisheries management. I am particularly interested in how LTMPs act as a vehicle for bringing actors together and how knowledge is shared, used and produced in such collaborations. Formalities: How interview data will be handled and used. Permission to record?

\section{Roles}

What was your role in the development of a LTMP for boarfish?

Who were the key actors through the different stages?

How did they contribute?

- Idea stage: Let's make a LTMP. What were the main drivers?

- Preparation phase: Identifying information needs, filling knowledge gaps.

- Production phase: Putting the plan together.

$\circ$ Who were involved in the deliberations?

- Were drafts produced / shared / versions adjusted, based on deliberations?

○ Who led/co-ordinated the work?

- Evaluation: What was the role of ICES? WGWIDE? STECF?

- Implementation: Used by management and/or as basis for ICES advice?

Were there any managers or policymakers involved? Was there any interest / pull from the Commission?

What was the role of the Pelagic Advisory Council?

\section{Content of the plan}

- The 6-tiered structure

- How did the tiered structure come about?

- Is this structure unique in the context of EU management plans?

- How did structure influence the process of evaluating the plan?

$\circ$ Is there a link between the boarfish LTMP process and ICES developing a procedure for handling data limited stocks?

$\circ \quad$ Why take away lower tiers now? Already Tier 1? Uncertainty high. Feedback.

- Beyond HCRs: The closures

- How were these elements brought into the LTMP process?

- Were there differences in opinion and interests related to these elements? How were such issues resolved?

- How do these voluntary measures work in practice? What do the fishermen think about them?

\section{Lessons learned}

What has been learned? What should be done differently next time?

Close

Follow-up and clarifications. Use of quotes. Planned output from my research. Thank you. 


\section{Appendix 3: List of interviews}

\begin{tabular}{|c|c|}
\hline Date & Name \\
\hline 2012-05-09 & Poul Degnbol \\
\hline $\begin{array}{l}2012-05-09 \text { and } \\
2013-04-10\end{array}$ & Mike Park \\
\hline 2013-02-18 & Steven Mackinson \\
\hline 2013-03-06 & Alan Coghill \\
\hline 2013-03-06 & Bertie Armstrong \\
\hline 2013-04-08 & Steven Alexander \\
\hline 2013-04-16 & Lorna Duguid \\
\hline 2013-04-23 & Ian Napier \\
\hline 2013-04-23 & Leslie Tait \\
\hline 2013-04-24 & Tony Hawkins \\
\hline 2013-04-25 & Angus Garrett \\
\hline 2013-06-11 & Giles Bartlett \\
\hline 2013-07-06 & Ned Clark \\
\hline 2013-07-17 & Ewen Bell \\
\hline
\end{tabular}

Affiliation (at the time of the interview)

Head of Advisory Services, ICES, Denmark.

CEO, Scottish Whitefish Producer Association, UK/Scotland.

Researcher, CEFAS, UK/England.

President, Scottish Fishermen's Federation, UK/Scotland.

Chief Executive, Scottish Fishermen's Federation, UK/Scotland.

Director of Marine Operations, Scottish Fishermen's Federation, UK/Scotland.

Executive Secretary, North Sea RAC

Fisheries Development Manager, North Atlantic Fisheries College, Shetland, UK.

Chairman, Shetland Fishermen's Association, UK/Scotland.

Rapporteur, North Sea RAC.

Scientist, SEAFISH, UK.

Fisheries Policy Officer, WWF, UK.

Chair of the North East Committee of the National Federation of Fishermen's Organisations, UK/England. Senior Inshore Fisheries Advisor, CEFAS, UK/England.

2013-11-04 Claus Reedtz Sparrevohn Scientist, Danish Pelagic Producers Organisation, Denmark.

2013-11-07～Dankert Skagen

2013-12-12 Jesper Raakjær

2014-01-15 Christian Olesen 2014-01-16 Mark Dickey-Collas

2014-01-16 John Simmons

2014-02-06 Gerard van Baalsfort
Scientist, Independent consultant, Norway.

Scientist, Aalborg University, Denmark. Pelagic RAC member representing The Association of Danish Fish Processing Industries and Experts. CEO, Danish Pelagic Producers Organisation, Denmark.

Scientist, ICES, Denmark.

Scientist and ACOM vice Chair, ICES, Denmark.

President, Dutch Pelagic Freezer-Trawler Association (PFA), Netherlands. 


\section{Date}

Name

2014-02-12 and Sean O'Donoghue 2014-07-09

2014-05-14 Maurice Clark

2014-06-06 Ciaran Kelly

2014-06-27 Edward Farrell

2014-07-01 Lotte Worsøe Clausen

2014-07-09 Esben Sverdrup Jensen

2014-07-15 Martin Howley

2014-07-16 Maurice Clarke

2014-07-16 Coilin Minto

2014-10-01 Frederik Schutyser

2014-10-01 Eihblin O’Sullivan

2014-10-21Ｃiaran O’Donnel

2014-11-12 Joost Paardekooper and Dominic Rhian

2014-11-12 Ken Patterson

2014-11-12 Evangelia Georgitsi

2014-11-12 Alexander Stein

2014-11-12 Peter Hopkins

2014-12-05 David Miller

2014-12-11 Katja Enberg

2014-12-11 Aukje Coers
Affiliation (at the time of the interview)

CEO, Killybegs Fishermen's Organisation, Ireland.

Scientist, Marine Institute, Ireland.

Scientist, Marine Institute, Ireland.

Scientist, University of Dublin/Cork, Ireland.

Scientist, DTU Aqua, Denmark.

CEO, Danish Pelagic Producers Organisation, Denmark.

Chairman, Killybegs Fishermen's Organisation, Ireland.

Scientist, Marine Institute, Ireland.

Scientist, Galway-Mayo Institute of Technology, Ireland.

Policy Officer, European Commission, DG MARE

CEO, Irish South \& West Producer Organisation, Ireland.

Scientist, Marine Institute, Ireland.

Policy officers, European Commission, DG MARE

European Commission, DG MARE

Policy officer, European Commission, DG MARE

Policy officer, European Commission, DG MARE

European Commission, DG MARE

Scientist, IMARES, Netherlands.

Scientist, Institute of Marine Research, Norway.

Scientist, Cornelis Vrolijk, Netherlands. 


\section{Appendix 4: Coding Scheme. (Supplement 2 to Paper III)}

\section{Code description}

Actors

Actor affiliation

Boundary

Knowledge forms

Barriers, knowledge exchange

Capacities, knowledge exchange
Code

Actor-Industry

Actor-NGO

Actor-Fisher

Actor-Scientist-Fisheries

Actor-Scientist-SocSci

Actor-Manager

Actor-Other

Actoraff-NL

Actoraff-UK

Actoraff-IRE

Actoraff-DK

Actoraff-RAC

Actoraff-EU-EC

Actoraff-ICES

Actoraff-STECF

Actoraff-EP

Actoraff-other

Boundary-Stakeholder-stakeholder

Boundary-Stakeholder-scientist

Boundary-Stakeholder-bureaucrat

Boundary-Scientist-scientist

Boundary-Scientist-bureaucrat

Boundary-Bureaucrat-bureaucrat

Knowledge-Experience based

Knowledge-Scientific-NatSci

Knowledge-Scientific-SocSci

Knowledge-Bureaucratic-EU

Knowledge-Bureaucratic-MS

Knowledge-Bureaucratic-local

Knowledge-Mixed

Knowledge-Common

Knowledge-Domain-specific

Barrier-Communication

Barrier-Diverging views

Barrier-Diverging interests

Barrier-Structure

Barrier-Politics

Barrier-Other

Capacities-Funding

Capacities-Facilitation

Capacities-Structure

Capacities-Knowledge

Capacities-Time

Capacities-Network

Capacities-Facilitation

Capacities-Boundary object

Capacities-Other 
Code description

Process, knowledge exchange

Factors, collaborations

Long Term Management Plan, process

Long Term Management Plan, content

Long Term Management Plan, issues

Participatory process, research

Participatory process, management

Participatory process, policy

\section{Code}

Process-Exchange

Process-Deliberation

Process-Negotiation

F-Problem

F-Solution

F-Innovation

F-Incentive

F-Driver

F-Milestone

F-Conflict

F-Compromising

LTMP-phase1-pre

LTMP-phase2-action

LTMP-phase3-production

LTMP-phase4-pre-evaluation

LTMP-phase5-implementation

LTMP-phase6-re-evaluation

LTMP-phase7-amend

LTMP-Cont-HCR

LTMP-Cont-Biological

LTMP-Cont-Ecological

LTMP-Cont-Economic

LTMP-Cont-Social

LTMP-Cont-Other

Issue-CFP-reform

Issue-HCR

Issue-Certification

Issue-Discards

Issue-MSY

Issue-Precautionary

Issue-Co-decision

Issue-LTMP-ownership

Issue-TAC

Particip-Research-idea

Particip-Research-approach

Particip-Research-data collection

Particip-Research-interpretation

Particip-Research-dissemination

Particip-Mgm-problem-id

Particip-Mgm-objectives

Particip-Mgm-actions

Particip-Mgm-implemetation

Particip-Mgm-evaluation

Particip-Policy-problem-id/framing

Particip-Policy-measure evaluation

Particip-Policy-measure development

Particip-Policy-implementation

Particip-Policy-effectiveness evaluation 


\section{Summary}

This thesis explores how knowledge is used and produced in stakeholder-led collaborations to make management plans for EU fishery management. In Europe, the policy instrument used for fishery management is the CFP. When the 2002 CFP reform introduced Advisory Councils, new opportunities emerged for stakeholder involvement in fishery management. The same reform also introduced multi-annual plans as tools to move towards longer-term perspectives on fishery management. These policy developments create opportunities for stakeholders to participate in building the knowledge base that supports EU fishery management decision-making through collaborations. However, collaborations between actors from different knowledge domains are faced with numerous challenges related to how various forms of knowledge interact. Recent knowledge exchange research points to our limited understanding of mixed-actor collaborative knowledge-production processes. This thesis makes a contribution to filling this knowledge gap by using and developing boundary object theory to investigate collaborative processes where stakeholders, scientists and managers are involved in development of management plans.

The thesis has a paper-bundle format; Chapters 3-6 are published separately as peerreviewed papers in scientific journals, while Chapters 1, 2, and 7 provide the "wrapping" that makes the thesis a coherent contribution to academic scholarship.

Chapter 1 sets the stage by identifying the need to increase our understanding of mixedactor knowledge production processes in EU fishery management. The overarching research questions posed is: How is knowledge used and produced in stakeholder-led collaborations to make management plans for EU fishery management? Three subquestions to guide the research were formulated: i) How do boundary processes and boundary objects explain knowledge-production processes in stakeholder-led collaborations to make management plans for EU fishery management? ii) How does stakeholder-led development of management plans provide arenas for bringing the knowledge and interests of different actors together? iii) How are stakeholders, scientists, and managers involved in stakeholder-led collaborations to make management plans for EU fishery management, and what roles do they play in these knowledge-production processes? Chapter 1 also introduces a conceptual framework developed by Carlile to investigate knowledge transfer across boundaries in mixed-actor collaborations. This framework focuses on how knowledge is exchanged between actors, and how actors are challenged to overcome their differences in perspectives and interests when aiming to produce new knowledge together. 
Chapter 2 presents the research methods at an overarching level, while details specific to each empirical study are found in Chapters 3-6. The research uses qualitative methodology and involves multiple case studies. A Nephrops case (Chapter 3) and a boarfish case (Chapter 4) represent two in-depth case studies of collaborations to make long-term management plans. Combined, the two cases form the empirical basis for a third analysis with emphasis on boundary spaces (Chapter 5). Two additional cases: NEA mackerel and North Sea horse mackerel, are analysed to illustrate multiple roles played by scientists in management plandevelopment processes (Chapter 6). Data were collected through semi-structured interviews, document studies and participant observation.

Chapter 3 introduces Carlile's conceptual framework and explores how it can be used to understand knowledge production in a stakeholder-led collaboration to make a long-term management plan for the North Sea Nephrops fishery. This collaboration was initiated by the NSAC, while a subgroup - the Nephrops Focus Group - did the hands-on work with producing the plan. The analysis clarified that knowledge production took place at several levels of complexity, corresponding to three knowledge-generating processes: transfer, translation, and negotiation. A theory-driven insight from the Nephrops case study is that knowledge transformation cannot occur if the resources available do not match the complexity of the collaborative setting.

In Chapter 4, the Carlile-inspired framework was applied to a case study of collaborations between pelagic fishing industry actors and fishery scientists, which aimed to produce a knowledge base for a new boarfish fishery in the Northeast Atlantic. In this case, the analytical approach was particularly useful in demonstrating how several boundary objects with various characteristics emerged during the collaborations. The two boarfish management-plan proposals that emerged - an interim plan and a long-term management plan - served as boundary objects to facilitate communication between actor groups. An insight from the boarfish case (Chapter 4) is that resources facilitating knowledge exchange can assume many different forms. Boundary objects exemplify such resources. Another example of a resource was the financial support mobilized by industry stakeholders to allow fishery scientists to quickly begin filling scientific knowledge gaps related to boarfish biology.

In Chapter 5, a boundary spaces framework is developed and applied in a study of the Nephrops and boarfish cases. In this study, activities and boundary objects were brought to the fore to analyse the interaction between actors, objects, and activities. The conceptual framework highlighted the importance of activities as entry point for actors' engagement. In the Nephrops case, Nephrops Focus Group meetings were key activities. These meetings 
provided a forum for knowledge-sharing between stakeholders and scientists as well as between different stakeholder interests. Over time, a common understanding evolved around key issues and challenges. Initiatives to address specific problems triggered new activities, which brought different sets of actors into the collaboration. In the boarfish case, scientific studies created entry points for direct engagement by fishers in roles as sample providers and financers. These activities created leverage for fruitful knowledge exchange, and a common understanding around the need for management measures for the new boarfish fishery developed. The study demonstrated that multiple boundary spaces evolve during a collaborative knowledge production process, and that inclusion of new actors and exclusion of others are elements in such processes.

Chapter 6 considers management-plan making as illustrative examples of how increased participation in EU fishery science and management influences the work of fishery scientists. The paper describes the multiple roles - as developer, reviewer, judge, and messenger - that scientists may assume in a process of promoting management plans, from idea to implementation. Interaction with stakeholders in the Advisory Councils in these contexts points to new tasks and roles for scientists in the ICES community, and to the need for clear procedures to ensure that different roles are acted out transparently. By asking the question "What hat are you wearing?", the paper aims to encourage individual fishery scientists, their employers, and ICES as a network organization of expertise to reflect on roles, affiliations, mandates, and possible consequences of wearing different "hats".

Chapter 7 summarizes and synthesizes the findings from the research presented in Chapters 3-6 and discusses their implications. The findings demonstrate that engagement in producing management plans through Advisory Councils has provided entry points for the fishing industry to take ownership of fishery-management dilemmas. With ownership comes a willingness to actively contribute to finding solutions to these dilemmas. The findings also point to the value of applying knowledge-exchange perspectives to the understanding of knowledge transfer between diverse groups of actors in marine science and management. Such perspectives give insights into resources and efforts that enable actors to share their knowledge at various levels of complexity. The boundary spaces framework presented in Chapter 5 is developed as a tangible contribution to our understanding of knowledge exchange. Applications of the framework in contexts and settings different from the ones investigated here are needed to test its robustness and reveal its broader potential for explaining knowledge exchange in mixed-actor collaborations. 


\title{
WASS education certificate
}

\author{
Kari Stange \\ Wageningen School of Social Sciences (WASS) \\ Completed Training and Supervision Plan
}

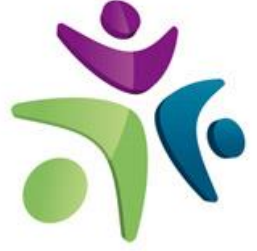

Wageningen School

of Social Sciences

\begin{tabular}{|c|c|c|c|}
\hline Name of the learning activity & Department/Institute & Year & $\begin{array}{c}\text { ECTS } \\
1=28 \mathrm{hrs}\end{array}$ \\
\hline \multicolumn{4}{|l|}{ A) Project related competences } \\
\hline \multicolumn{4}{|l|}{ Meetings and workshops: } \\
\hline GAP2 Workshops (3) and Annual meetings (4) & $\begin{array}{l}\text { Brussels/Chioggia/London/Am } \\
\text { sterdam/Rome/Barcelona }\end{array}$ & 2012-2014 & 1 \\
\hline $\begin{array}{l}\text { Regional Advisory Council meetings (11) and } \\
\text { workshops (1) }\end{array}$ & Amsterdam/London/The Hague & 2012-2014 & 1 \\
\hline Workshops on Mixed fisheries management (2) & COMFISH/DGMARE & 2013-2014 & 1 \\
\hline \multicolumn{4}{|l|}{ Oral conference presentations: } \\
\hline \\
\hline $\begin{array}{l}\text { Expanding the knowledge base for EU fisheries } \\
\text { management through participation }\end{array}$ & $\begin{array}{l}\text { MARE People and the Sea } \\
\text { Conference, Amsterdam, NL }\end{array}$ & 2013 & 1 \\
\hline $\begin{array}{l}\text { The North Sea RACs making of a long term } \\
\text { management plan for North Sea Nephrops } \\
\text { fisheries: Stakeholder-led knowledge production in } \\
\text { a mixed actor setting }\end{array}$ & $\begin{array}{l}\text { Fisheries Dependent } \\
\text { Information Conference, FAO, } \\
\text { Rome, IT }\end{array}$ & 2013 & 1 \\
\hline $\begin{array}{l}\text { When stakeholders take the driver's seat: Making } \\
\text { EU fisheries management plans "bottom up" }\end{array}$ & EASST Conference, Torun, PL & 2014 & 1 \\
\hline $\begin{array}{l}\text { Visiting scholar at the Scottish Fishermen's } \\
\text { Federation, SFF, Aberdeen, UK (1Month) }\end{array}$ & GAP2 exchange program & 2013 & 6 \\
\hline \multicolumn{4}{|l|}{ B) General research related competences } \\
\hline Introduction course & WASS & 2011 & 1 \\
\hline Research Methodology: From topic to proposal & WASS & 2011 & 4 \\
\hline Social theory and the environment & WASS & 2012 & 6 \\
\hline Atlas.ti introduction & WASS & 2012 & 0.5 \\
\hline Scientific writing & WUR languages & 2013 & 1.8 \\
\hline Reviewing a scientific paper & WUR Graduate School & 2014 & 0.1 \\
\hline Writing $\mathrm{PhD}$ research proposal & Environmental Policy Group & 2011-2012 & 4 \\
\hline Marine Group colloquia & Environmental Policy Group & 2011-2014 & 4 \\
\hline WASS PhD Symposium (panel organiser) & Wageningen PhD Council & 2013 & 1 \\
\hline MARE Conference (panel organiser) & $\begin{array}{l}\text { MARE people and the Sea } \\
\text { Conference, Amsterdam }\end{array}$ & 2013 & 1 \\
\hline $\begin{array}{l}\text { Science for Policy: Post-Normal Science in Action } \\
\text { (discussant) }\end{array}$ & $\begin{array}{l}\text { Centre for the Study of the } \\
\text { Sciences and the Humanities, } \\
\text { UiB, NO }\end{array}$ & 2014 & 1 \\
\hline \multicolumn{4}{|l|}{ C) Career related competences/personal development } \\
\hline Dutch for foreigners & Volksuniv. Groningen & 2011 & 2 \\
\hline Nederlands als tweede taal & Niewland, Wageningen & 2013 & 3 \\
\hline Total & & & 42,4 \\
\hline
\end{tabular}




\section{About the author}

Kari Stange (born in Oslo 19 April 1964) is an environmental scientist with broad interests. She holds a Cand. Mag. degree in biology from University of Trondheim (1987), a Master of Science degree in public health and environmental chemistry from University of Minnesota (1992), a Master of Arts degree in library \& information science from Uppsala University (1999), and a Master of Science degree in ecosystems, governance and globalisation from Stockholm University (2010). She worked at the Norwegian Institute of Marine Research with Artic marine pollution issues 1993-1997. Her interest in scientific communication and publishing led her to the National Library of Sweden to work with consortium licence agreements 1999-2008. Her interest in interdisciplinary approaches to environmental challenges brought her back to academia and to the Stockholm Resilience Centre 2008-2010. She joined the Environmental Policy Group at Wageningen University in 2011. Kari currently works at the Stockholm office of the Marine Stewardship Council as senior stakeholder engagement manager for Scandinavia and the Baltic Sea region.

\section{Selected publications}

Stange, K., Van Leeuwen, J., and Van Tatenhove, J. 2016. Boundary spaces, objects and activities in mixed-actor knowledge production: Making fisheries management plans in collaboration. Maritime Studies, 15:14. (Chapter 5 in this thesis)

Stange, K. 2016. Building a knowledge base for management of a new fishery: Boarfish (Capros aper) in the Northeast Atlantic. Fisheries Research, 174: 94-102. (Chapter 4 in this thesis)

Dankel, D. J., Stange, K., and Nielsen, K. N. 2016. What hat are you wearing? On the multiple roles of fishery scientists in the ICES community. ICES Journal of Marine Science, 73: 209-216. (Chapter 6 in this thesis)

Stange, K., Van Tatenhove, J., and Van Leeuwen, J. 2015. Stakeholder-led knowledge production: Development of a long-term management plan for North Sea Nephrops fisheries. Science and Public Policy, 42: 501-513. (Chapter 3 in this thesis)

Stange, K., Olsson, P., and Österblom, H. 2012. Managing organizational change in an international scientific network: A study of ICES reform processes. Marine Policy, 36: 681-688.

Stange, Kari. 2005. Library consortia and Open Access initiatives. Nordic journal for information specialists 60: 107-112.

Stange, K., Hormia-Poutanen, K., Grönvall, K., and Laurila, E. 2003. Cost division models in BIBSAM and FinELib consortia. Serials: The Journal for the Serials Community, 16: 285-292.

Stange, K., and Klungsøyr, J. 1997. Organochlorine contaminants in fish and polycyclic aromatic hydrocarbons in sediments from the Barents Sea. ICES Journal of Marine Science, 54: 318-332.

Stange, Kari and Swackhamer. D. L. 1994. Factors affecting phytoplankton species-specific differences in accumulation of 40 polychlorinated biphenyls (PCBs). Environmental Toxicology and Chemistry, 13: 1849-1860. 
The research described in this thesis was financially supported by the European Commission's FP7 Capacities' Programme Part 5, Science in Society: 'Bridging the gap between science, stakeholders, and policy makers. Phase 2 - Integration of evidence-based knowledge and its application to science and management of fisheries and the marine environment (GAP2)'. Grant agreement 266544.

Cover design by Lars André

Printed by Digiforce 


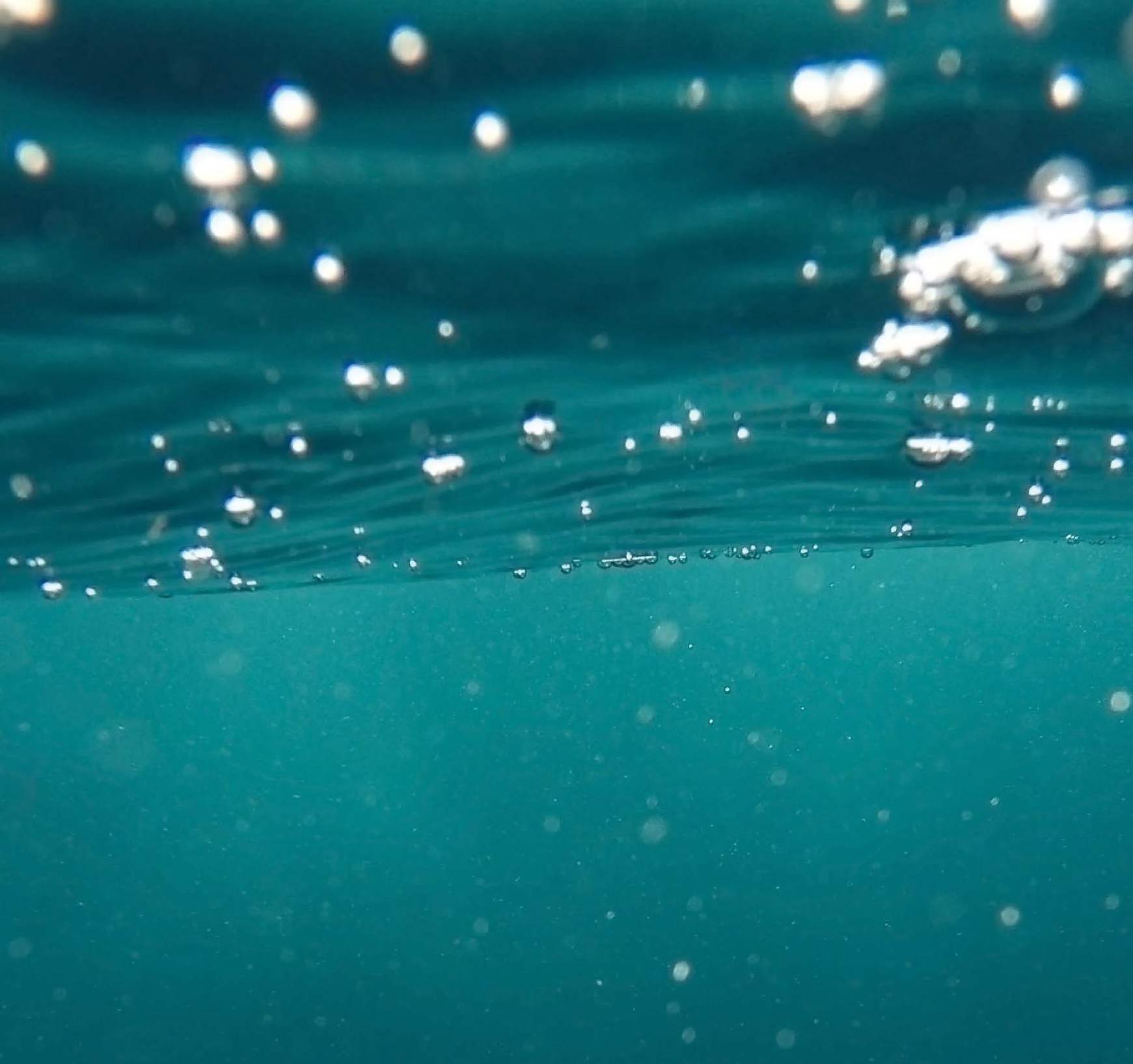

